\title{
PERFIL DE UTILIZAÇÃO DE MEDICAMENTOS NA GESTAÇÃO: UM ESTUDO FARMACOEPIDEMIOLÓGICO NO MUNICÍPIO DE PIRACICABA
}

\section{THAIS ADRIANA DO CARMO}

Tese apresentada ao Departamento de Prática de Saúde Pública, da Faculdade de Saúde Pública da Universidade de São Paulo, para a obtenção do Grau de Doutor.

Área de concentração: Serviços de Saúde Pública

Orientadora: Prof.a. Dra. Sandra Ma. Ottatti Oliveira Nitrini

São Paulo

2002 
Autorizo, exclusivamente para fins acadêmicos e científicos, a reprodução total ou parcial desta tese, por processos fotocopiadores.

Assinatura:

Data:

$$
4275512002 d 00
$$


"Tudo é loucura ou sonho no começo.

Nada do que o homem fez no mundo teve inicio de outra maneira.

Mas já tantos sonhos se realizaram que não temos o direito de duvidar de nenhum."

Monteiro Lobato 
Dedico esta tese à uma lembrança :

Luciano

"Não sei porque você se foi, tanta saudade eu senti e de tristeza vou vivendo e aquele adeus não pude dar". 
Agradecimentos especiais :

- para Fernando, Rafael e Sofia por compartilharem minha vida;

aos meus pais Caury e Mariuza pelo apoio, sempre 


\section{AGRADECIMENTOS}

'A Prof.a. Dra. Sandra M. Oliveira Otatti Nitrini, orientadora desta tese, cujo apoio foi fundamental para sua conclusão;

Às Prof.as Dra. Vânia dos Santos, Dra. Maria Jacira Simōes e Dra. Lia Lusitana, membros titulares da banca de doutoramento, pelas sugestōes oferecidas;

. À Prof.a Dra. Nicolina S. R. Lieber, membro titular da banca de doutoramento, pela colaboração no desenvolvimento do trabalho, mas principalmente pela amizade e incentivo nas horas dificeis;

Ao Dr. João Amaurício Pauli, Secretário Municipal de Saúde de Piracicaba, que abriu as portas dos Serviços de Saúde acreditando na importância do projeto;

Às alunas Juliana, Anabelle, Anelise e Nédia pela realização das entrevistas;

À todas as gestantes que se dispuseram a contribuir nas entrevistas;

Ao meu irmão Leandro, pela ajuda e paciência na finalização da tese;

À Prof.a. Raquel C. D. R. Grecchi, amiga no caminhar cotidiano;

Ao prof. José Eduardo da Fonseca pelo apoio e ombro amigo;

E a todos aqueles que me incentivaram a continuar na estrada na fase mais difícil da vida. 


\section{RESUMO}

A utilização de medicamentos por gestantes deve ser considerado como um problema de saúde pública. Revisando-se a literatura percebe-se que se trata de um comportamento de alto risco terapêutico pois existem inúmeras lacunas sobre suas conseqüências ao feto e à gestante. Neste sentido, a utilização de medicamentos no período de gravidez deve ser feita com muita cautela.

Os estudos farmacoepidemiológicos podem contribuir para minimizar os riscos inerentes à terapia medicamentosa, traçando um perfil do consumo de medicamentos na gestação, identificando quais, quantos e como estão sendo utilizados os medicamentos, propiciando uma avaliação e apontando medidas de intervenção.

Partindo desses pressupostos, o objetivo deste trabalho foi traçar um perfil de consumo de medicamentos em gestantes usuárias do Sistema Único de Saúde do municipio de Piracicaba, através de um estudo transversal, utilizandose os indicadores de prescrição selecionados pela Organização Mundial de Saúde e a classificação de medicamentos segundo risco ao feto do Food and Drug Administration.

Encontrou-se que $61,6 \%$ das entrevistadas utilizaram pelo menos um medicamento na semana anterior a pesquisa e 18,6\% delas referiram ter se automedicado. $\mathrm{Na}$ consulta de pré-natal $44,7 \%$ receberam prescrição medicamentosa, sendo os grupos de medicamentos mais prescritos aqueles que atuam sobre o sistema hematopoiético $(34,9 \%)$ e os antiinfecciosos $(21,2 \%)$. Preocupa o fato de que, do total de medicamentos prescritos, $77,7 \%$ apresentavam alguma inadequação, incluindo medicamentos absolutamente contra-indicados na gravidez $(1,5 \%)$.

Estes dados sugerem uma medicalização da gestação e a necessidade de medidas de intervenção para uma utilização racional dos medicamentos no pré-natal.

Descritores: medicamentos, gestação, estudo farmacoepidemiológico, indicadores de prescrição 


\section{SUMMARY}

The drug use by pregnant must be considered as a public health problem. Revising literature it is noticed that it deals with a behaviour of high therapeutical risk therefore it does innumerable gaps on its effects to the embryo and the pregnant. In this way, a drug use in pregnancy must be made caution.

Pharmacoepidemiologic studies can contribute to minimize the inherent risks the drug use, tracing a pattern on the drug consumption in the pregnancy, identifying which, how many and pointing measured of intervention.

Leaving for estimated, the objective of this study was to trace a pattern of drug consumption in using pregnant 's Health Public System of the city of Piracicaba, SP, through study using the descriptive prescription's indicator WHO and Food and Drug Administration's classification of drug risk to embryo.

One met that: $61,6 \%$ of the pregnant women they utones had used at least one drug in the previous week to research and $18,6 \%$ of then related selfadministered. In medical's consultation $44,7 \%$ had received drug prescription, being the groups of drug mores prescribed those the antianemics (34,9\%) and the antiinfectives $(21,2 \%)$. Ones wory the fact of that, of the prescribed drugs, $77,7 \%$ presented some problem, including drugs absoluted no used in the pregnancy $(1,5 \%)$.

It suggests large drug use during pregnancy and necessary intervention measures need for a rational use of drugs in the pregnancy.

Descriptors: drugs, pregnancy, pharmacoepidemiologic studies, prescription's indicators 


\section{TABELAS / FIGURAS}

FIGURA 1: Distribuição das mulheres entrevistadas por trimestre de gestação, SUS. Piracicaba - SP, 2001 p. 45

FIGURA 2: Fonte de indicação dos medicamentos utilizados pelas gestantes atendidas pelo SUS na semana anterior a consulta. Piracicaba - SP, 2001. p. 47

FIGURA 3: Prática de automedicação entre gestantes atendidas pelo SUS na semana anterior a pesquisa segundo o número de filhos. Piracicaba - SP, 2001. p.49

FIGURA 4: Número e freqüência de prescrição medicamentosa em consulta de pré-natal, SUS. Piracicaba - SP, 2001 p. 57

FIGURA 5: Distribuição das prescrições de medicamentos em consultas de prénatal (SUS) e, relação a Lista de Medicamentos Padronizados pelo município. Piracicaba - SP, 2001 p.64

FIGURA 6: Distribuição dos medicamentos prescritos dentro da dose terapêutica nas consultadas de pré-natal (SUS) segundo a dose recomendada na gravidez. Piracicaba - SP, 2001. p.67

FIGURA 7: Sais de ferro e respectivas concentrações do elemento ferro......p.79 
FIGURA 8: Quadro comparativo entre a distribuição dos medicamentos encontrados por GOMES et al. (1999) e os obtidos no presente trabalho (Piracicaba) nas categorias de risco ao feto (FDA). 89

FIGURA 9: Quadro comparativo entre os indicadores de prescrição relatados por HOGERZEIL (1993) e os obtidos no presente trabalho (Piracicaba). 96

FIGURA 10: FIGURA 10 - Quadro comparativo entre indicadores de prescrição relatados em artigos referenciados e os obtidos no presente trabalho (Piracicaba). 97

TABELA 1: Distribuição dos óbitos segundo os grupos de causa (CID $10^{\mathrm{a}}$ ). Piracicaba - SP, 2000 .p. 28

TABELA 2: Distribuição das gestantes entrevistadas por Unidade Básica de Saúde (UBS) de origem. Piracicaba - SP, 2001. p. 40

TABELA 3: Distribuição das gestantes atendidas pelo SUS segundo a faixa etária. Piracicaba - SP, 2001 p. 41

TABELA 4: Distribuição das gestantes atendidas pelo SUS segundo o grau de escolaridade. Piracicaba - SP, 2001. p.41

TABELA 5: Distribuição das gestantes atendidas pelo SUS segundo a profissão ou ocupação. Piracicaba - SP, 2001. p. 42

TABELA 6: Distribuição das gestantes atendidas pelo SUS segundo a renda familiar referida em salários mínimos (sm). Piracicaba - SP, 2001 p. 43 
TABELA 7: Distribuição das gestantes atendidas pelo SUS segundo o número de pessoas residentes no domicílio. Piracicaba - SP, 2001. p. 44

TABELA 8: Distribuição das gestantes atendidas pelo SUS segundo número de filhos. Piracicaba - SP, 2001 p. 45

TABELA 9: Distribuição das gestantes atendidas pelo SUS segundo a utilização de medicamentos na semana anterior a pesquisa. Piracicaba - SP, 2001_.....p.46

TABELA 10: Distribuição das gestantes atendidas pelo SUS segundo utilização de medicamentos na semana anterior a pesquisa e trimestre de gravidez. Piracicaba - SP, 2001 p.48

TABELA 11: Utilização de medicamentos por gestantes atendidas pelo SUS na semana anterior a pesquisa, segundo fonte de indicação e escolaridade. Piracicaba - SP, 2001 p. 50

TABELA 12: Utilização de medicamentos por gestantes atendidas pelo SUS na semana anterior a pesquisa segundo trimestre da gestação e fonte de indicação. Piracicaba - SP, 2001 p.51

TABELA 13: Distribuição das gestantes atendidas pelo SUS segundo renda per capita, em salários mínimos (sm), e uso de medicação na semana anterior a pesquisa. Piracicaba - SP, 2001 p.51

TABELA 14: Distribuição das gestantes atendidas pelo SUS, que referiram uso de medicamentos na semana anterior a pesquisa, segundo renda per capita, em salários mínimos $(\mathrm{sm}), \mathrm{e}$ fonte de indicação. Piracicaba - SP, 2001 p.52 
TABELA 15: Relação das classes terapêuticas (Sistema ALFA) utilizadas pelas gestantes atendidas pelo SUS na semana anterior a entrevista, por trimestre de gravidez e com os medicamentos mais consumidos dentro de cada classe. Piracicaba - SP, 2001 p.53

TABELA 16: Distribuição dos medicamentos referidos pelas gestantes (SUS) por trimestre de gestação, município de Piracicaba, 2001. p.55

TABELA 17: Relação dos medicamentos mais utilizados por automedicação, referidos pelas gestantes atendidas pelo SUS. Piracicaba - SP, 2001. p. 57

TABELA 18: Distribuição das consultas de pré-natal (SUS) segundo prescrição medicamentosa e trimestre de gestação. Piracicaba - SP, 2001 p.58

TABELA 19: Distribuição das prescrições medicamentosas em consultas de prénatal (SUS) segundo a escolaridade das gestantes. Piracicaba - SP, 2001 p.58

TABELA 20: Medicamentos prescritos nas consultas de pré-natal (SUS) distribuídos segundo trimestre de gestação. Piracicaba - SP, 2001 .p.59

TABELA 21: Medicamentos, por nome genérico, prescritos em consultas de prénatal (SUS) segundo grupo farmacológico (RENAME). Piracicaba - SP, 2001 ..p.61 
TABELA 22: Prescrição de medicamentos em consultas de pré-natal (SUS) segundo nome genérico e trimestre de gestação. Piracicaba - SP, 2001 p. 64

TABELA 23: Distribuição dos medicamentos prescritos em consultas de prénatal (SUS) segundo categorias de risco ao feto (FDA) e os três mais freqüentes (por nome genérico) dentro de cada categoria. Piracicaba - SP, 2001 p.66

TABELA 24: Distribuição dos medicamentos prescritos em consultas de prénatal (SUS) segundo adequação de dose. Piracicaba - SP, 2001 p.67

TABELA 265: Distribuição dos medicamentos prescritos, dentro da dose terapêutica, nas consultas de pré-natal (SUS) segundo adequação de posologia. Piracicaba - SP, 2001 .p. 67 


\section{ÍNDICE}

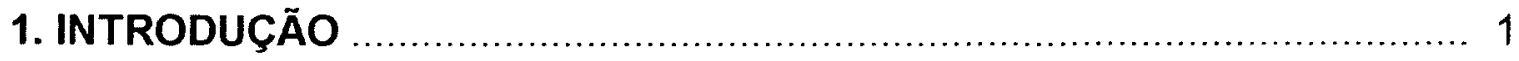

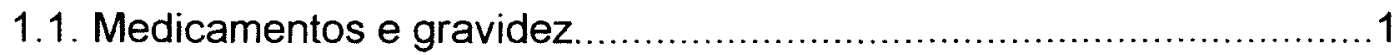

1.2. Estudos de Utilização de Medicamentos .........................................12

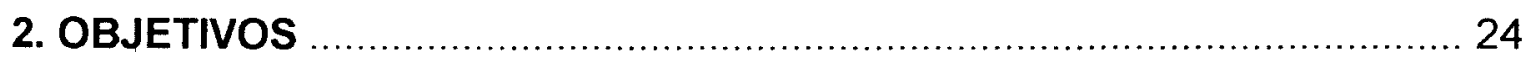

3. METODOLOGIA

3.1. Local de Estudo: Município de Piracicaba - SP ............................26

3.2. Os Serviços de Saúde e o Atendimento a Gestante...........................28

3.3. Os Indicadores Básicos do Uso de Medicamentos...........................30

3.3.1. Seleção dos Serviços de Saúde............................................... 31

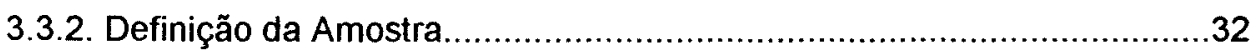

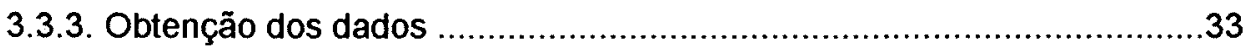

3.4. Indicadores de Prescrição selecionados pela Organização Mundial

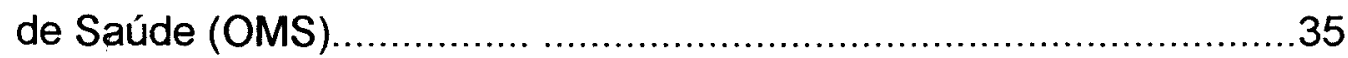

3.5. Categoria de Risco ao Feto - Classificação de Medicamentos segundo o Food and Drug Administration (FDA)..........................39

3.6. Dose e Esquema Terapêutico dos Medicamentos Prescritos............39

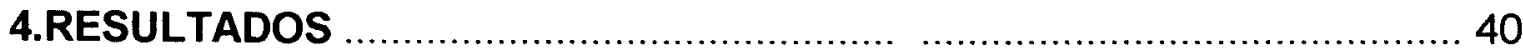

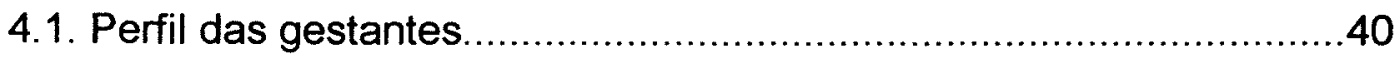

4.2. Dados obtidos na Fase I: pré-consulta.............................................46

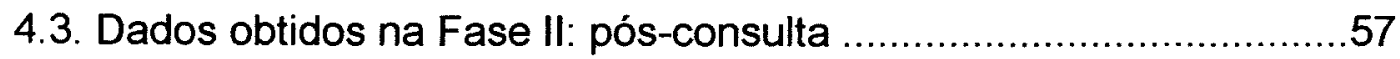

4.4. Indicadores Básicos de Utilização de Medicamentos (OMS):

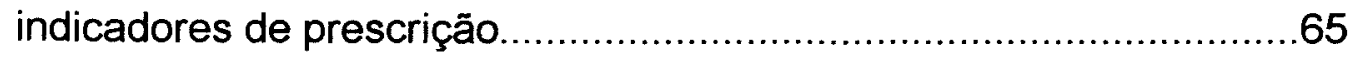


4.5. Classificação dos medicamentos prescritos nas categorias de risco ao feto (FDA)

4.6. Análise da dose e esquema terapêutico dos medicamentos prescritos. 66

5. DISCUSSÃO. 68

5.1. Perfil da gestante e do consumo de medicamentos. .68

5.2. Perfil da prescrição. 74

5.2.1 Medicamentos que atuam sobre o sistema hematopoiético .76

5.2.2 Antiinfecciosos 82

5.2.3 Medicamentos que atuam sobre o sistema digestivo 85

5.2.4 Classificação dos medicamentos prescritos por categoria de risco ao feto (FDA) .88

5.2.5 Análise da dose $e$ do esquema terapêutico dos medicamentos prescritos.

5.2.6 Indicadores Básicos de Utilização de Medicamentos (OMS). 92

6. CONCLUSÃO .98

7. REFERÊNCIAS BIBLIOGRÁFICAS 100

\section{ANEXOS}

Anexo 1: Indicadores de prescrição selecionados pela OMS relatados em artigos referenciados.

Anexo 2: Questionário utilizado para coleta de dados

Anexo 3: Termo de consentimento

Anexo 4: Informações da Vigilância Epidemiológica do Município de Piracicaba

Anexo 5: Lista de Medicamentos Padronizados da Secretaria Municipal de Saúde de Piracicaba / 2001. 


\section{1- INTRODUÇÃO}

\section{1 - MEDICAMENTOS E GRAVIDEZ}

A utilização de medicamentos por gestantes e seus efeitos sobre as futuras crianças passou a ser objeto de grande preocupação após fatos ocorridos entre o final da década de 50 e o início dos anos 60 .

Segundo a literatura consultada', cerca de 10.000 crianças recémnascidas naquele período apresentaram focomelia (até então má-formação rara), bem como outras alterações tais como surdez, paralisia oculomotora e facial, dano ocular e estenose anal, má-formações cardiacas (fatais), além de neuropatia e má-formações vaginais e uterinas identificadas posteriormente.

O primeiro caso descrito, desta natureza, foi em 1959 na Alemanha: uma menina nascida sem os membros superiores e inferiores, de uma mãe primigesta e sem antecedentes familiares de má-formaçōes congênitas (MELLIN \& KATZENSTEIN, 1962).

Após várias observações semelhantes considerou-se a hipótese de que fatores externos, talvez um medicamento novo, recém-lançado, estivesse envolvido com a epidemia.

Em 1961, pesquisadores sugeriram a associação do uso da talidomida durante a gestação aos casos de focomelia e demais alterações. Tratava-se de um medicamento sedativo, utilizado no tratamento de náuseas e vômitos na gravidez, colocado no mercado mundial em 1956 e considerado pela indústria responsável por sua produção um medicamento pouco tóxico ${ }^{2}$. Na verdade, foi

\footnotetext{
${ }^{1}$ MELLIN \& KATZENSTEIN (1962), PRESCRIRE INTERNATIONAL (1998)

${ }^{2}$ Estudos em ratos realizados antes da liberação do medicamento mostraram toxicidade aguda muito débil. Os Estados Unidos baseado em perícias realizadas pelo Food and Drug Administration (FDA) que demonstraram alteraç̃̃es neurológicas em coelhos adultos proibiram sua comercialização. A França também não permitiu seu uso. (PRESCRIRE INTERNATIONAL, 1998).
} 
veiculado como sendo um "medicamento ideal", com eficácia e segurança respaldadas por estudos em animais e testes clínicos (MELLIN \& KATZENSTEIN, 1962).

Este evento, considerado uma catástrofe social, teve importante repercussão internacional constituindo-se um alerta sobre a questão da segurança na utilização de novos fármacos, da importância de normas mais rigorosas em estudos clínicos antes da liberação de medicamentos para o consumo e a necessidade de criação de órgãos de Farmacovigilância. Especificamente em relação a gravidez, provocou decisivas mudanças nas atitudes e práticas relativas a prescrição ao levantar a hipótese de que outros medicamentos comercializados, assim como a talidomida, pudessem ser teratogênicos sem ser reconhecidos como tais ${ }^{3}$.

Segundo MATHIAS \& NOBILE (1981), acreditava-se até então, que a placenta funcionava como uma barreira, protegendo o feto de qualquer agressão farmacológica. A tragédia da talidomida abalou esta crença provocando uma maior cautela na prescrição e utilização de medicamentos na gestação.

De fato, encontra-se em ROZENFELD \& PEPE (1992) a afirmação de que como se dispõe de poucas informações sobre o risco de má-formações congênitas produzidas pelos medicamentos e sobre a excreção dos fármacos pelo leite materno " é essencial evitar na medida do possível, a administração de fármacos durante a gravidez e a lactação".

Atualmente sabe-se que a maioria dos fármacos contidos nos medicamentos utilizados por gestantes atravessa a placenta e atinge a corrente sangüinea do feto. Não se trabalha mais com o conceito de "barreira placentária" (BRIGGS et al., 1987). Deve-se considerar então, que quando uma grávida ingere ou recebe qualquer medicamento dois organismos serão afetados, sendo que um deles (o feto) ainda não tem a mesma capacidade de metabolizar tais substâncias que a mãe, pois não tem os sistemas corporais

\footnotetext{
${ }^{3}$ Collaborative Group on Drug in Pregnancy (CGDUP, 1992) e FORFAR \& NELSON (1990)
} 
plenamente desenvolvidos, estando portanto, mais sujeitos a efeitos negativos não esperados (United Nations Children's Fund - UNICEF, 1992).

MEADOWS (2001) observa que enquanto há certeza do uso, sucesso no tratamento e segurança ao feto de alguns medicamentos na gravidez, na maioria dos casos o conhecimento é limitado, transformando a prescrição de medicamentos neste periodo num grande dilema que deve ser bem avaliado entre o médico e a paciente.

Além das seqüelas da talidomida, o aparecimento de efeitos adversos ${ }^{4}$ envolvendo medicamentos considerados seguros (tais como o ácido acetil salicilico e o cloranfenicol) também contribuiu para que o medicamento, de agente terapêutico por excelência, passasse a ser visto como "elemento problemático" que solicitava estudo (CASTRO, 1998). Corroborando esta afirmação pode-se citar ZENKER et al. (1998) e STAGE et al. (1998).

ZENKER et al. (1998) descrevem um caso de hipertensão pulmonar severa com danos irreversiveis em um recém-nascido decorrente de tratamento da mãe durante cinco dias com diclofenaco (antiinflamatório não esteroidal), duas semanas antes do parto.

SATGE et al. (1998) relatam, que ao realizarem uma revisão sistemática da literatura no que diz respeito a tumores fetais e neonatais, identificaram 89 casos (36 malignos e 54 benignos) em crianças cujas mães utilizaram vários medicamentos no período pré-natal. Segundo os autores seis associaçōes são dignas de nota, entre elas: fenitoína e a ocorrência de neuroblastoma; antibióticos e leucemias e, paracetamol e sarcoma fusocelular.

Neste sentido, da absoluta segurança ao feto e à mãe, CASTRO (1998) ressalta que não há como privar gestantes e crianças aos riscos inerentes à terapia medicamentosa, já que nenhum medicamento é isento totalmente de

\footnotetext{
${ }^{4}$ De acordo com Strom (1994), efeitos adversos ou reações adversas são os efeitos incomuns decorrentes da utilização de medicamentos, não relacionados a dose, imprevisiveis, potencialmewnte sérios e que geralmente exigem a cessação da medicação.
} 
riscos, a não ser pela suspensão total do uso de fármacos, o que seria inadequado. Até porque, assim como no restante da população, durante a gravidez a mulher está sujeita a intercorrências que podem gerar a necessidade de intervenção medicamentosa (GOMES et al., 1999).

Em SETO et al. (1997) encontra-se um exemplo de uma situação extremada: no ano de 1983 o medicamento Bendectin ${ }^{\circledR}$ (antihistamínico composto de doxilamina e piridoxina) foi retirado do mercado devido a um movimento generalizado contra medicamentos utilizados durante a gestação. Logo após tal medida, a taxa de hospitalização de mulheres por hiperemese gravídica dobrou. Os autores lembram que numa atitude precipitada um medicamento seguro foi negado a mulheres que realmente necessitavam dele.

Deve-se considerar entretanto, que crianças e gestantes são grupos de alto risco terapêutico, isto porque os ensaios clínicos exigidos para a comercialização de medicamentos novos, geralmente, são feitos em grupos selecionados de pacientes ${ }^{5}$ e por razões morais e éticas não envolvem gestantes, crianças e idosos.

Desta forma, considera-se que para a maioria dos fármacos não existem dados científicos sobre o verdadeiro risco associado ao seu uso durante a gravidez, ou seja, para maioria dos medicamentos o potencial teratogênico é desconhecido. É importante lembrar, que com exceção dos androgênicos, de alguns medicamentos mitóticos, do valproato de sódio e da Vitamina A e seus derivados, todos os medicamentos identificados como teratogênicos foram conhecidos depois de utilizados por seres humanos e, não em estudos préclínicos em animais (MENGUE et. al., 2001) ${ }^{6}$.

CASTRO (1998) afirma que, em decorrência da realidade encontrada, questões relacionadas à seleção de fármacos, posologia, monitorização

\footnotetext{
${ }^{5}$ CASTRO, 1998, STROM, (1994), LAPORTE et al. (1989) e GOMES et al. (1999)

${ }^{6}$ Segundo FUCHS \& WANNMACHER (1998) os estudos pré-clínicos em animais têm papel fundamental no esclarecimento de princípios e mecanismos de teratogênese, fornecendo uma base para triagem de medicamentos quanto ao potencial teratogênico. Entretanto, são limitados na identificação de teratógenos em humanos devido a diferenças genéticas entre as espécies.
} 
terapêutica e cuidados durante o consumo contam com um grande grau de empirismo. PIPER et al. (1987) ressaltam que na gestação os medicamentos só devem ser utilizados quanto houver um benefício muito claro para a mãe e o medicamento estiver sendo comercializado há um tempo suficiente para ser considerado seguro em relação ao aparecimento de efeitos adversos na população exposta. De modo categórico a UNICEF (1992) recomenda que na ausência de dados sobre a utilização de um medicamento específico na gravidez, ele não deve ser receitado de forma alguma para gestantes.

Existem algumas classificações de medicamentos conforme o risco associado ao seu uso durante a gravidez. Desde 1975, a Food and Drug Administration (FDA) (agência do governo americano responsável pela avaliação, autorização de comercialização e controle de medicamentos e alimentos no país) adota uma classificação de acordo com o risco de um medicamento causar defeitos congênitos e, outros efeitos, na reprodução e na gestação (MEADOWS, 2001). Tal classificação tem o objetivo de auxiliar e orientar a prescrição de medicamentos à gestante.

Segundo a classificação adotada pelo FDA os medicamentos podem ser enquadrados em cinco categorias ${ }^{7}$ :

- CATEGORIA A: Medicamentos para os quais não foram constatados riscos para o feto em ensaios clínicos cientificamente desenhados e controlados;

- CATEGORIA B: Medicamentos para os quais os estudos com animais de laboratório não demonstraram risco fetal (mas não existem estudos adequados em humanos) e medicamentos cujos estudos com animais indicaram algum risco, mas que não foram comprovados em humanos em estudos devidamente controlados;

\footnotetext{
${ }^{7}$ MEADOWS (2001), MENGUE et al. (2001), FUCHS \& WANNMACHER (1998)
} 
. CATEGORIA C: Medicamentos para os quais os estudos em animais de laboratório revelaram efeitos adversos ao feto, mas não existem estudos adequados em humanos e medicamentos para os quais não existem estudos disponíveis;

- CATEGORIA D: Medicamentos para os quais a experiência de uso durante a gravidez mostrou associação com o aparecimento de má-formações, mas que a relação risco-benefício pode ser avaliada;

- CATEGORIA X: Medicamentos associados com anormalidades fetais em estudos com animais e em humanos e ou cuja relação risco-benefício contra indica seu uso na gravidez

É importante salientar que as categorias listadas pelo FDA não implicam necessariamente em uma gradação de risco ou de toxicidade, mas devem ser entendidas com uma avaliação de risco-benefício na gestação (MEADOWS, 2001).

Os medicamentos podem ser ainda classificados quanto à teratogenicidade. Em CASTRO(1998) encontra-se duas categorias:

. os que são "claramente" teratogênicos: aqueles que afetam a maioria dos embriōes expostos, e portanto, são mais facilmente identificados;

. os que "não tem situação teratogênica bem definida": medicamentos que apresentam taxas de risco mais baixas e taxas de exposição variadas ou mesmo desconhecidas, representando perigo latente.

Quanto à teratogenicidade, um agente pode ser considerado teratogênico quando produz uma alteração, maior ou menor, na morfologia e ou fisiologia 
normais do feto, quando administrados durante o desenvolvimento embriológico ou fetal.

Segundo NIEBYL (1989) tem-se historicamente enfocado, principalmente, as anomalias morfológicas evidentes e graves (maiores), mas a tendência é de se ampliar o conceito para inclusão das anomalias estruturais menores, das latentes (que podem aparecer anos depois do nascimento) e das alterações funcionais.

Tais alterações, principalmente as má-formações congênitas, têm maior risco de acontecer quando o medicamento com potencial teratogênico é utilizado no $1^{\circ}$. trimestre de gravidez (periodo de diferenciação embriológica). ROZENFELD \& PEPE (1993) ressaltam que durante a maior parte deste período a mulher pode não saber que está gravida, o que gera um outro problema: a gravidez durante o uso de fármacos.

Nos outros períodos da gravidez podem ocorrer danos fetais decorrentes de alterações na fisiologia materna provocadas por medicamentos, efeitos farmacológicos sobre o feto e interferência no desenvolvimento fetal. Segundo FUCHS \& WANNMACHER (1998) têm-se como exemplo alguns antiiinflamatórios não esteroidais (ibuprofeno, naproxeno e fenoprofeno) que não devem ser utilizados no terceiro trimestre da gravidez pois o uso destes medicamentos nesta fase está associado ao fechamento prematuro do canal arterial e conseqüente hipertensão pulmonar no feto ou neonato. Em CHETLEY (1994) encontra-se relatado que o uso do ácido acetil salicílico no final da gestação pode deter a contração uterina, levar a complicações durante o parto e causar hemorragia no recém-nascido.

Embora sejam úteis, os sistemas atuais de classificação de medicamentos e seus efeitos associados à gestação devem ser utilizados com cautela, pois fornecem informações limitadas sobre a maioria dos medicamentos. Diferentes autores consultados ${ }^{8}$ ressaltam a inexistência de

\footnotetext{
${ }^{8}$ CASTRO (1998), ROZENFELD \& PEPE (1993), STROM (1994), LAPORTE et al. (1989), UNICEF (1992), GOMES et al. (1999).
} 
ensaios clínicos controlados em gestantes e que a maioria dos dados disponiveis referem-se a relato de casos onde um medicamento foi utilizado coincidentemente com a gravidez.

Outro aspecto que deve ser observado quando se trata da utilização de medicamentos por mulheres grávidas é a provável alteração de características farmacocinéticas dos medicamentos no período da gestação (FUCHS \& WANNMACHER, 1998).

BOOBIS \& LEWIS (1982) conceituam farmacocinética como o aspecto da farmacologia clínica que engloba o processo de absorção, distribuição, metabolismo e excreção dos medicamentos e também a relação deste processo com a resposta terapêutica obtida e o aparecimento de efeitos adversos.

Segundo dados da literatura internacional ${ }^{9}$, muito pouco se sabe sobre as mudanças farmacocinéticas na gravidez, isto porque, de acordo com MEADOWS (2001) ainda são necessários muitos estudos para preencher as lacunas existentes sobre as mudanças fisiológicas que ocorrem na gestação e suas conseqüências sobre a farmacocinética dos medicamentos.

De uma forma geral ${ }^{10}$ considera-se que devido ao esvaziamento gástrico mais lento e diminuição da motilidade intestinal na gravidez, a absorção dos fármacos contidos nos medicamentos ingeridos por via oral pode ser retardada.

Durante a gestação ocorre também uma expansão do plasma (e conseqüente aumento do volume sangüíneo) e a diminuição da concentração das proteínas plasmáticas, o que pode interferir na distribuição de algumas substâncias medicamentosas, principalmente daquelas que se ligam fortemente às proteínas plasmáticas.

O metabolismo e a excreção dos medicamentos também podem sofrer alterações devido a aceleração de reações metabólicas (devido ao elevado nivel de progesterona encontrado) e a um aumento da filtração glomerular (decorrente principalmente do aumento do volume sangüíneo).

\footnotetext{
${ }^{9}$ BOOBIS \& LEWIS (1982), MEADOWS (2001)

${ }^{10}$ BOOBIS \& LEWIS (1982), LITTLE (1999) \& MEADOWS (2001)
} 
Acredita-se que tais alterações possam interferir na resposta dosedependente e na toxicidade, mas inexistem dados suficientes na literatura cientifica para se determinar para a maioria dos medicamentos a dose segura e necessária na gravidez.

Apesar de todos os riscos apresentados o quadro que se apresenta atualmente é o da medicalização ${ }^{11}$ da gestante .

PIPER et al. (1987) em estudo retrospectivo realizado em 18.886 mulheres entre 15 e 44 anos, de baixo poder aquisitivo e residentes em zonas urbanas, usuárias do serviço de saúde Medicaid de Michigan no período de 1981 a 1983, observaram que, apesar do consumo de medicamentos ter caído durante a gravidez quando comparado com o periodo pré-gravidez ( 3 meses antes), cerca de $80 \%$ das mulheres receberam pelo menos um medicamento durante o pré-natal (excluindo-se deste percentual aquelas que só receberam vitaminas). Segundo os autores, os medicamentos mais utilizados foram as vitaminas, os antiinfecciosos, medicamentos para pele e mucosas e os analgésicos, em uma média de 3,9 medicamentos/mulher (sendo que quanto maior a idade, maior o número de medicamentos utilizados). Entre os resultados encontrados, o que mais preocupou os autores foi a constatação de que houve consumo de medicamentos conhecidamente contra-indicados para gestantes, tais como tetraciclina e contraceptivos orais.

Em estudo multicêntrico iniciado em 1987, sob patrocínio da OMS Européia, pelo Collaborative Group on Drug Use in Pregnancy (CGDUP, 1992) envolvendo 22 países dos 4 continentes e um total de 14.778 mulheres no pósparto, encontrou-se também um índice de medicalização bastante alto. Apesar das inúmeras diferenças entre as populações estudadas, cerca de $86 \%$ do total

\footnotetext{
11 Segundo BARROS (1995), entende-se por medicalização fenômeno percebido na sociedade contemporânea que se constitui na elevada dependência de serviços ou bens de natureza médico assistencial e conseqüente consumo intensivo das práticas e instrumento considerados de "saúde". Este fenômeno contribui para a transformação de processos fisiológicos normais em estados patológicos, tais como a gestação e o parto, processos que vem sofrendo ao longo do tempo cada vez mais intervençðes médicas (indução artificial e aceleração do trabalho de parto, utilização de anestesia, alto índice de cesáreas, disseminação do uso de medicamentos, entre outros).
} 
das mulheres consumiram pelo menos um medicamento no decorrer da gestação, com uma média de 2,9 medicamentos / mulher. Destas, 85\% receberam prescrição média, $6 \%$ se automedicaram e $1 \%$ recebeu indicação de farmacêutico. Medicamentos a base de ferro $(50,5 \%)$ e suplementos vitamínicos $(46,3 \%)$, sozinhos ou combinados foram os medicamentos mais prescritos, seguidos pelos antiinfecciosos (cerca de 17\%) e pelos analgésicos e antiiinflamatórios (aproximadamente 15\%). Entre os medicamentos utilizados por automedicação foram observados principalmente antiiinflamatórios, analgésicos e antipiréticos (41\%), suplementos nutricionais / hematológicos (33\%) e gastrointestinais (12\%).

FORFAR \& NELSON (1990), em estudo realizado retrospectivamente em 911 mulheres de Edimburgo, encontraram uma prevalência de $65 \%$ de automedicação e $83,1 \%$ de utilização de medicamentos com prescrição médica. As classes de medicamentos mais prescritas foram os suplementos de ferro, vitaminas e sedativos, antidepressivos, tranqüilizantes e estimulantes do sistema nervoso central

No Brasil, trabalhos consultados demonstram que a medicalização da gestante também é um fato.

FONSECA (1998) observou, na cidade de Campinas - SP, uma taxa de $94,6 \%$ de gestantes que tomaram pelo menos um medicamentos durante a gestação, com uma mediana de 3 medicamentos por mulher, sendo que do total de medicamentos utilizados, $21,5 \%$ foram usados no primeiro trimestre e $88,8 \%$ prescritos pelos médicos.

GOMES et al. (1999) encontraram uma prevalência de $94,9 \%$ de gestantes que utilizaram pelo menos um medicamento com indicação médica e $33,5 \%$ por automedicação, sendo que, de uma forma geral, 97,6\% das entrevistadas tomou pelo menos um medicamento durante a gravidez, com uma média de 4,2 medicamentos por mulher. Os medicamentos mais utilizados foram aqueles contendo vitaminas e sais minerais (incluindo aqui os anti-anêmicos) $(86,7 \%)$, seguidos por vacina anti-tetânica $(39,7 \%)$, analgésicos $(30,9 \%)$, 
antiácidos $(27,0 \%)$ e antiespasmódicos $(25,1 \%)$. Ressaltam que a utilização de medicamentos, independente da fonte de indicação (médica ou não médica), foi maior entre as mulheres com grau de escolaridade mais alta, que teoricamente teriam mais acesso a informação sobre os riscos da terapia medicamentosa ao feto.

MENGUE et al. (2001), em estudo realizado em seis cidades brasileiras, com 5.564 gestantes entre a $21^{\mathrm{a}}$. e a $28^{\mathrm{a}}$. semanas de gravidez, observaram que $83,8 \%$ das entrevistadas usaram pelo menos um medicamento na gestação. Os mais utilizados foram em primeiro lugar as vitaminas associadas a antianêmicos $(33,5 \%)$, seguidos pelos medicamentos que atuam sobre o aparelho digestivo $(31,3 \%)$, os analgésicos / antiinflamatórios $(22,2 \%)$, os antianêmicos $(19,8 \%)$ e os antimicrobianos $(11,1 \%)$. Quanto à classificação de risco para o feto, segundo as categorias propostas pelo FDA, $34,0 \%$ dos medicamentos foram enquadrados na categoria $A, 22,6 \%$ na categoria $B, 39,7 \%$ na categoria $C, 3,0 \%$ na categoria $D$ e $0,6 \%$ na categoria $X$. Do total, $12,9 \%$ não foram enquadrados em nenhuma categoria pois não foram encontradas informações suficientes na literatura para tal procedimento. Os dados relatados demonstram que cerca de $40 \%$ dos medicamentos foram utilizados sem bases definidas de segurança. Os medicamentos totalmente contra-indicados corresponderam a 3,0\%. Os autores relatam ainda terem encontrado uma diversidade muito grande em relação ao uso de medicamentos entre as cidades pesquisadas, o que pode ser explicado pelas particularidades dos vários serviços de atenção à saúde, dos problemas de saúde pública pertinentes a cada região e da cultura local.

Em relação ao uso indiscriminado de medicamentos descritos nestes e em outros trabalhos, CASTRO (1998) salienta ainda que, especificamente no Brasil, a falta de controle na venda de medicamentos a gestantes ou a mulheres em idade fértil são fatores contribuintes e preponderantes e, que o panorama brasileiro é o mesmo encontrado em outros países latino-americanos. 


\section{2. ESTUDOS DE UTILIZAÇÃO DE MEDICAMENTOS}

Partindo do pressuposto que não há como abster gestantes da utilização de medicamentos e, consequentemente, da exposição de seus filhos aos riscos inerentes a uma terapia medicamentosa, os estudos epidemiológicos, realizados pós-comercialização dos medicamentos podem ser utilizados para protegê-los de riscos desnecessários ${ }^{12}$. De fato, MITCHELL et al. (1986) relatam que devido aos efeitos teratogênicos de medicamentos tomados durante a gravidez, tem havido um aumento no número de estudos epidemiológicos nesta área.

STROM (1994) salienta que tais estudos podem contribuir entre outras questōes:

para complementar informações disponiveis pelos estudos realizados antes do lançamento dos medicamentos no mercado, ou seja, melhor quantificação da incidência de efeitos adversos ou benéficos já conhecidos, principalmente em pacientes que não foram atingidos antes da comercialização, por exemplo: idosos, crianças e gestantes;

- para obter novas informações além das fornecidas pelos estudos précomercialização, assim como: a descoberta de efeitos adversos ou benéficos indetectáveis previamente (efeitos incomuns ou retardados), modelos de consumo e efeitos de uso abusivo de medicamentos;

. para reafirmar a segurança dos medicamentos.

Isto porque os estudos pré-comercialização ${ }^{13}$ são, necessariamente, limitados em tamanho, tempo e grupos de sujeitos submetidos à pesquisa.

Quanto ao tamanho e grupos de pacientes sob estudo, pode-se dizer que são artificiais, pois trabalham uma amostra (pacientes selecionados) o mais

\footnotetext{
${ }^{12}$ CASTRO (1998) e FONSECA (1998)

${ }^{13}$ STROM (1994) e SPITZER(1991)
} 
homogênea possivel (em termos de idade e patologias definidas) e observada o mais rigorosamente possivel (inclusive quanto ao regime terapêutico).

Em relação ao tempo, eles têm prazo definido para começar e para acabar, ou o medicamento pode nunca ser comercializado. Entretanto, os efeitos adversos do uso de alguns medicamentos podem aparecer depois de anos de latência.

A incorporação dos métodos epidemiológicos para estudar e mensurar os eventos medicamento-mediados que ocorrem nas populações, começou a surgir há cerca de 30 anos e a partir daí uma nova ciência: a "Farmacoepidemiologia" ou a "Epidemiologia dos Medicamentos" (CASTRO, 1998).

Segundo STROM (1994), os anos 60 podem ser considerados como o início do campo da Farmacoepidemiologia, com a publicação de uma série de estudos de utilização de medicamentos.

$\mathrm{Na}$ verdade, o surgimento da Farmacoepidemiologia e o processo de regulamentação governamental dos medicamentos são áreas que evoluíram juntas à partir do aparecimento de sérios efeitos adversos relacionados ao uso destes produtos. STROM (1994) cita, dentre outros, a morte em 1937 de mais de 100 pessoas de insuficiência renal decorrente da utilização de um elixir de sulfanilamida em dietileno-glicol; a descoberta na década de 50 de que o cloranfenicol poderia causar anemia aplástica e o "desastre da Talidomida" na década de 60 . Sem dúvida a epidemia de focomelia, causada pelo uso da talidomida por gestantes, contribuiu decisivamente para o desenvolvimento de ações visando a garantia da segurança dos medicamentos consumidos pela população. Neste sentido destacam-se a criação em 1966 do "Comittee on Safety of Medicines" no Reino Unido, a promulgação em 1962 da emenda "Kefauver-Harris" nos Estados Unidos reforçando a exigência de provas de segurança dos medicamentos $\mathrm{e}$, o desenvolvimento de estudos de utilização de medicamentos que forneceram as primeiras informações sobre a qualidade das prescriçōes médicas. Além disso, em 1960 o FDA iniciou a coleta de notificações espontâneas de reações adversas e começou a patrocinar 
programas de monitorização do uso de medicamentos em hospitais, organizando um dos primeiros sistemas de Farmacovigilância (BARROS, 1992).

Em 1969, em Oslo, num simpósio organizado pela OMS sobre consumo de medicamentos, foi ressaltada a importância dos estudos já conduzidos e a aplicação de métodos epidemiológicos e, sob o patrocinio da entidade, foi criado um grupo com representantes de 14 países para coordenar e realizar pesquisas sobre o tema. Em 1979, o grupo publicou um resumo de suas atividades manifestando um parecer otimista de que, ao levantarem uma série de problemas sem explicação adequada, os estudos e outras análises do uso de medicamentos chegariam com o tempo a constituir uma base importante para melhorar a relação custo / eficácia do tratamento medicamentoso (OMS, 1986).

$\mathrm{Na}$ década de 80, uma série de pesquisadores, entre eles Strom, Porta e Laporte, aliando a epidemiologia e a farmacologia, moldaram a Farmacoepidemiologia (SPITZER, 1991). A primeira vez que o termo foi utilizado em um jornal científico foi em 1984 (COBERT \& BIRON, 2002).

STROM (1994), define a Farmacoepidemiologia como o estudo do uso e dos efeitos dos medicamentos em um grande número de pessoas. Considera que o termo "Farmacoepidemiologia" contém dois componentes: "fármaco" e "epidemiologia". Trata-se, portanto, de um novo campo de aplicação que forma uma ponte entre a farmacologia clínica e a epidemiologia. Em outras palavras é a aplicação dos métodos epidemiológicos no conteúdo da área da farmacologia clínica.

Segundo PORTA et al. (1998) a Farmacoepidemiologia é definida como a aplicação do conhecimento, métodos e raciocínio epidemiológico para o estudo do uso e efeitos (benéficos e adversos) dos medicamentos nas populações humanas. Ressaltam que esta ciência fornece elementos para responder muitas questões que surgem com o desenvolvimento, prescrição e uso dos medicamentos, tais como os impactos médicos, sociais e econômicos do uso dos medicamentos pela sociedade. Seus objetivos são descrever, 
explicar, controlar e predizer o uso e os efeitos dos tratamentos farmacológicos em um definido tempo, espaço e população.

SPITZER (1991) afirma que a Farmacoepidemiologia é uma ciência básica para estudar problemas de saúde medicamento-mediados. Para tanto, cria e refina métodos de estudo, valida as táticas usadas na aplicação de atividades de vigilância e testa hipóteses gerais. Engloba, além de elemento da epidemiologia e da farmacologia, instrumentos da estatística e conhecimento da terapêutica, caracterizando-se como uma ciência "ponte", repleta de interfaces com outras áreas do conhecimento.

Segundo alguns autores ${ }^{14}$, a Farmacoepidemiologia é composta por duas vertentes complementares: a Farmacovigilância e os estudos de Utilização de Medicamentos.

De acordo com NUNES (2000), a Farmacovigilância pode ser conceituada como "o processo de identificação e resposta às alterações previamente conhecidas do binômio benefício-risco que podem surgir durante a comercialização dos medicamentos", correspondendo à Fase IV dos estudos clínicos que buscam demonstrar a eficácia e segurança de cada novo medicamento lançado no mercado, analisando seu uso e efeitos nas condições habituais de consumo ${ }^{15}$.

A Farmacovigilância permite a identificação e avaliação dos efeitos do uso efetivo, agudo ou crônico, dos tratamentos farmacológicos em uma população ou em subgrupos específicos ${ }^{16}$.

\footnotetext{
${ }^{14}$ CASTRO (1998), FONSECA (1998), CASTRO et al. (2000), LAPORTE et al. (1989)

${ }^{15}$ As três fases anteriores dos estudos clínicos ocorrem após os estudos pré-clínicos e antes da comercialização dos medicamentos. Compreendem:

Fase I - teste clínico de um medicamento que jả passou por todos ou pela maioria dos requisitos pré-clinicos. Seu objetivo principal é deterninar a dose máxima tolerada em voluntários saudáveis.

Fase II - testes clínicos de substâncias que já passaram com sucesso através de todos ou quase todos os testes pré-clínicos e pela Fase I. Seu objetivo principal é determinar a dose mínima efetiva baseada em critérios farmacológicos.

Fase III - fase de estudo de um medicamento depois de passar pelas fases I e II. A meta é reunir dados suficientes para garantir a eficácia e a segurança visando autorizar a comercialização do mesmo. (COBERT \& BIRON, 2002).

${ }^{16}$ LAPORTE (1989), BARROS (1991), CASTRO (1998), FONSECA (1998) e CASTRO et al. (2000)
} 
Entretanto, SPITZER (1991) ressalta que a Farmacovigilância ( ou vigilância de medicamentos pós-comercialização), não pode ser confundida com a Farmacoepidemiologia. Segundo o autor, a Farmacovigilância representa um componente da prática de saúde pública que obtêm dados importantes para o uso seguro de medicamentos de forma sistematizada, mas espontânea, ou seja, através de relatos de casos de efeitos adversos. A Farmacoepidemiologia, por sua vez, utiliza-se de metodologia própria, científica, para coletar e analisar os dados

A partir do exposto, pode-se considerar então que a Farmacoepidemiologia é constituida por duas grandes áreas:

estudo de eventos adversos ou benéficos decorrentes do uso de medicamentos através de estudos controlados (caso-controle, estudos de coorte, análise de tendência secular, testes clínicos aleatórios, entre outros desenhos de estudo) (STROM, 1994);

- estudos de utilização de medicamentos (EUM), que segundo a Organização Mundial de Saúde (OMS) são estudos sobre a comercialização, distribuição, prescrição e uso de medicamentos em uma sociedade, com ênfase sobre os resultados médicos, sociais e econômicos (LEE \& BERGMAN, 1994).

Os EUM têm como objetivos identificar os sujeitos, os fatores interferentes e o modo como os medicamentos são utilizados nas populações. Isto inclui saber como se utilizam realmente os medicamentos que estão disponiveis (padrão de consumo), qual o efeito da comercialização, da aquisição e outros fatores sobre esse uso, e, como se comparam os novos medicamentos com seus predecessores no que se refere a eficácia terapêutica e custo

LEE \& BERGMAN (1994) ressaltam que os objetivos gerais dos EUM são a identificação e a análise dos problemas em relação a importância, causas e conseqüências; estabelecendo bases para decisões sobre a solução dos mesmos. Estes objetivos são importantes para tomada de decisões não somente em relação aos medicamentos, mas também sobre a cadeia de saúde 
de forma global, já que o uso de medicamentos se dá dentro de um contexto mais amplo.

Isto porque, levando-se em consideração as orientações do Norsk Medicinal Depot (Noruega), os dados sobre utilização de medicamentos podem empregar-se para as seguintes finalidades (OMS, 1996):

. descrever as características gerais do uso de medicamentos; - facilitar a preparação de perfis terapêuticos ao longo do tempo;

. formular estimativas aproximadas a respeito do número de doentes que recebem diversos medicamentos;

determinar o efeito dos esforços educativos, informativos, regulatórios e das políticas de preços;

definir novas áreas de investigação da eficácia e da inocuidade da farmacoterapia;

. identificar os usos excessivos, insuficientes, indevidos e abusivos dos medicamento;

- determinar as necessidades de medicamentos em função da estrutura de morbidade, para contribuir com o planejamento da seleção e da distribuição de medicamentos.

Os EUM podem ser quantitativos ou qualitativos (LEE \& BERGMAN, 1994).

Os estudos quantitativos têm como objetivo quantificar a condição encontrada, a tendência de crescimento e o tempo decorrido da utilização do medicamento nos vários níveis dos sistemas de saúde, seja nacional, regional, local ou institucional. Rotineiramente são usados para estimar a utilização de medicamentos em uma população por variáveis, tais como idade, sexo, classe social e morbidade; para identificar áreas de pouca ou muita utilização; calcular padrão de reações adversas ou monitorar a utilização de categorias específicas de medicamentos. São úteis principalmente em ações administrativas e na definição de políticas sanitárias, pois fornecem dados que subsidiam um melhor 
planejamento da importação, produção e distribuição de medicamentos, bem como estimativas dos gastos com medicamentos.

Por outro lado, os estudos qualitativos avaliam a adequação da utilização dos medicamentos, usualmente pela vinculação aos dados de prescrição e aos fatores que a influenciam.

A diferença crucial entre os dois tipos de estudos é que o último inclui o conceito de "adequação". Através de parâmetros como indicação de uso, dose diária e extensão da terapia, permitem a comparação da qualidade da prescrição, a avaliação da necessidade e ou o uso inapropriado dos medicamentos.

Os EUM podem também ser classificados em função do elemento principal que pretendem analisar (CÁRDENAS \& OBREGÓN, 1997):

estudos de consumo;

estudos de prescrição - indicação;

estudos de indicação - prescrição;

estudos sobre o esquema terapêutico;

estudos dos fatores que determinam os hábitos de prescrição ou

dispensação;

estudos das conseqüências práticas da utilização dos

medicamentos;

estudos de intervenção.

Segundo SIMÕES (2000) diferentes aspectos podem ser abordados nos EUM, destacando-se os aspectos médicos (eficácia na prevenção, reações adversas, riscos especiais associados a situações específicas, como por exemplo: gravidez); os aspectos sociais (uso irracional, atitudes frente ao medicamento) e os aspectos econômicos (custos referentes ao preço de produção e importação, à prescrição, distribuição e uso).

A OMS baseada nos conceitos que embasam os EUM e no reconhecimento de que se tratam de importante instrumento na busca do uso racional de medicamentos, publicou, na década de 90 , manuais com 
metodologias para investigar o uso de medicamentos nas comunidades visando subsidiar o estabelecimento de programas e politicas em diferentes paises.

Estes manuais surgiram a partir de discussões, avaliações e proposições definidas na "Conferencia de expertos sobre uso racional de medicamentos" promovida pela OMS em Nairobi (Kenia) em 1985 (OMS, 1986).

Durante este congresso alguns participantes formularam propostas para o estabelecimento de um programa especial que permitisse uma avaliação das ações de atenção a saúde em geral e da utilização de medicamentos em particular.

Em relação aos medicamentos conclui-se que, no que dizia respeito ao seu uso e a prática da prescrição, faltavam mais informações.

Observou-se também que para produzir dados que possibilitassem posterior análise e comparações, se fazia necessário a construção de um instrumento objetivo e padronizado que pudesse ser utilizado em diferentes serviços de saúde e em diferentes localidades, tanto em países desenvolvidos como subdesenvolvidos.

A OMS coordenou então alguns estudos iniciais no Yemen e em Uganda e depois de analisá-los, membros do "International Network for the Racional Use of Drugs" (INRUD) em colaboração com o "WHO - Action Programme on Essential Drugs" Medicamentos Essenciais da OMS empreenderam esforços para desenvolver, padronizar, testar e refinar um conjunto de indicadores básicos de utilização de medicamentos (HOGERZEIL, 1995). Os indicadores propostos foram primeiros testados na Indonésia, Bangladesh, Nepal e posteriormente em outros países subdesenvolvidos (HOGERZEIL et al., 1993).

A partir dos trabalhos realizados, em 1992 foi publicado o manual How to investigate drug use in communities, onde se encontra uma metodologia própria para investigar quais as formas de utilização de medicamentos em populações levando-se em consideração, principalmente, os seguintes fatores: formas de aquisição, características das unidades de saúde, adesão ou não às prescrições 
dos profissionais de saúde, prática de automedicação e medicamentos mais utilizados com ou sem prescrição.

Em 1993, outro manual, Como investigar el uso de medicamentos en los servicios de saúde, trouxe a metodologia de construção de indicadores selecionados para caracterizar e avaliar o uso de medicamentos a partir dos serviços de saúde estabelecendo três níveis de diagnóstico:

a . as práticas de prescrição dos profissionais do serviço de saúde;

b. a assistência ao paciente (tanto em relação à consulta ambulatorial quanto à prescrição);

c. a disponibilidade de fatores específicos de serviços propiciadores do uso racional, como existência de medicamentos essenciais e um mínimo de informação farmacêutica.

A metodologia proposta parte de um reduzido número de indicadores básicos do uso de medicamentos, divididos em três grupos, e de indicadores complementares. Os indicadores básicos são:

\section{Indicadores de prescrição:}

1. número médio de medicamentos por consulta

2. porcentagem de medicamentos prescritos pelo seu nome genérico

3. porcentagem de consultas em que se prescrevem antibióticos

4. porcentagem de consultas em que se prescrevem medicamentos injetáveis

5. porcentagem de medicamentos prescritos que figuram na lista de medicamentos essenciais do serviço

\section{Indicadores da assistência ao paciente:}

6. tempo médio de consulta

7. tempo médio da dispensação de medicamentos

8. porcentagem de medicamentos realmente dispensados 
9. porcentagem de medicamentos corretamente rotulados

10. conhecimento da dose correta por parte dos pacientes

\section{Indicadores sobre o serviço:}

11. disponibilidade de cópias da lista de medicamentos essenciais

12. disponibilidade dos medicamentos essenciais

E os indicadores complementares:

1. Porcentagem de pacientes tratados sem medicamentos

2. Custo médio de medicamentos por consulta

3. Porcentagem de custo dos medicamentos correspondente a antibióticos

4. Porcentagem de custo dos medicamentos correspondente a injetáveis

5. Prescrição conforme as diretrizes terapêuticas

6. Porcentagem de pacientes satisfeitos com a assistência recebida

7. Porcentagem de serviços de saúde com acesso a informação imparcial sobre os medicamentos.

Quanto aos indicadores básicos, a OMS considera que são parâmetros altamente normatizados, objetivos, que não tem que ser adaptados a cada país, e ou a cada realidade e cujo emprego é recomendado para qualquer estudo sobre o uso de medicamentos realizados por meio de indicadores. Pelo contrário, os indicadores complementares são extremamente sensiveis aos contextos locais sendo considerados ferramentas adicionais de avaliação das práticas de utilização de medicamentos

Todos os dados necessários para determinar os indicadores básicos se extraem de arquivos clínicos (prontuários individuais de pacientes) ou provêm de observações diretas realizadas nos serviços de saúde. Os dados podem ser 
obtidos retrospectivamente ou prospectivamente ou, ainda, baseados em pesquisas transversais.

Para sua construção são recomendados desenhos de estudo norteados por parâmetros básicos que possibilitam uma comparação entre indicadores construídos em diferentes localidade e serviços.

É importante ressaltar que a própria OMS admite que estes indicadores não quantificam todos os aspectos importantes da utilização de medicamentos (o que necessitaria de metodologia mais detalhada), entretanto, se constituem em um instrumento sensível que permite avaliar com rapidez e segurança um reduzido número de aspectos decisivos da prática farmacêutica na atenção primária à saúde.

No Brasil, apesar dos EUM terem crescido nos últimos anos (Castro, 2000), são poucos os pesquisadores que usaram esses indicadores na metodologia de estudo ${ }^{17}$. Pode-se citar LOPES et al. (1986) com uma pesquisa realizada em Fortaleza, CE, CUNHA \& CASTRO (1999) em Campo Grande , MS, SIMÕES \& FEGADOLLI (1996) em Araraquara, SP, SIMÕES \& SOLER (1996) em Tabatinga, SP, SIMÕES \& MOTTA (1996) em Ribeirão Preto, SP, SANTOS (1999) em Ribeirão Preto, SP e SIMÕES \& CARNEIRO (2001) em Araraquara, SP. Sendo que a maioria delas não chegou a ser publicada em revistas cientificas, mas apresentados em congressos científicos, na forma de monografia (SIMÕES \& SOLER, 1998) ou dissertação de mestrado (SANTOS, 1999). No anexo 1 pode-se verificar os indicadores de prescrição obtidos nestes trabalhos.

Finalizando, a partir da literatura revisada, è importante salientar que cada vez mais os EUM têm sido considerados como importante ferramenta para planejar e gerenciar os serviços de Assistência Farmacêutica, nortear a Política de Medicamentos e subsidiar a Política de Saúde no país. Isto porque os medicamentos ocupam, atualmente um lugar importante nos sistemas de saúde,

\footnotetext{
17 Ver SANTOS (1999) e SIMÕES (2000)
} 
tanto no aspecto económico ${ }^{18}$,quanto nos aspectos técnicos (resolutividade dos serviços) e sociais (uso racional de medicamentos).

${ }^{18}$ Segundo Joncheere (1997) as porcentagens do gasto com medicamentos variam de $8 \%$ do total do investimento em saúde em países desenvolvidos, até $40 \%$ em países em desenvolvimento. 


\section{2 - OBJETIVOS}

Considerando as particularidades apresentadas em relação ao uso de medicamentos na gestação e aceitando como premissa a necessidade de estudos farmacoepidemiológicos para subsidiar e minimizar os riscos da terapia medicamentosa neste período, este trabalho apresenta como objetivo geral a investigação do uso de medicamentos em gestantes usuárias do Serviço Municipal de Saúde de Piracicaba.

E, como objetivos específicos:

caracterizar as gestantes usuárias do serviço através de levantamento de dados sócio - econômicos, idade e mês de gestação;

identificar os medicamentos utilizados pelas gestantes (tanto os prescritos pelos médicos, quanto os utilizados por automedicação);

construir os indicadores de prescrição preconizados pela OMS;

classificar os medicamentos nas categorias de risco ao feto segundo proposição do FDA;

analisar o esquema terapêutico dos medicamentos prescritos;

levantar possiveis riscos e efeitos adversos dos medicamentos mais freqüentemente prescritos. 


\section{3 - METODOLOGIA}

Este trabalho foi desenvolvido no município de Piracicaba - SP, com gestantes usuárias de serviços de pré-natal de atenção primária, no período de janeiro a outubro de 2001. No total foram entrevistadas 427 mulheres, que faziam o acompanhamento de pré-natal em Unidades Básicas de Saúde e na maternidade da Santa Casa de Misericórdia (nesta última somente com gestantes encaminhadas pelo Sistema Único de Saúde (SUS) e matriculadas em UBS sem o serviço de pré-natal estruturado).

A metodologia utilizada envolveu cinco etapas:

1. caracterização do atendimento de pré-natal do Serviço Municipal de Saúde de Piracicaba, identificação das UBS (atenção primária) que faziam o atendimento às gestantes e dos procedimentos adotados pelas unidades que não tinham o serviço estruturado;

2. definição da metodologia de abordagem das gestantes, construção do instrumento de pesquisa (questionário) e realização de pré-teste para sua aferição e treinamento dos entrevistadores;

3. entrevistas às pacientes nas unidades de saúde, antes (Fase I) e depois (Fase II) da consulta médica, através da aplicação de questionários ${ }^{19}$, posterior ao consentimento das mesmas ${ }^{20}$;

4. construção dos indicadores de prescrição preconizados pela OMS;

5. identificação dos medicamentos utilizados pelas gestantes (sejam eles prescritos por médicos ou utilizados por automedicação), posterior classificação dos mesmos nas categorias de risco para o feto propostas pelo FDA, quantificação de medicamentos por paciente,

\footnotetext{
${ }^{19}$ Anexo 2

${ }^{20}$ Anexo 3
} 
6. caracterização do tempo de gestação e da posologia (dose e horário de tomada) do medicamento, discussão sobre possíveis riscos e efeitos adversos e levantamento de alguns dados sócio-econômicos (renda familiar e grau de instrução), entendendo-se que a discussão sobre a utilização de medicamentos durante a gravidez requeria um maior refinamento não permitido pelos indicadores básicos de utilização de medicamentos.

Tratou-se, segundo ROUQUAYROL \& ALMEIDA FILHO (1998), de um estudo individuado - observacional - transversal (ou seccional), baseado em avaliações individuais

Para JARAMILLO \& MORENO ROJAS (1994), estudos deste tipo são utilizados quando se quer quantificar um efeito, avaliar a freqüência de exposição a fatores de risco e ou explorar a associação entre esses fatores e o efeito, enfim, metodologia adequada aos objetivos deste trabalho. Entretanto, é importante salientar que como não possibilitam medir fatores de risco antes do efeito, não se prestam para determinar relações de causalidade, mas apenas para estimar associações, limitação esta que não interfere nos objetivos traçados.

Os resultados obtidos foram organizados através do Software Epi Info 6.0.

\section{1 - LOCAL DE ESTUDO: MUNICÍPIO DE PIRACICABA - SP}

Piracicaba, situada em uma das regiōes mais industrializadas do Estado de São Paulo, é uma cidade de porte médio, com população no ano 2000 de 329.158 habitantes (FUNDAÇÃO SEADE, 2002) e, segundo dados tabulados pelo Projeto Piracicaba 2010 (MOURÃO, 2001), com atividade produtiva diversificada mas com predominância das áreas econômicas tradicionais (atividades agrícolas - que integram a história do município através do plantio da cana de açúcar e atividades industriais - especialmente a metal - mecânica). 
Cerca de $21,0 \%$ de sua população está empregada no setor formal da economia e $48,0 \%$ do total de trabalhadores não possuem sequer $01^{\circ}$. grau (Ensino Fundamental).

Apesar da baixa taxa de escolaridade da mão de obra, possui forte presença de instituições de ensino superior e pesquisa, atraindo estudantes e profissionais de várias cidades da região.

Quanto ao perfil da Educação do municipio, a ausência de um banco de dados sobre o tema dificulta o conhecimento real da situação. Sabe-se que existem atualmente cerca de 50.910 alunos matriculados no ensino fundamental (90,3\% do total de habitantes na faixa etária entre 05 e 14 anos) e 16.860 alunos no ensino médio $(51,6 \%$ do total de habitantes na faixa etária entre $15 \mathrm{e}$ 19 anos).

Em relação a estrutura etária, percebe-se um processo de envelhecimento populacional com um aumento progressivo de pessoas na faixa etária de 65 anos e mais e diminuição na redução de nascimentos (MOURÃO, 2001).

Segundo os censos do IBGE, a taxa de crescimento da população vêm se reduzindo desde a década de 70 , diminuindo a pressão por novos empregos e infra estrutura urbana, facilitando o planejamento político - administrativo do município.

Em relação ao sexo, $50,6 \%$ da população é feminina, sendo que $61,8 \%$ dela se encontra em idade fértil ${ }^{21}$.

As principais causas de morte observadas no ano 2000 foram as doenças do aparelho circulatório, causas mal definidas, neoplasias, causas externas e doenças do aparelho respiratória. A mortalidade por causa ligadas a gravidez, parto e puerpério representou $0,1 \%$ do total de mortes. Na Tabela 1 pode-se verificar a distribuição dos óbitos segundo os principais grupos de causa.

\footnotetext{
${ }^{21}$ A idade fértil ou período reprodutivo corresponde a faixa etária de 14 a 49 anos, segundo Rouquayrol \& Almeida Filho (1999)
} 
TABELA 1: Distribuição dos óbitos segundo os grupos de causa (CID $10^{a}$ ). Piracicaba - SP, 2000

\begin{tabular}{lccc}
\hline \multicolumn{2}{c}{ Grupo de causa } & freqüencia & $\%$ \\
$\begin{array}{l}\text { doenças do aparelho } \\
\text { circulatório }\end{array}$ & 437 & 21,7 \\
mal definidas & 327 & 16,3 \\
neoplasias & 312 & 15,5 \\
causas externas & 193 & 9,6 \\
$\begin{array}{l}\text { doenças do } \\
\text { respiratório }\end{array}$ & aparelho & 180 & 9,0 \\
outras & & 561 & 27,9 \\
\hline Total & & 2010 & 100,0 \\
\hline
\end{tabular}

Fonte: Banco de dados da Divisão de Vigilância Epidemiológica do Município de Piracicaba

De acordo com a Vigilância Epidemiológica Municipal (anexo 4) os coeficientes mortalidade geral (CMG), mortalidade infantil (CMI) e mortalidade materna encontrados no ano 2000 foram respectivamente 6,1 por 1000 habitantes, 13,2 por 1000 nascidos vivos e 0,4 por 1000 nascidos vivos.

Em relação ao saneamento básico, 99,0\% da população tem acesso a suprimento de água potável e $98,0 \%$ conta com rede coletora de esgotos. Entretanto, apenas $36 \%$ do esgoto é tratado, sendo o restante lançado in natura nos rios que cortam a cidade (Piracicaba e Corumbataí), causando um problema sério de saúde ambiental.

\section{3 . 2 - OS SERVIÇOS DE SAÚDE E O ATENDIMENTO À GESTANTE}

No âmbito da gestão do Sistema Único de Saúde, Piracicaba está enquadrada na Gestão Plena, sendo o município, portanto, responsável pela gerência de todos os serviços de saúde vinculados ao SUS, tanto públicos como os privados contratados e conveniados. 
Segundo informações da Secretaria Municipal de Saúde (SMS), no ano de 2000 a cidade contava com uma rede SUS composta de:

288 leitos hospitalares ofertados por 2 hospitais filantrópicos;

26 Unidades Básicas de Saúde;

17 Unidades de Saúde da Familia (USF) como sede de 20 equipes do Programa de Saúde da Família (PSF);

1 Ambulatório de Especialidades;

1 Ambulatório do Servidor;

1 Ambulatório do Trabalhador;

1 Centro de Atendimento Psicológico (CAPS Vila Sônia);

1 Centro de Atendimento de Saúde Mental (CASME);

1 Centro de Atendimento à Criança e ao Adolescente (CACAD);

1 Centro de Doenças infecto-contagiosas (CEDIC);

1 Centro de Especialidades Odontológicas (CEO);

1 Centro de Ortopedia (COT);

1 Laboratório Municipal;

1 Núcleo do Adolescente - atenção primária;

1 Programa de Atendimento Domiciliar (PAD);

. 1 Programa de Atendimento Integrado de Saúde da Mulher (PAISM) exames preventivos e diagnósticos;

4 Unidades de Atendimento de Urgência (UAU);

1 Serviço de Fisioterapia;

1 almoxarifado central;

4 Farmácias Regionais;

1 Farmácia de Medicamentos Excepcionais de Alto custo;

1 Farmácia no CEDIC;

7 Unidades de Dispensação Descentralizada (5 em UBSs urbanas, 1 em UBS rural e 1 em uma USF).

A rede de serviços apresentava-se dividida territorialmente em 5 macroregiões administrativas: Macro-região Central, Macro-região Vila Cristina; 
Macro-região Santa Terezinha; Macro-região Piracicamirim e Macro-região Rural, oferecendo uma relação aproximada de 1 UBS / 8.100 habitantes e 1 equipe de PSF / 800 familias.

Esta rede produziu em 1999 um total de 2,2 milhões de consultas, 43,3\% em atendimentos ambulatoriais e 56,7\% em atendimentos de urgência (MOURÃO, 2001). Percebe-se pelos dados uma inversão do modelo assistencial proposto pelo SUS, que tem na atenção primária a porta de entrada do sistema. Em Piracicaba, observa-se um serviço centrado no prontoatendimento

Quanto ao atendimento hospitalar, além dos leitos SUS, o município possuía 392 leitos para atendimento de pacientes particulares, o que representa, considerando-se o total de leitos, uma relação de 2,06 leitos / 1.000 habitantes.

Em relação ao atendimento à gestante, apenas 6 unidades de atenção primária à saúde apresentavam atendimento de pré-natal no periodo do levantamento de dados. A maior parte dos pré-natais eram realizados nas maternidades dos hospitais filantrópicos conveniados ao SUS.

\section{3 - OS INDICADORES BÁSICOS DO USO DE MEDICAMENTOS}

A partir dos objetivos traçados neste trabalho, isto é a obtenção do perfil de utilização de medicamentos por gestantes atendidas na atenção primária do município, optou-se, dentre os indicadores propostos pela OMS, por se construir apenas aqueles que estivessem diretamente relacionados à composição deste perfil

Após análise detalhada dos indicadores básicos, decidiu-se pelos indicadores de prescrição, entendendo-se que tais indicadores refletem o funcionamento da assistência à saúde em relação a diversos aspectos chaves relacionados à utilização de medicamentos, tais como: grau de polimedicação, tendência de prescrição por nome genérico, abuso de medicamentos 
específicos (antibióticos e injetáveis) e porcentagem de adesão dos prescritores à lista de medicamentos considerados essenciais pelo município.

Segundo a OMS (1993), para construção dos indicadores de prescrição deve ser feita:

. a seleção dos serviços de saúde que serão objetos do estudo;

. a definição do tamanho da amostra necessária;

. o estabelecimento da forma de obtenção dos dados.

\section{3. 1 - Seleção dos serviços de saúde}

Em relação aos serviços, num primeiro momento foi estabelecido que a obtenção dos dados necessários à construção dos indicadores se daria por meio de entrevistas de gestantes usuárias de UBSs que possuíssem atendimento de pré-natal.

Entretanto, após consulta à Secretaria Municipal de Saúde, foram identificadas apenas 4 UBSs com atendimento à gestante (UBS Piracicamirim, UBS Santa Terezinha, UBS Vila Cristina e UBS Alvorada), além da Unidade de Saúde da Família do Cecap e do Núcleo do Adolescente. O restante das 26 UBSs não possuía o serviço estruturado. É importante ressaltar que a pesquisa ocorreu em um período de transição de governo (mudança de Prefeito, Secretários e consequentemente reformulação das políticas públicas e de alguns serviços). Segundo dados da SMS, havia no início do ano um déficit de obstetras na rede municipal de saúde. Para equacionar a demanda, foi readequado um convênio já existente entre o município e dois hospitais filantrópicos (a Santa Casa de Misericórdia e o Hospital dos Fornecedores de Cana) para oferecimento de consultas de pré-natal às gestantes matriculadas em UBSs sem obstetras.

A partir destas informações, optou-se por entrevistar as gestantes nas seis unidades já citadas e na maternidade da Santa Casa de Misericórdia. As mulheres atendidas na Santa Casa foram posteriormente identificadas e 
relacionadas por UBS de origem. A Santa Casa foi escolhida, em detrimento do outro hospital, pela sua localização geográfica centralizada, facilitada do acesso das usuárias e, consequentemente, da adesão ao pré-natal, bem como pelo seu volume de atendimento (cerca de $80 \%$ das consultas de pré-natal realizadas em maternidades).

Para tentar evitar qualquer viés metodológico, não entrevistou-se gestantes de risco ou em atendimento de urgência, mas apenas aquelas em consultas de rotina.

Também não foram construídos indicadores por unidade de saúde, conforme proposição da OMS, para impossibilitar comparações entre condutas particulares de prescritores. Vale ressaltar que nas seis unidades envolvidas no estudo havia, com exceção de uma unidade com dois profissionais, apenas um obstetra em cada uma delas.

\section{3. 2 - Definição da amostra}

Para definição do tamanho da amostra, partiu-se da hipótese de que em Piracicaba a prevalência de utilização de pelo menos um medicamento por gestante seria de cerca de $80 \%$. Tal hipótese foi elaborada baseando-se em trabalhos relatados sobre consumo de medicamentos na gestação ${ }^{22}$.

Considerando a prevalência ao redor de $80 \%$ e estabelecida uma margem de erro tolerável de $5 \%$ (com um nível de confiança de 95\%), foi definido segundo metodologia referenciada por VAUGHAN \& MORROW (1992) uma amostra com no mínimo 246 entrevistadas. Para se chegar a este resultado utilizou-se a seguinte fórmula:

$$
n=\frac{p \cdot q}{(E \div 1,96)^{2}}
$$

${ }^{22}$ PIPER et al. (1987), CGDUP (1987), FONSECA (1998), GOMES et al. (1999) e MENGUE et al. (2001). 
onde: n é o tamanho mínimo da amostra

$p$ é a taxa de prevalência esperada (\%)

$q=100-p$

E é a margem de erro tolerada (\%)

$$
\text { então: } \mathbf{n}=\frac{80 \cdot 20}{(5 \div 1,96)^{2}}=\mathbf{2 4 6} \text { indivíduos }
$$

Visando-se garantir o necessário para assegurar a relevância estatística da amostra e também seguir a recomendações da OMS (1993) de realização de 30 entrevistas por serviço de saúde, estabeleceu-se que nas unidades onde havia pré-natal seriam envolvidas no mínimo 30 gestantes de cada uma. As demais seriam entrevistadas na maternidade.

No total foram ouvidas 427 mulheres, no período de janeiro a outubro de 2001, o que segundo dados fornecidos pela SMS representou cerca de $5,6 \%$ do total de consultas de pré-natal realizadas no periodo ( 7546 consultas).

\section{2.3 - Obtenção dos dados}

Para obtenção dos dados foi utilizado questionário estruturado com algumas perguntas abertas e outras fechadas, aferido em pré-teste realizado com 15 gestantes na UBS do CECAP, nos meses de novembro e dezembro de 2000, após análise e aprovação do projeto de pesquisa pelo Comitê de Ética em Pesquisa da Faculdade de Saúde Pública (FSP) da Universidade de São Paulo (USP).

As entrevistas foram realizadas por 4 alunos do curso de Farmácia da Universidade Metodista de Piracicaba e pela autora deste trabalho, em duas fases. A primeira fase constituiu-se em inquérito sobre dados gerais da gestante e sobre o consumo de medicamentos na última semana anterior a entrevista. Já 
a segunda caracterizou-se pela verificação da existência ou não de prescrição de tratamento medicamentoso e, em caso positivo, posterior anotação da receita médica na integra.

A primeira fase era realizada antes da consulta médica para se tentar levantar dados de automedicação na semana anterior sem a interferência de qualquer observação médica (que pudesse ocorrer durante a consulta). O prazo de uma semana foi estabelecido para minimizar o que MITCHELL et al. (1986) chamam de "viés materno de recordação", ou seja, a não menção da utilização de medicamentos por esquecimento ou por outros motivos.

No caso de esquecimento, VAUGHAN \& MORROW (1993) afirmam que o máxìmo que se pode esperar para dar fidedignidade aos dados é recordação de fatos ocorridos nas últimas duas semanas antes da entrevista.

Em outros casos, o viés de recordação pode acontecer por omissão, principalmente quando se trata de automedicação. A gestante têm a informação de que não deve se automedicar porque isto pode trazer prejuízos ao feto e então não relatar o fato para não ser recriminada. $O$ dado encontrado portanto pode estar subestimado, o que não invalida a pesquisa, pois este fenômeno é relatado e tolerado em trabalhos similares já citados.

Os dados obtidos na Fase II foram destinados à construção dos indicadores.

Vale ressaltar ainda que para a elaboração dos indicadores básicos de prescrição não há a necessidade de se levantar informações sobre sinais ou sintomas das pacientes, pois eles refletem as práticas gerais de prescrição em determinadas circunstâncias, independentemente de diagnósticos específicos e também de sazonalidade ${ }^{23}$.

\footnotetext{
${ }^{23}$ OMS (1993) e Santos (1998)
} 
3. 4 - Indicadores de prescrição selecionados pela Organização Mundial de Saúde (OMS)

Os indicadores de prescrição propostos pelas OMS (1993) são cinco:

\section{1. número médio de medicamentos por consulta:}

objetivo: determinar o grau de polimedicação

. requisitos: considerar especialidades farmacêuticas compostas por combinações medicamentosas com um único medicamento

cálculo:

média obtida dividindo-se o número total de medicamentos prescritos pelo total de entrevistas realizadas

Obs.: foi considerado como denominador o número de consultas (e não o de prescrições) conforme orientação da OMS (1993).

\section{2. porcentagem de medicamentos prescritos por nome genérico}

objetivo: determinar o grau de prescrição de medicamentos pelo nome genérico

. requisitos: considerar o nome genérico a partir de uma lista de referência

cálculo : 
$\%=$ número de medicamentos prescritos pelo nome genérico $\times 100$ número total de medicamentos receitados

Obs. : 1. Neste trabalho a lista de referência utilizada foi a Denominação Comum Brasileira - DCB (1996) ${ }^{24}$

2. foi considerado prescrição por nome genérico as receitas que utilizaram a nomenclatura "Vitaminas e Sais Minerais", medicamento constante da Relação Nacional de Medicamentos Essenciais (2000) e da Lista de Medicamentos Padronizados da SMS de Piracicaba.

\section{3. porcentagem de consultas em que se prescreve antibióticos}

objetivo: determinar o nivel geral de uma das mais importantes modalidades de tratamento farmacológico que é ao mesmo tempo geralmente custosa e objeto de abuso

requisitos: definição dos medicamentos que serão classificados como antibióticos

cálculo:

$\%=\underline{\text { número de consultas em que se receita um antibiótico }} \times 100$ número total de consultas envolvidas no estudo

Obs. : 1. foram considerados antibióticos os medicamentos assim classificados pela RENAME (2000) e ou por Fuchs (1998), mesmo quando em associação com outras substâncias ativas.

\footnotetext{
${ }^{24}$ Portaria no. $1179-17 / 06 / 96$ - Ministério da Saúde
} 
mesmo quando em associação com outras substâncias ativas.

2. assim como em Santos (1998), o metronidazol não foi classificado como antibiótico, mas sim como antiparasitário, já que esta é sua principal indicação terapêutica no Brasil.

\section{4. porcentagem de consultas em que se prescreve um medicamento}

injetável

objetivo: determinar o nivel geral de uma das mais importantes modalidades de tratamento farmacológico que é ao mesmo tempo comumente custosa e objeto de abuso

requisitos: não classificar vacinas como injetáveis

cálculo:

$\%=$ número de consultas em que se receita um injetáveis $\times 100$ número total de consultas envolvidas no estudo

Obs.: a única vacina mencionada - dupla adulta (DPT - contra difteria e tétano) não foi contabilizada como injetável.

\section{5. porcentagem de medicamentos prescritos que figuram na lista de} medicamentos essenciais

objetivo: determinar o grau de adequação das práticas à política nacional de medicamentos a partir da lista de medicamentos essenciais do país, ou da lista de medicamentos essenciais utilizada no serviço estudado. 
. requisitos: existência de cópia de uma lista de medicamentos essenciais, quando se trata de uma lista de nacional publicada ou de uma lista institucional local, para se comparar com os medicamentos prescritos. Estabelecer procedimentos que permitam determinar se os produtos de nome comercial eqüivalem aos que são listados pelo nome genérico.

cálculo:

número de medicamentos prescritos mencionados na lista de

$\%$ medicamentos essenciais $\times 100$ número total de consultas envolvidas no estudo

Obs. : Para referência foi utilizada a Lista de Medicamentos Padronizados da SMS do Município de Piracicaba (LMP) vigente no ano de 2001 (anexo 5), com um total de 98 itens. Foram considerados medicamentos padronizados aqueles prescritos na forma farmacêutica e dosagem da LMP, por nome genérico ou nome comercial, já que o procedimento adotado pelas farmácias municipais é de substituir os similares terapêuticos com mesmo princípio ativo, forma farmacêutica e concentração.

\section{5 - CATEgorias de RISCO AO FETO - CLASSIFICAÇÃO DE MEDICAMENTOS SEGUNDO O FOOD AND DRUG ADMINISTRATION (FDA)}

Partindo do pressuposto de que os indicadores do uso de medicamentos são parâmetros de primeiro nivel, concebidos, entre outras coisas, para estimular uma análise mais profunda e detalhada em situações específicas e orientar medidas subsequentes (OMS, 1993), buscou-se após identificação dos medicamentos prescritos e posterior classificação dos mesmos por grupos 
farmacológicos segundo critério adotado pela RENAME (2000), categorizá-los segundo potencial de risco para o feto, utilizando-se a proposição do FDA (categorias $A, B, C, D$ e X) ${ }^{25}$.

A classificação de cada um dos medicamentos foi obtida em consulta a BRIGGS et al. (1987), a ZANNINI et al. (1997), ao BPR - Guia de Remédios ${ }^{\circledR}$ (1999) e a BERGLUND (1984) nesta ordem de preferência.

Os medicamentos para os quais não se obteve nenhuma referência foram agrupados em uma categoria denominada "sem informação".

No caso de especialidades farmacêuticas compostas por associações de duas ou mais substâncias ativas, a classificação foi feita considerando-se a substância de maior risco.

\section{6 - DOSE E ESQUEMA TERAPÊUTICO DOS MEDICAMENTOS PRESCRITOS}

Considerando-se as poucas informações existentes na literatura científica sobre a segurança e a farmacocinética dos medicamentos utilizados durante a gravidez, e acreditando-se que no período gestacional a prescrição medicamentosa deve ser realizada com o máximo de cautela e precisão, buscou-se fazer uma análise das doses e esquema terapêutico identificados na Fase II.

Para esta análise, foram usados dados relacionados por FUCHS \& WANNMACHER (1998) e ZANINI et al. (1997), nesta ordem de prioridade. Levantou-se as doses terapêuticas e tóxicas de cada um dos medicamentos receitados (doses máximas e mínimas) com a respectiva posologia recomendada (intervalo entre as doses) e procedeu-se, então, uma comparação com os esquemas terapêuticos prescritos.

\footnotetext{
${ }^{25}$ Para se trabalhar com dados mais fidedignos, optou-se por não utilizar este procedimento com os medicamentos referenciados na Fase I, devido a impossibilidade de comprovação da informação fornecida pela gestante.
} 


\section{4 - RESULTADOS}

\section{1 - PERFIL DAS GESTANTES}

A grande maioria das mulheres envolvidas na pesquisa eram de regiões periféricas do município de Piracicaba, sendo apenas $5,9 \%$ da região central, conforme pode ser percebido na Tabela 2.

Tabela 2: Distribuição das gestantes entrevistadas por Unidade Básica de Saúde (UBS) de origem. Piracicaba - SP, 2001.

\begin{tabular}{lcc}
\hline Unidades Básicas de Saúde & número & freqüência (\%) \\
\hline Não identificada & 2 & 0,5 \\
Alvorada & 42 & 9,8 \\
Balbo & 3 & 0,7 \\
Campestre & 6 & 1,4 \\
Caxambu & 6 & 1,4 \\
Cecap & 44 & 10,3 \\
Centro & 25 & 5,9 \\
Esplanada & 16 & 3,7 \\
Independência & 4 & 0,9 \\
Jaraguá & 20 & 4,7 \\
Jupiá & 1 & 0,2 \\
Novo Horizonte & 5 & 1,2 \\
Núcleo do Adolescente & 43 & 10,1 \\
Paulicéia & 17 & 4,0 \\
Piracicamirim & 70 & 16,4 \\
Planalto & 11 & 2,6 \\
Santa Terezinha & 40 & 9,4 \\
São Paulo & 13 & 3,0 \\
Tupi & 4 & 0,9 \\
Vila Cristina & 30 & 7,0 \\
Vila Fátima & 22 & 5,2 \\
Vila Rezende & 3 & 0,7 \\
\hline TOTAL & 427 & 100,0 \\
\hline
\end{tabular}


A idade das gestantes estudadas variou de 13 a 43 anos, sendo que a idade média foi de 23,4 anos, com desvio padrão de 5,9 anos e intervalo de confiança entre 5,7 a 41,1 anos. Apenas $25 \%$ delas tinham idade acima de 28 anos. A distribuição da faixa etária das gestantes está apresentada na Tabela 3.

TABELA 3: Distribuição das gestantes atendidas pelo SUS segundo a faixa etária. Piracicaba - SP, 2001.

\begin{tabular}{|c|c|c|}
\hline Faixa etária (anos) & número & freqüência $(\%)$ \\
\hline não respondeu & 1 & 0,2 \\
\hline $13-14$ & 2 & 0,5 \\
\hline $15-19$ & 89 & 20,8 \\
\hline $20-24$ & 152 & 35,6 \\
\hline $25-29$ & 101 & 23,7 \\
\hline $30-34$ & 49 & 11,5 \\
\hline $35-39$ & 30 & 7,0 \\
\hline $40-43$ & 3 & 0,7 \\
\hline Total & 427 & 100,0 \\
\hline
\end{tabular}

Na Tabela 4 está a distribuição das gestantes entrevistadas, pelo nivel de escolaridade.

TABELA 4: Distribuição das gestantes atendidas pelo SUS segundo o grau de escolaridade. Piracicaba - SP, 2001.

\begin{tabular}{lcc}
\hline \multicolumn{1}{c}{ Escolaridade } & número & freqüência (\%) \\
\hline analfabeta & 4 & 0,9 \\
$1^{\text {a }}$ a $4^{\text {a }}$. série do $1^{\circ}$. grau & 67 & 15,7 \\
$5^{\text {a }}$ a $8^{\text {a }}$. série do $1^{\circ}$. grau & 217 & 50,8 \\
$2^{\circ}$. grau incompleto & 66 & 15,5 \\
$2^{\circ}$. grau completo & 69 & 16,2 \\
superior incompleto & 0 & 0.0 \\
superior completo & 4 & 0,9 \\
\hline Total & 427 & 100,0 \\
\hline
\end{tabular}


A tabela 5 mostra a distribuição das gestantes de acordo com as profissões / ocupaçōes referidas. As profissōes / ocupações cujas freqüencias foram menores que 3 estão agrupadas na categoria "outras". Do total de gestantes $64,2 \%$ eram donas de casa ("do lar"), não exercendo atividade remunerada. A profissão mais citada foi a de empregada doméstica, em 10,1\% dos questionários.

TABELA 5: Distribuição das gestantes atendidas pelo SUS segundo a profissão ou ocupação. Piracicaba - SP, 2001.

\begin{tabular}{lcc}
\hline \multicolumn{1}{c}{ Profissão / ocupação } & número & freqüência (\%) \\
\hline do lar & 274 & 64,2 \\
doméstica & 43 & 10,1 \\
estudante & 27 & 6,3 \\
serviços gerais & 12 & 2,8 \\
balconista & 11 & 2,6 \\
autônoma & 11 & 2,6 \\
outras & 40 & 9,3 \\
não respondeu & 9 & 2,1 \\
\hline Total & 427 & 100,0 \\
\hline
\end{tabular}

Considerando-se as 379 respostas obtidas, a renda familiar média foi de $R \$ 612,37$ (3,4 salários mínimo vigentes ${ }^{26}$ ), com desvio padrão de $R \$ 372,98$ ( 2,1 salários mínimos) e intervalo de confiança entre $R \$-506,57$ e $R \$ 1731,31$. Pelo desvio padrão encontrado, pode-se dizer que não existiu uma homogeneidade de renda entre as gestante, sendo que $75 \%$ delas tinham renda familiar inferior a 4,4 salários mínimos (sm) e a freqüência modal foi entre mais de 2 a $3 \mathrm{sm}$ (124 gestantes $-29,0 \%$ ). Na tabela 6 está a distribuição de renda, em salários minimos.

\footnotetext{
${ }^{26}$ Valor do Salário Mínimo na época da pesquisa $=$ R\$ 180,00
} 
TABELA 6: Distribuição das gestantes atendidas pelo SUS segundo a renda familiar referida em salários mínimos (sm). Piracicaba - SP, 2001.

\begin{tabular}{lcc}
\hline \multicolumn{1}{c}{ Renda familiar $(\mathrm{sm})$} & número & freqüência $(\%)$ \\
\hline não respondeu & 48 & 11,3 \\
$<1$ & 7 & 1,6 \\
$1 \mid-2$ & 75 & 17,6 \\
$2 \mid-3$ & 124 & 29,0 \\
$3 \mid-4$ & 69 & 16,2 \\
$4 \mid-5$ & 46 & 10,8 \\
$5 \mid-6$ & 26 & 6,1 \\
$6 \mid-7$ & 10 & 2,3 \\
$7 \mid-8$ & 5 & 1,2 \\
$8 \mid-9$ & 10 & 2,3 \\
9 e + & 7 & 1,6 \\
\hline Total & 427 & 100,0 \\
\hline
\end{tabular}

A renda per capita por domicilio foi calculada considerando-se apenas o número de entrevistadas que declararam a renda e correspondeu a $R \$ 155,87$ $(0,9 \mathrm{sm})$

O número médio de pessoas residentes no domicílio era de 3,9 , com desvio padrão de 1,96. A moda foi de 3 pessoas por domicílio. A Tabela 7 apresenta a distribuição do número de pessoas por domicílio. 
TABELA 7: Distribuição das gestantes atendidas pelo SUS segundo número de pessoas residentes no domicílio. Piracicaba - SP, 2001.

\begin{tabular}{ccc}
\hline Residentes no domicilio & número & freqüência (\%) \\
\hline 1 & 6 & 1,4 \\
2 & 87 & 20,4 \\
4 & 119 & 27,9 \\
5 & 88 & 20,6 \\
6 & 52 & 12,2 \\
7 & 41 & 3,3 \\
8 & 14 & 6,1 \\
9 & 9 & 2,1 \\
10 & 4 & 0,9 \\
11 & 1 & 0,2 \\
12 & 2 & 0,5 \\
13 & 1 & 0,2 \\
14 & 1 & 0,2 \\
16 & 1 & 0,2 \\
\hline Total & 1 & 0,2 \\
\hline
\end{tabular}

Em relação ao número de filhos anteriores, a média de filhos foi de 1 filho por gestante, com desvio padrão de 1,2. A porcentagem de mulheres que iriam ter seu primeiro filho foi de $45,7 \%$. Na Tabela 8 encontra-se a distribuição das gestantes por número de filhos. 
TABELA 8: Distribuição das gestantes atendidas pelo SUS segundo número de filhos. Piracicaba - SP, 2001.

\begin{tabular}{cccc}
\hline Número de filhos & número & freqüência (\%) \\
\hline 0 & 195 & 17,6 \\
1 & 115 & 26,9 \\
2 & 71 & 16,6 \\
3 & 29 & 6,8 \\
& 4 & 14 & 3,3 \\
& 5 & 2 & 0,5 \\
& 11 & 1 & 0,2 \\
\hline Total & & 427 & 100,0 \\
\hline
\end{tabular}

Em relação ao trimestre de gestação, $46,7 \%$ das mulheres entrevistadas estavam no último trimestre. Os dados podem ser observados na figura 1.

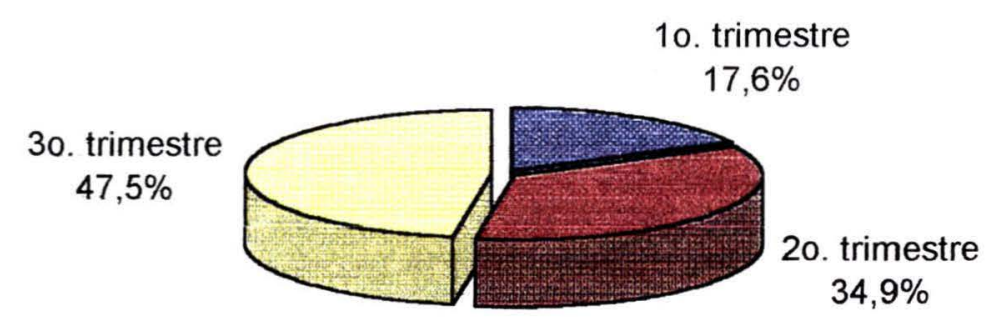

FIGURA 1: Distribuição das gestantes atendidas em consultas de pré-natal (SUS) segundo o trimestre de gestação. Piracicaba - SP, 2001. 


\section{2 - DADOS OBTIDOS NA FASE I: PRÉ-CONSULTA}

O número de gestantes que afirmou ter tomado alguma medicação na semana anterior a pesquisa, foi de $61,6 \%$. Os dados estão apresentados na Tabela 9.

TABELA 9: Distribuição das gestantes atendidas pelo SUS segundo a utilização de medicamentos na semana anterior a pesquisa. Piracicaba - SP, 2001.

\begin{tabular}{|c|c|c|}
\hline Uso de medicamentos & número & freqüência (\%) \\
\hline Sim & 263 & 61,6 \\
\hline Não & 164 & 38,4 \\
\hline Total & 427 & 100,0 \\
\hline
\end{tabular}

Das gestantes que tomaram medicamentos, $80,2 \%$ referiram que o fizeram a partir de indicação médica e 18,6\% por automedicação, dados que estão demonstrados na figura 2. 


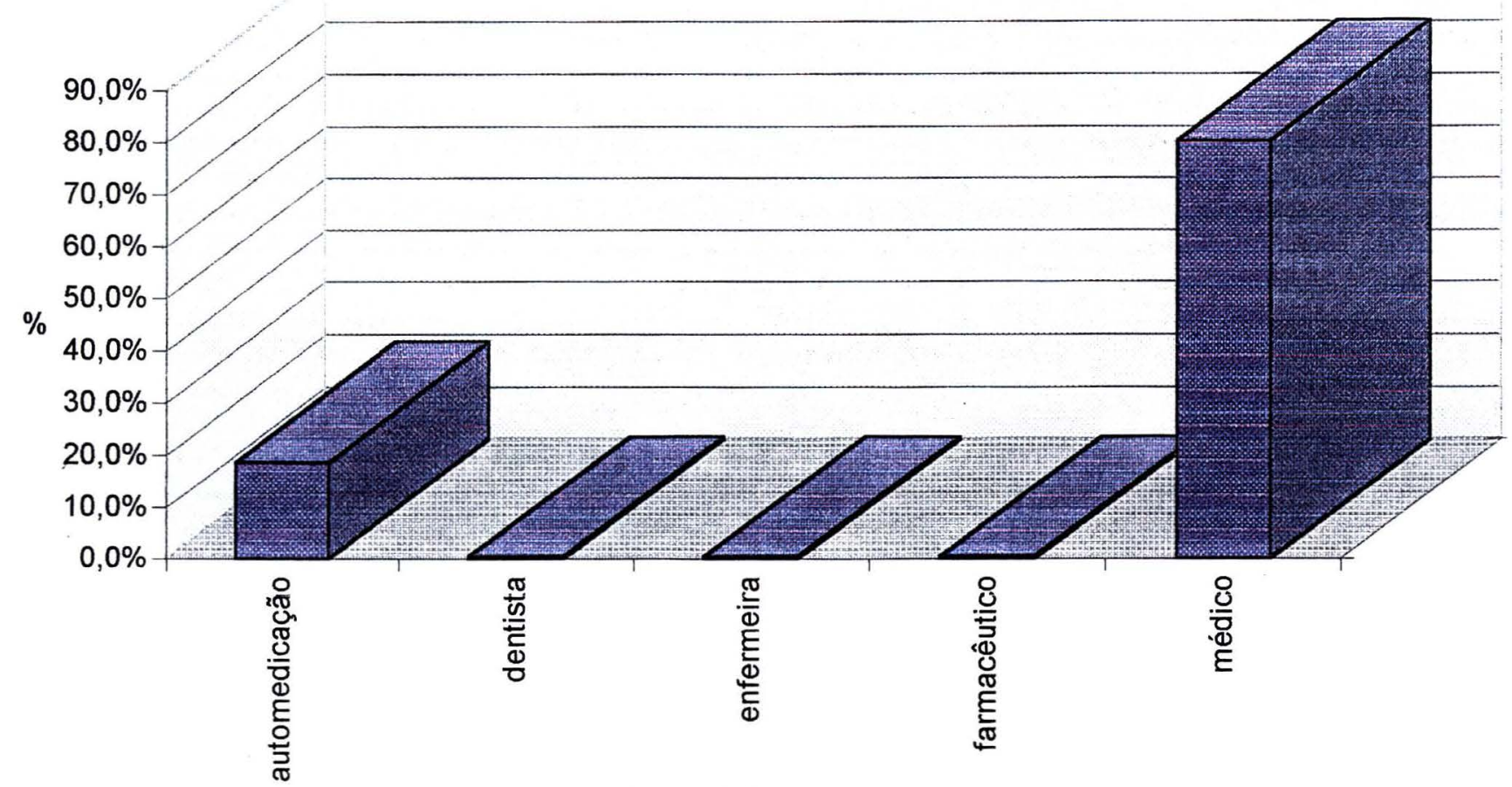

Fonte de indicação

FIGURA 2: Fonte de indicação dos medicamentos utilizados pelas gestantes atendidas pelo SUS na semana anterior a consulta. Piracicaba - SP, 2001.

Segundo as informações obtidas (Tabela 10), a maior porcentagem de medicamentos utilizados na semana anterior a pesquisa ocorreu em gestantes que estavam no terceiro trimestre de gravidez (64,5\%), e a menor entre aquelas que estavam no primeiro trimestre $(50,7 \%)$. Entretanto, baseando-se no teste de associação do qui-quadrado, pode-se dizer que a diferença de consumo 
observada não é estatiscamente significativa, isto é, o padrão de uso de medicamentos foi independente do trimestre de gestação $\left(x^{2}=4,6 ; p=0,05\right)$.

TABELA 10: Distribuição das gestantes atendidas pelo SUS segundo utilização de medicamentos na semana anterior a pesquisa e trimestre de gravidez. Piracicaba - SP, 2001.

\begin{tabular}{cccc}
\hline $\begin{array}{c}\text { Trimestre de } \\
\text { gestação }\end{array}$ & \multicolumn{2}{c}{ Uso de medicação } & Total \\
\hline $1^{\circ}$. & 38 & não & \\
$2^{\circ}$. & 94 & 37 & 75 \\
$3^{\circ}$. & 131 & 55 & 149 \\
\hline Total & 263 & 72 & 203 \\
\hline
\end{tabular}

A figura 3 mostra que 33 das gestantes que se automedicaram $(67,3 \%)$ tinham no mínimo um filho. Porém, aplicando-se o teste de associação do quiquadrado percebe-se que não existe correlação estatisticamente significativa entre tais variáveis $\left(x^{2}=12,59 ; p=0,05\right)$. 


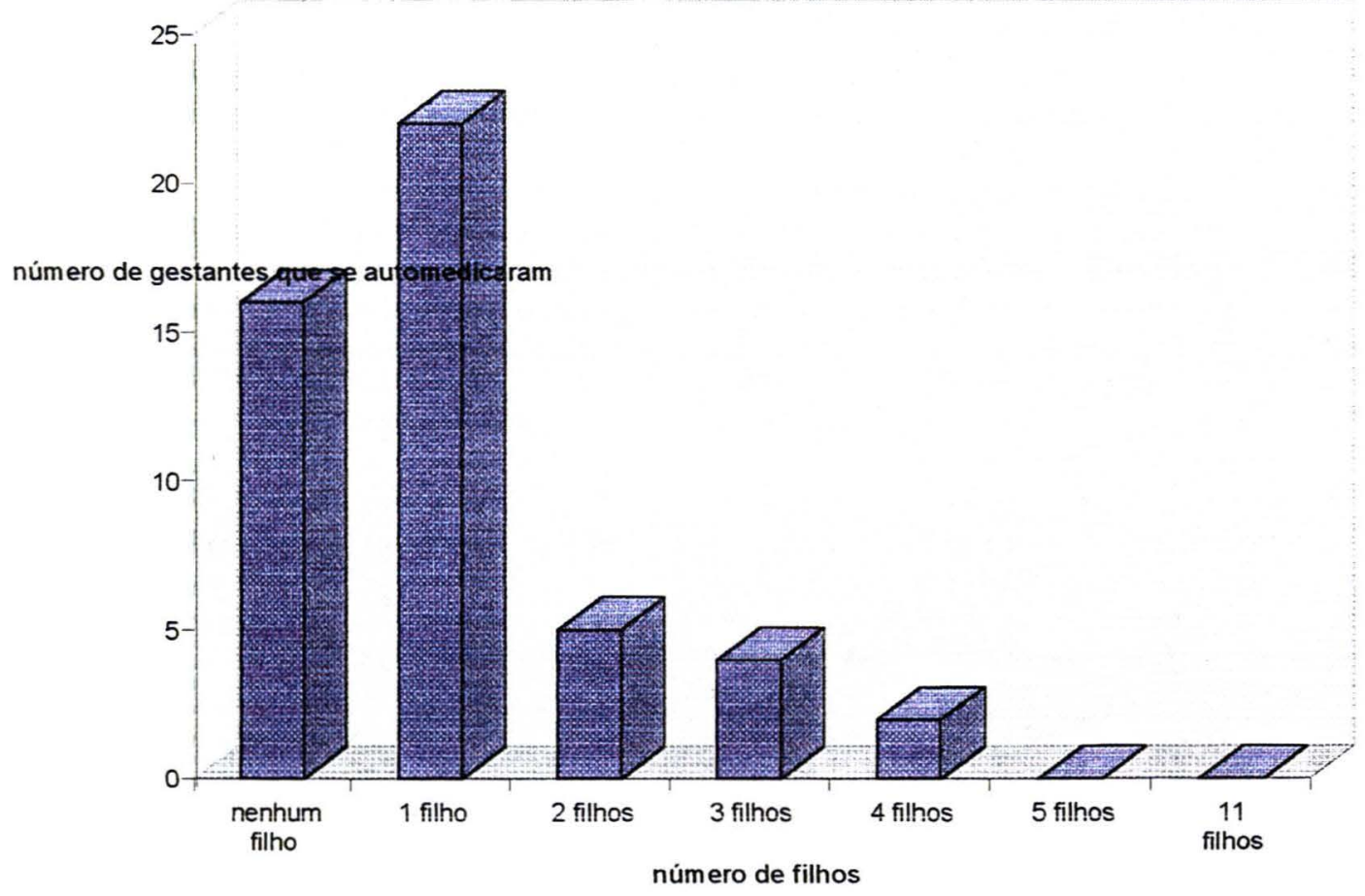

FIGURA 3: Prática de automedicação entre gestantes atendidas pelo SUS na semana anterior a pesquisa segundo número de filhos. Piracicaba - SP, 2001.

A maior freqüência de automedicação, assim como a maior porcentagem de gestantes que referiram ter se medicado por orientação médica, ocorreu entre aquelas cujo grau de escolaridade era da $5^{a}$. a $8^{a}$. série do $1^{\circ}$. grau $(46,9 \%)$. Estes dados podem ser verificados na Tabela 11. 
TABELA 11: Utilização de medicamentos por gestantes atendidas pelo SUS na semana anterior a pesquisa, segundo fonte de indicação e escolaridade. Piracicaba - SP, 2001.

\begin{tabular}{|c|c|c|c|c|c|c|c|}
\hline Indicação & $\begin{array}{l}\text { Escolaridade } \\
\text { Analfabeto }\end{array}$ & $\begin{array}{l}1^{a} \cdot \text { a } 4^{a} . \\
\text { série do } \\
1^{o} \text { grau }\end{array}$ & $\begin{array}{l}5^{a} \text { a } 8^{a} . \\
\text { série do } \\
1^{\circ} \text { grau }\end{array}$ & $\begin{array}{c}2^{\circ} . \text { grau } \\
\text { incompleto }\end{array}$ & $\begin{array}{l}2^{\circ} \text {.grau } \\
\text { completo }\end{array}$ & $\begin{array}{l}\text { superior } \\
\text { completo }\end{array}$ & TOTAL \\
\hline Automedicação & 1 & 13 & 23 & 7 & 5 & 0 & 49 \\
\hline Dentista & 0 & 1 & 0 & 0 & 0 & 0 & 1 \\
\hline Enfermeira & 0 & 0 & 1 & 0 & 0 & 0 & 1 \\
\hline Farmacêutiço & 0 & 0 & 1 & 0 & 0 & 0 & 1 \\
\hline Médico & 2 & 27 & 107 & 34 & 39 & 2 & 211 \\
\hline TOTAL & 3 & 41 & 132 & 41 & 44 & 2 & 263 \\
\hline
\end{tabular}

Na tabela 12 está descrito o uso de medicamentos por trimestre de gestação. O maior consumo de medicamentos ocorreu entre as gestantes que estavam no terceiro trimestre, sendo $16,0 \%$ por automedicação e $51,7 \%$ por indicação médica. Quanto a automedicação, a maior freqüência referida ocorreu no primeiro trimestre $(31,6 \%)$. 
TABELA 12: Utilização de medicamentos por gestantes atendidas pelo SUS na semana anterior a pesquisa segundo trimestre da gestação e fonte de indicação. Piracicaba - SP, 2001.

\begin{tabular}{lrrrr}
\hline \multirow{1}{*}{ Indicação } & \multicolumn{3}{c}{ Trimestre } & Total \\
\cline { 2 - 4 } & $1^{\mathbf{a}}$ & $2^{\mathbf{a}}$ & $3^{\mathbf{a}}$ & \\
\hline automedicação & 12 & 16 & 21 & 49 \\
Dentista & 0 & 1 & 0 & 1 \\
Enfermeira & 1 & 0 & 0 & 1 \\
Farmacêutico & 0 & 0 & 1 & 1 \\
Médico & 25 & 77 & 109 & 211 \\
\hline \multicolumn{1}{c}{ Total } & 38 & 94 & 131 & 263 \\
\hline
\end{tabular}

Em relação a renda per capita familiar, $55,6 \%$ das gestantes que utilizaram medicamentos na semana anterior a pesquisa relataram uma renda inferior a um salário mínimo (Tabela 13). Vale destacar que para o cálculo deste dado foram consideradas somente as gestantes que declararam renda (239 de um total de 269).

Tabela 13: Distribuição das gestantes atendidas pelo SUS segundo renda per capita, em salários mínimos (sm), e uso de medicação na semana anterior a pesquisa. Piracicaba - SP, 2001.

\begin{tabular}{|c|c|c|c|}
\hline \multirow{2}{*}{$\begin{array}{c}\text { Renda per capita } \\
\text { (sm) }\end{array}$} & \multicolumn{2}{|c|}{ Uso de Medicação } & \multirow[t]{2}{*}{ Total } \\
\hline & Sim & Não & \\
\hline$<1$ & 133 & 87 & 220 \\
\hline $1 \mid-2$ & 92 & 42 & 134 \\
\hline $21-3$ & 10 & 8 & 18 \\
\hline $3 \mid-4$ & 3 & 1 & 4 \\
\hline $4 e+$ & 1 & 2 & 3 \\
\hline Total & 239 & 140 & 379 \\
\hline
\end{tabular}


Daquelas que se automedicaram, $76,7 \%$ tinham uma renda per capita menor que um salário mínimo. Além disto, $74,4 \%$ das mulheres com esta renda tomaram medicamentos por indicação médica, conforme demonstrado na Tabela (14).

TABELA 14 - Distribuição das gestantes atendidas pelo SUS, que referiram uso de medicamentos na semana anterior a pesquisa, segundo renda per capita, em salários mínimos (s.m.), e fonte de indicação. Piracicaba - SP, 2001.

\begin{tabular}{|c|c|c|c|c|c|}
\hline $\begin{array}{c}\text { Renda per capita } \\
\text { (sm) }\end{array}$ & Automedicação & Enfermeira & Farmacêutico & Médico & Total \\
\hline$<1$ & 33 & 0 & 1 & 99 & 133 \\
\hline $1 \mid-2$ & 10 & 1 & 0 & 81 & 92 \\
\hline $2 \mid-3$ & 0 & 0 & 0 & 10 & 10 \\
\hline $3 \mid-4$ & 0 & 0 & 0 & 3 & 3 \\
\hline $4 e+$ & 0 & 0 & 0 & 1 & 1 \\
\hline Total & 43 & 1 & 1 & 194 & 239 \\
\hline
\end{tabular}

A Tabela 15 apresenta a relação de medicamentos com uso referido pelas gestantes na semana anterior a consulta de pré-natal, por classe terapêutica e destacando o medicamento mais utilizado dentro de cada classe. Os medicamentos foram divididos em 22 classes terapêuticas, segundo a Classificação Terapêutica de Medicamentos e Suprimentos (Sistema ALFA) ${ }^{27}$. As classes mais mencionadas com seus respectivos medicamentos mais freqüentes foram:

. hematopoese, estimulantes $(38,2 \%)$ - Sulfato Ferroso $(91,7 \%)$;

\footnotetext{
${ }^{27}$ Classificação que prioriza o uso terapêutico dos medicamentos (ZANINI \& OGA, 1997).
} 
anticolinérgicos e antiespasmódicos $(17,5 \%)$ - Buscopan ${ }^{\circledR}(80,3 \%)$;

vitaminas $(15,2 \%)$ - Rarical $\circledast(35,8 \%)$.

Os medicamentos referidos nas entrevistas pelo nome comercial estão grafados nas tabelas juntamente com o símbolo $\circledast$, aqueles que foram mencionados pelo nome genérico não estão acompanhados por ele. Em alguns caso, não foi possivel identificar o medicamento utilizado, ou porque a gestante não sabia o nome do mesmo (mencionando por exemplo: xarope, inalação) ou porque 0 nome fornecido não correspondeu a nenhuma especialidade farmacêutica no mercado.

Tabela 15 - Relação das classes terapêuticas (Sistema ALFA) utilizadas pelas gestantes atendidas pelo SUS na semana anterior a entrevista, por trimestre de gravidez e com os medicamentos mais consumidos dentro de cada classe. Piracicaba - SP, 2001.

\begin{tabular}{|c|c|c|c|c|c|c|c|c|}
\hline \multirow[t]{2}{*}{ Classe terapêutica } & \multicolumn{3}{|c|}{$\begin{array}{c}\text { trimestre de } \\
\text { gravidez }\end{array}$} & \multicolumn{2}{|c|}{ total } & \multirow[t]{2}{*}{$\begin{array}{l}\text { medicamentos mais } \\
\text { utilizados }\end{array}$} & \multirow[t]{2}{*}{ n. ${ }^{\circ}$} & \multirow[t]{2}{*}{$\begin{array}{c}\text { freq. } \\
\%\end{array}$} \\
\hline & $1^{\circ}$ & $2^{\circ}$ & $3^{\circ}$ & n. ${ }^{\circ}$ & $\begin{array}{c}\text { freq. } \\
\%\end{array}$ & & & \\
\hline $\begin{array}{l}\text { Analgésicos e } \\
\text { antitérmicos }\end{array}$ & 8 & 19 & 3 & 30 & 8,6 & Tylenol® & 13 & 43,3 \\
\hline $\begin{array}{l}\text { anticolinérgicos e } \\
\text { antiespasmódicos }\end{array}$ & 15 & 12 & 34 & 61 & 17,5 & Buscopan $\circledast$ & 49 & 80,3 \\
\hline $\begin{array}{l}\text { analgésicos para } \\
\text { enxaqueca }\end{array}$ & 0 & 0 & 1 & 1 & 0,3 & Cefalium $\otimes$ & 1 & 100,0 \\
\hline $\begin{array}{l}\text { Anttiinflamatórios } \\
\text { não esteroidais e } \\
\text { anti-reumáticos }\end{array}$ & 0 & 0 & 2 & 2 & 0,6 & $\begin{array}{l}\text { Cataflan } \circledast \\
\text { Scaflan } \circledast\end{array}$ & $\begin{array}{l}1 \\
1\end{array}$ & $\begin{array}{l}50,0 \\
50,0\end{array}$ \\
\hline antihipertensivos & 0 & 0 & 4 & 4 & 1,2 & Metildopa & 3 & 75,0 \\
\hline $\begin{array}{l}\text { antiácidos e } \\
\text { antiúlceras }\end{array}$ & 0 & 2 & 5 & 7 & 2,0 & $\begin{array}{l}\text { Hidróxido de } \\
\text { Alumínio }\end{array}$ & 2 & 28,6 \\
\hline antieméticos & 6 & 5 & 4 & 15 & 4,3 & Dramin $\circledast$ & 8 & 53,3 \\
\hline $\begin{array}{l}\text { soluções } \\
\text { parenterais, } \\
\text { eletrólitos } \\
\text { diluentes }\end{array}$ & 1 & 1 & 1 & 3 & 0,9 & Glicose $25 \%$ & 2 & 66,7 \\
\hline vitaminas & 8 & 19 & 26 & 53 & 15,2 & Rarical® & 19 & 35,8 \\
\hline
\end{tabular}




\begin{tabular}{|c|c|c|c|c|c|c|c|c|}
\hline $\begin{array}{l}\text { vias urinárias, } \\
\text { produtos para uso } \\
\text { oral e injetável }\end{array}$ & 1 & 0 & 0 & 1 & 0,3 & Pipurol $\circledast$ & 1 & 100,0 \\
\hline $\begin{array}{l}\text { alergia, anti- } \\
\text { histaminicos }\end{array}$ & 0 & 1 & 0 & 1 & 0,3 & Polaramine $\circledast$ & 1 & 100,0 \\
\hline imunoprotetores & 0 & 0 & 1 & 1 & 0,3 & Vacina antitetânica & 1 & 100,0 \\
\hline $\begin{array}{l}\text { convulsões e } \\
\text { epilepsia }\end{array}$ & 0 & 0 & 1 & 1 & 0,3 & Epilepsina® & 1 & 100,0 \\
\hline $\begin{array}{l}\text { relaxantes } \\
\text { musculares }\end{array}$ & 0 & 0 & 2 & 2 & 0,6 & Dorflex® & 2 & 100,0 \\
\hline otologia & 1 & 0 & 0 & 1 & 0,3 & Dramin $B 6 \otimes$ & 1 & 100,0 \\
\hline $\begin{array}{l}\text { bactérias } \\
\text { (quimioterapia) }\end{array}$ & 4 & 3 & 6 & 13 & 3,6 & $\begin{array}{l}\text { Ampicilina } \\
\text { Cefalexina }\end{array}$ & $\begin{array}{l}3 \\
3\end{array}$ & $\begin{array}{l}23,1 \\
23,1\end{array}$ \\
\hline $\begin{array}{l}\text { Parasitoses } \\
\text { (quimioterapia) }\end{array}$ & 0 & 1 & 0 & 1 & 0,3 & Metronidazol & 1 & 100,0 \\
\hline $\begin{array}{l}\text { broncodilatadores e } \\
\text { antiasmáticos }\end{array}$ & 0 & 0 & 3 & 3 & 0,9 & $\begin{array}{l}\text { Atrovent@ } \\
\text { Berotec® } \\
\text { Salbutamol }\end{array}$ & $\begin{array}{l}1 \\
1 \\
1\end{array}$ & $\begin{array}{l}33,3 \\
33,3 \\
33,3\end{array}$ \\
\hline gripe & 0 & 1 & 1 & 2 & 0,6 & $\begin{array}{l}\text { Resprin® } \\
\text { Trimedal } \circledast\end{array}$ & $\begin{array}{l}1 \\
1\end{array}$ & $\begin{array}{l}50,0 \\
50,0\end{array}$ \\
\hline nariz & 0 & 0 & 1 & 1 & 0,3 & Vick vaporub® & 1 & 100,0 \\
\hline $\begin{array}{l}\text { tosse } \mathrm{e} \\
\text { expectoração }\end{array}$ & 0 & 2 & 2 & 4 & 1,2 & $\begin{array}{l}\text { Calmatosse } \$ \\
\text { Frenotosse } \$ \\
\text { Silomat plus } \otimes \\
\text { Transpulmin } \otimes\end{array}$ & $\begin{array}{l}1 \\
1 \\
1 \\
1\end{array}$ & $\begin{array}{l}25,0 \\
25,0 \\
25,0 \\
25,0\end{array}$ \\
\hline $\begin{array}{l}\text { hematopoese, } \\
\text { estimulantes }\end{array}$ & 8 & 51 & 74 & 133 & 38,2 & Sulfato Ferroso & 122 & 91,7 \\
\hline sem identificação & 2 & 2 & 4 & 8 & 2,2 & & & \\
\hline TOTAL & 54 & 119 & 175 & 348 & 100,0 & & & \\
\hline
\end{tabular}

A relação total de medicamentos utilizados na semana anterior a pesquisa é apresentada na Tabela 16. Os medicamentos mais citados foram: sulfato ferroso $(35,1 \%)$, Buscopan $\AA(14,1 \%)$ e Rarical $\AA(5,5 \%)$, sendo que o uso mais freqüente desses medicamentos ocorreu no $3^{\circ}$. trimestre de gestação. 
TABELA 16 - Distribuição dos medicamentos referidos pelas gestantes atendidas pelo SUS segundo trimestre de gestação. Piracicaba - SP, 2001.

\begin{tabular}{|c|c|c|c|c|}
\hline \multirow[t]{2}{*}{ medicamentos } & \multicolumn{3}{|c|}{ Trimestre } & \multirow[t]{2}{*}{ Total } \\
\hline & $1^{\circ}$ & $2^{\circ}$ & $3^{0}$ & \\
\hline Ácido fólico $5 \mathrm{mg}$ & 0 & 2 & 1 & 3 \\
\hline Adalat $\circledast$ & 0 & 0 & 1 & 1 \\
\hline Ampicilina $500 \mathrm{mg}$ & 1 & 2 & 0 & 3 \\
\hline Anador $\circledast$ & 2 & 2 & 0 & 4 \\
\hline Antibiótico & 2 & 0 & 0 & 2 \\
\hline Aspirina® & 0 & 1 & 0 & 1 \\
\hline Atrovent $\circledast$ & 0 & 0 & 1 & 1 \\
\hline Azia (medicamento para) & 0 & 0 & 1 & 1 \\
\hline Berotec $\circledast$ & 0 & 0 & 1 & 1 \\
\hline Bicarbonato de sódio & 0 & 1 & 0 & 1 \\
\hline Buscopan $®$ & 12 & 10 & 27 & 49 \\
\hline Buscopan $\circledast$ injetável & 0 & 0 & 1 & 1 \\
\hline Calmatosse $\circledast$ & 0 & 1 & 0 & 1 \\
\hline Cataflan $\circledast$ & 0 & 0 & 1 & 1 \\
\hline Cefalexina $500 \mathrm{mg}$ & 0 & 1 & 2 & 3 \\
\hline Cefalium $\circledast$ & 0 & 0 & 1 & 1 \\
\hline Cimetidina & 0 & 0 & 1 & 1 \\
\hline Combiron $\circledast$ & 0 & 1 & 3 & 4 \\
\hline Complexo B & 2 & 0 & 0 & 2 \\
\hline Dactil $O B \circledast$ & 2 & 2 & 5 & 9 \\
\hline Dióxido de alumínio & 0 & 0 & 1 & 1 \\
\hline Dipirona ${ }^{\circ}$ & 2 & 1 & 0 & 3 \\
\hline Dorflex® & 0 & 0 & 2 & 2 \\
\hline Doril@ & 0 & 1 & 0 & 1 \\
\hline Dramim® & 2 & 2 & 4 & 8 \\
\hline Dramim $\mathrm{B} 6 \circledast$ & 1 & 0 & 0 & 1 \\
\hline Epilepsina ${ }^{\circledR}$ & 0 & 0 & 1 & 1 \\
\hline Espiramicina & 0 & 0 & 1 & 1 \\
\hline Exem & 1 & 0 & 0 & 1 \\
\hline Expectorante (medicamento) & 0 & 0 & 1 & 1 \\
\hline Femme com flúor® & 0 & 2 & 1 & 3 \\
\hline Ferrotrat $\circledast$ & 0 & 0 & 1 & 1 \\
\hline Fremitosse $\circledast$ & 0 & 1 & 0 & 1 \\
\hline Glicose $25 \%$ & 1 & 1 & 0 & 2 \\
\hline Hidróxido de alumínio & 0 & 1 & 1 & 2 \\
\hline Hioscina & 1 & 0 & 1 & 2 \\
\hline Iberim fólico $\circledast$ & 1 & 0 & 1 & 2 \\
\hline Infecção (medicamento para) & 0 & 1 & 0 & 1 \\
\hline Infecção de urina (medicamento para) & 0 & 0 & 1 & 1 \\
\hline Injeção Antitetânica & 0 & 0 & 1 & 1 \\
\hline Injeção para dor & 1 & 0 & 0 & 1 \\
\hline Keflex® & 0 & 0 & 2 & 2 \\
\hline Magnopirol@ & 0 & 3 & 0 & 3 \\
\hline Materna $\circledast$ & 1 & 0 & 4 & 5 \\
\hline Metildopa $500 \mathrm{mg}$ & 0 & 0 & 3 & 3 \\
\hline Metronidazol & 0 & 1 & 0 & 1 \\
\hline
\end{tabular}


Mylanta plus $\circledast$

Natalins fólico $\circledast$

Natiglot $\circledast$

Novalgina ${ }^{\circledR}$

Novofer ${ }^{\circledR}$

Paracetamol $\circledast$

Pastilha azia

Penicilina

Plamet $\circledast$

Plasil $\circledast$

Polaramine ${ }^{\circledR}$

Pupirol ${ }^{\circledR}$

Rarical ${ }^{8}$

Resprin $\circledast$

Rovamicina ${ }^{\circledR}$

Sais minerais ${ }^{\circledR}$

Salbutamol

Scaflan (8)

Silomat plus $\circledast$

Sonrisal®

Soro

Sulfato ferroso

Supervit $(8)$

Supradin $\circledast$

Transpulmin ${ }^{\circledR}$

Trimedal $($ )

Tylenol ${ }^{\circledR}$

Vick vaporub $(\AA$

Vitafole

Vitafom $\circledast$

Vitaminas e Sais minerais ${ }^{\circledR}$

Vitergam ${ }^{\circledR}$

Vitergam pré-natal®

Xarope

Total

\begin{tabular}{|c|c|c|c|}
\hline 0 & 0 & 1 & 1 \\
\hline 1 & 2 & 3 & 6 \\
\hline 0 & 1 & 0 & 1 \\
\hline 1 & 0 & 0 & 1 \\
\hline 0 & 0 & 1 & 1 \\
\hline 0 & 2 & 0 & 2 \\
\hline 0 & 0 & 1 & 1 \\
\hline 1 & 0 & 0 & 1 \\
\hline 1 & 1 & 0 & 2 \\
\hline 3 & 2 & 0 & 5 \\
\hline 0 & 1 & 0 & 1 \\
\hline 1 & 0 & 0 & 1 \\
\hline 4 & 6 & 9 & 19 \\
\hline 0 & 1 & 0 & 1 \\
\hline 0 & 0 & 1 & 1 \\
\hline 0 & 1 & 1 & 2 \\
\hline 0 & 0 & 1 & 1 \\
\hline 0 & 0 & 1 & 1 \\
\hline 0 & 0 & 1 & 1 \\
\hline 0 & 2 & 0 & 2 \\
\hline 0 & 0 & 1 & 1 \\
\hline 7 & 48 & 67 & 122 \\
\hline 0 & 1 & 0 & 1 \\
\hline 0 & 0 & 1 & 1 \\
\hline 0 & 0 & 1 & 1 \\
\hline 0 & 0 & 1 & 1 \\
\hline 3 & 7 & 3 & 13 \\
\hline 0 & 0 & 1 & 1 \\
\hline 0 & 1 & 1 & 2 \\
\hline 0 & 1 & 0 & 1 \\
\hline 0 & 2 & 4 & 6 \\
\hline 0 & 1 & 1 & 2 \\
\hline 0 & 1 & 1 & 2 \\
\hline 0 & 1 & 0 & 1 \\
\hline 54 & 119 & 175 & 348 \\
\hline
\end{tabular}

A Tabela 17 apresenta os medicamentos mais utilizados por automedicação na semana anterior a entrevista e referidos pelas gestantes. 
Tabela 17 - Relação dos medicamentos mais utilizados por automedicação referidos pelas gestantes atendidas pelo SUS. Piracicaba - SP, 2001.

\begin{tabular}{|c|c|c|}
\hline Medicamentos & freqüência & Porcentagem \% \\
\hline Buscopan $\AA$ & 16 & 23,3 \\
\hline Sulfato ferroso & 13 & 18,8 \\
\hline Dactil @ & 3 & 4,3 \\
\hline Anador $\circledast$ & 3 & 4,3 \\
\hline Tylenol $®$ & 3 & 4,3 \\
\hline Metildopa & 2 & 2,9 \\
\hline Sonrisal $\AA^{8}$ & 2 & 2,9 \\
\hline Dramin ${ }^{\circledR}$ & 2 & 2,9 \\
\hline Magnopirol $®$ & 2 & 2,9 \\
\hline Outros & 23 & 33,5 \\
\hline Total & 69 & 100,0 \\
\hline
\end{tabular}

\section{3 - DADOS OBTIDOS NA PÓS-CONSULTA (RELATIVOS A PRESCRIÇÃO MÉDICA)}

Após serem consultadas, $44,7 \%$ das gestantes tiveram prescrição medicamentosa, fato que pode ser observado na Figura 4.

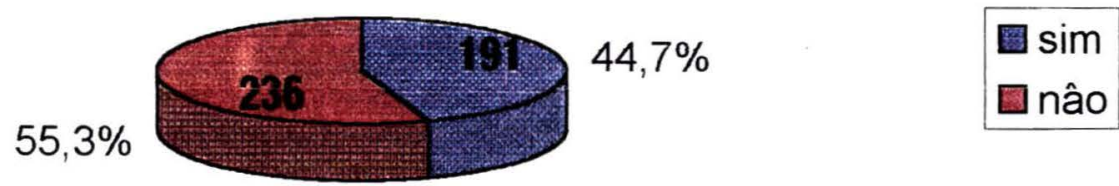

FIGURA 4 - Número e freqüência de prescrições medicamentosas em consultas de pré-natal (SUS). Piracicaba - SP, 2001. 
A Tabela 18 apresenta o número de prescrições distribuidas pelos trimestres de gestaçāo. O maior número de prescrições medicamentosas ocorreu em gestantes que estavam no $2^{\circ}$ trimestre de gestação $(43,5 \%)$.

Tabela 18: Distribuição das consultas de pré-natal (SUS) segundo prescrição medicamentosa e trimestre de gestação. Piracicaba - SP, 2001.

\begin{tabular}{|c|c|c|c|c|}
\hline \multirow[t]{2}{*}{ Prescrição } & \multicolumn{3}{|c|}{ Trimestre } & \multirow[t]{2}{*}{ Total } \\
\hline & $1^{\circ}$ & $2^{\circ}$ & $3^{\circ}$ & \\
\hline Sim & 57 & 83 & 51 & 191 \\
\hline Não & 18 & 66 & 152 & 236 \\
\hline Total & 75 & 149 & 203 & 427 \\
\hline
\end{tabular}

A Tabela 19 apresenta os números de prescrições médicas em relação à escolaridade das gestantes: $100 \%$ das analfabetas recebeu prescrição medicamentosa e $100 \%$ das mulheres com nível superior não recebeu nenhuma prescrição.

TABELA 19: Distribuição das prescrições medicamentosas em consultas de prénatal (SUS) segundo a escolaridade das gestantes. Piracicaba - SP, 2001.

\begin{tabular}{lcccccccc}
\hline \multirow{2}{*}{ Prescrição } & Analfabeta & $\begin{array}{c}1^{\mathrm{a}} \mathbf{a} \mathbf{4}^{\mathrm{a}} \\
\text { série do } \\
1^{\circ} \text { grau }\end{array}$ & $\begin{array}{c}5^{\mathrm{a}} \text { a } 8^{\mathrm{a}} \\
\text { série do } \\
1^{\circ} \text { grau }\end{array}$ & $\begin{array}{c}2^{\circ} \text { grau } \\
\text { incompleto }\end{array}$ & $\begin{array}{c}2^{\circ} \text { grau } \\
\text { completo }\end{array}$ & $\begin{array}{c}\text { Superior } \\
\text { completo }\end{array}$ & Total \\
\hline Sim & 2 & 31 & 98 & 22 & 38 & 0 & 191 \\
Não & 2 & 36 & 119 & 44 & 31 & 4 & 236 \\
\hline Total & 4 & 64 & 217 & 66 & 69 & 4 & 427 \\
\hline
\end{tabular}

O número médio de medicamentos prescritos por consulta foi de 1,41 , se considerarmos apenas as gestantes que tiveram prescrição medicamentosa. Se considerarmos todas as gestantes atendidas nas 21 UBS's, então o número médio de prescrições por consulta cai para 0,63 . 
Os medicamentos prescritos, por trimestre de gestação, são apresentados na Tabela 20. Os medicamentos mais prescritos foram: sulfato ferroso $(23,0 \%)$, Rarical $\otimes(6,3 \%)$ e nistatina creme $(6,0 \%)$.

Tabela 20- Medicamentos prescritos nas consultas de pré-natal (SUS) distribuidos segundo trimestre de gestação. Piracicaba - SP, 2001.

\begin{tabular}{|c|c|c|c|c|}
\hline \multirow[t]{2}{*}{ Medicamentos } & \multicolumn{3}{|c|}{ Trimestre } & \multirow[t]{2}{*}{ Total } \\
\hline & $1^{\circ}$ & 2 & $3^{0}$ & \\
\hline Ácido fólico $5 \mathrm{mg}$ & 4 & 0 & 1 & 5 \\
\hline Aldomet 259mg $\circledast$ & 0 & 0 & 1 & 1 \\
\hline Amoxacilina $500 \mathrm{mg}$ & 0 & 1 & 0 & 1 \\
\hline Ampicilina $500 \mathrm{mg}$ & 3 & 2 & 1 & 6 \\
\hline Bepantol creme $\circledast$ & 0 & 1 & 0 & 1 \\
\hline Bisolvon ® & 1 & 0 & 1 & 2 \\
\hline Buscopan @ & 4 & 5 & 2 & 11 \\
\hline Buscopan composto ${ }^{8}$ & 1 & 0 & 0 & 1 \\
\hline Buscopan injetável @ & 0 & 0 & 1 & 1 \\
\hline Cálcio sandoz @ & 0 & 0 & 1 & 1 \\
\hline Candicort pomada $\otimes$ & 1 & 1 & 0 & 2 \\
\hline Cefalexina $500 \mathrm{mg}$ & 5 & 5 & 4 & 14 \\
\hline Cimetidina & 0 & 1 & 1 & 2 \\
\hline Combiron $\circledast$ & 1 & 1 & 0 & 2 \\
\hline Dactil OB $\circledast$ & 3 & 3 & 3 & 9 \\
\hline Diclofenaco de sódio & 0 & 1 & 0 & 1 \\
\hline Dorico $® 750 \mathrm{mg}$ & 1 & 0 & 1 & 2 \\
\hline Dramim @ & 2 & 0 & 0 & 2 \\
\hline Dramim B6 @ & 4 & 2 & 0 & 6 \\
\hline Dulcolax ® & 0 & 1 & 0 & 1 \\
\hline Espiramicina $500 \mathrm{mg}$ & 1 & 0 & 0 & 1 \\
\hline Femme com flúor $\mathbb{8}$ & 0 & 0 & 1 & 1 \\
\hline Flagyl @ & 0 & 2 & 0 & 2 \\
\hline Gino-pletil ® & 0 & 1 & 0 & 1 \\
\hline Glicose $25 \%$ & 0 & 0 & 1 & 1 \\
\hline Gyno-fungix ® & 0 & 1 & 0 & 1 \\
\hline Gyno-icaden ® & 0 & 2 & 0 & 2 \\
\hline Hidróxido alumínio & 0 & 1 & 2 & 3 \\
\hline Hioscina & 3 & 1 & 2 & 6 \\
\hline Hirudoid ® & 0 & 1 & 0 & 1 \\
\hline Iberim fólico ® & 1 & 1 & 0 & 2 \\
\hline Indocid $\otimes 250 \mathrm{mg}$ & 0 & 0 & 1 & 1 \\
\hline Inibina \& & 0 & 0 & 1 & 1 \\
\hline Luftal gotas ® & 0 & 1 & 0 & 1 \\
\hline Maalox $\gtrsim$ & 0 & 1 & 1 & 2 \\
\hline Macrodantina $®$ & 1 & 0 & 2 & 3 \\
\hline Materna ® & 0 & 1 & 2 & 3 \\
\hline Metildopa $500 \mathrm{mg}$ & 0 & 0 & 2 & 2 \\
\hline Metocloropamida & 2 & 0 & 0 & 2 \\
\hline Metronidazol & 0 & 1 & 1 & 2 \\
\hline Metronidazol creme & 0 & 0 & 1 & 1 \\
\hline Mm expectorante (®) & 0 & 1 & 1 & 2 \\
\hline
\end{tabular}




\begin{tabular}{|c|c|c|c|c|}
\hline Mucosolvam @ & 1 & 1 & 0 & 2 \\
\hline Murazine ® & 0 & 0 & 1 & 1 \\
\hline Mylanta plus $\otimes$ & 4 & 2 & 2 & 8 \\
\hline Naetene @ & 0 & 0 & 1 & 1 \\
\hline Natalins fólico $®$ & 2 & 4 & 2 & 8 \\
\hline Nativit @ & 1 & 0 & 0 & 1 \\
\hline Nistatina creme & 4 & 8 & 4 & 16 \\
\hline Novofer $@$ & 1 & 0 & 0 & 1 \\
\hline Omcilon ® & 0 & 1 & 0 & 1 \\
\hline $\begin{array}{l}\text { Paracetamol } \\
\text { comprimidos }\end{array}$ & 1 & 3 & 0 & 4 \\
\hline Passiflora @ & 1 & 0 & 0 & 1 \\
\hline Penicilina benzatina & 0 & 1 & 0 & 1 \\
\hline Plamet @ & 1 & 0 & 0 & 1 \\
\hline Plamet gotas $\circledast$ & 1 & 0 & 1 & 2 \\
\hline Pondicilina @ & 0 & 1 & 0 & 1 \\
\hline Rarical @ & 6 & 8 & 3 & 17 \\
\hline Redoxon $\otimes 1 \mathrm{~g}$ & 0 & 1 & 0 & 1 \\
\hline Revenil $\otimes$ & 0 & 0 & 1 & 1 \\
\hline Rovamicina @ & 0 & 0 & 1 & 1 \\
\hline Sorine gotas $\otimes$ & 0 & 2 & 0 & 2 \\
\hline Sulfato ferroso & 19 & 25 & 6 & 60 \\
\hline Talsutim creme $®$ & 0 & 0 & 1 & 1 \\
\hline Trimedal $®$ & 0 & 1 & 1 & 2 \\
\hline Trinizol M @ & 2 & 0 & 0 & 2 \\
\hline Tylenol ® & 5 & 3 & 2 & 10 \\
\hline Tylenol @ 750mg & 0 & 1 & 0 & 1 \\
\hline Vacina dupla adulta & 1 & 0 & 1 & 2 \\
\hline $\begin{array}{l}\text { Vitaminas e sais } \\
\text { minerais }\end{array}$ & 0 & 4 & 2 & 6 \\
\hline Vitergam ® & 0 & 1 & 0 & 1 \\
\hline Xiloproct gel ® & 0 & 0 & 1 & 1 \\
\hline Total & 88 & 116 & 65 & 269 \\
\hline
\end{tabular}

A tabela 21 apresenta a classificação dos medicamentos prescritos nas consultas de pré-natal segundo os grupos e subgrupos farmacológicos definidos pela RENAME (2000) e, dentro de cada grupo, os medicamentos mais freqüentes. Os grupos de medicamentos mais prescritos foram:

1 - Medicamentos que atuem sobre o sistema hematopoiético - 34,9\%;

2 - Antiinfecciosos - 21,2\%;

3 - Medicamentos que atuam sobre o sistema digestivo - 15,6\%. 
Tabela 21: Medicamentos, por nome genérico, prescritos em consultas de prénatal (SUS) segundo grupo farmacológico (RENAME). Piracicaba - SP, 2001.

\begin{tabular}{|c|c|c|c|c|}
\hline $\begin{array}{l}\text { Grupo } \\
\text { farmacológico }\end{array}$ & Sub grupo & Medicamento & Freqüência & $\%$ \\
\hline $\begin{array}{l}\text { Analgésicos e } \\
\text { medicamentos } \\
\text { antienxaquecas }\end{array}$ & $\begin{array}{l}\text { Analgésicos não } \\
\text { opióides }\end{array}$ & $\begin{array}{l}\text { Dipirona * } \\
\text { Paracetamol }\end{array}$ & $\begin{array}{r}1 \\
17\end{array}$ & $\begin{array}{l}0,4 \\
6,3\end{array}$ \\
\hline $\begin{array}{l}\text { Antiinflamatórios } \\
\text { e antigotosas }\end{array}$ & $\begin{array}{l}\text { Antiinflamatórios } \\
\text { não esteróides } \\
\text { Antiinflamatórios } \\
\text { esteróides }\end{array}$ & $\begin{array}{l}\text { Indometacina } \\
\text { Diclofenaco de sódio } \\
\text { Triancinolona } \\
\text { Hidrocortisona * } \\
\end{array}$ & $\begin{array}{l}1 \\
1 \\
1 \\
1 \\
\end{array}$ & $\begin{array}{l}0,4 \\
0,4 \\
0,4 \\
0,4\end{array}$ \\
\hline \multirow{3}{*}{ Antiinfecciosos } & Antibióticos & $\begin{array}{l}\text { Amoxacilina } \\
\text { Ampicilina } \\
\text { Benzil penicilina } \\
\text { benzatina } \\
\text { Cefalexina } \\
\text { Tetraciclina * } \\
\text { Nitrofurantoina }\end{array}$ & $\begin{array}{r}1 \\
6 \\
1 \\
14 \\
1 \\
3\end{array}$ & $\begin{array}{l}0,4 \\
2,2 \\
0,4\end{array}$ \\
\hline & Antifúngicos & $\begin{array}{l}\text { Nistatina } \\
\text { Cetoconazol * } \\
\text { Tinidazol * } \\
\text { Isoconazol }\end{array}$ & $\begin{array}{r}16 \\
2 \\
3 \\
2\end{array}$ & $\begin{array}{l}5,9 \\
0,7 \\
1,1 \\
0,7\end{array}$ \\
\hline & $\begin{array}{l}\text { Antiparasitários } \\
\text { Anti-sépticos e } \\
\text { desinfetantes }\end{array}$ & $\begin{array}{l}\text { Terconazol } \\
\text { Metronidazol } \\
\text { Espiramicina } \\
\text { Cetilpiridinio }\end{array}$ & $\begin{array}{l}1 \\
4 \\
2 \\
1\end{array}$ & $\begin{array}{l}0,4 \\
1,5 \\
0,7 \\
0,4\end{array}$ \\
\hline $\begin{array}{l}\text { Imuno- } \\
\text { moduladores e } \\
\text { imunoterápicos }\end{array}$ & Vacina e toxóides & Vacina dupla-adulta & 2 & 0,7 \\
\hline \multirow[b]{2}{*}{ Nutrientes } & $\begin{array}{l}\text { Nutrição e reposição } \\
\text { hídrica parental }\end{array}$ & Glicose $25 \%$ & 1 & 0,4 \\
\hline & $\begin{array}{l}\text { Vitaminas e sais } \\
\text { minerais }\end{array}$ & $\begin{array}{l}\text { Vitamina A * } \\
\text { Vitamina C } \\
\text { Vitamina C * } \\
\text { Cálcio } \\
\text { Vitamina B6 * }\end{array}$ & $\begin{array}{l}7 \\
1 \\
3 \\
1 \\
7 \\
\end{array}$ & $\begin{array}{l}2,6 \\
0,4 \\
1,1 \\
0,4 \\
2,6 \\
\end{array}$ \\
\hline $\begin{array}{l}\text { Medicamentos que } \\
\text { atuam sobre o } \\
\text { sistema } \\
\text { cardiovascular }\end{array}$ & Antihipertensivos & Metildopa & 3 & 1,1 \\
\hline Dermatológicos & $\begin{array}{l}\text { Medicamentos } \\
\text { antipruriginosos e } \\
\text { antiinflamatórios tópicos }\end{array}$ & $\begin{array}{l}\text { Lisozima } \\
\text { Ácido } \\
\text { mucopolissacárido- } \\
\text { polissulfúrico }\end{array}$ & $\begin{array}{l}1 \\
1\end{array}$ & $\begin{array}{l}0,4 \\
0,4\end{array}$ \\
\hline
\end{tabular}




\begin{tabular}{|c|c|c|c|c|}
\hline \multirow[t]{2}{*}{$\begin{array}{l}\text { Medicamentos que } \\
\text { atuam sobre o } \\
\text { sistema } \\
\text { respiratório }\end{array}$} & \multirow[t]{2}{*}{$\begin{array}{l}\text { Anti-asmáticos } \\
\text { Antitussigenos e } \\
\text { fluidificantes }\end{array}$} & $\begin{array}{l}\text { Fenilefrina * } \\
\text { Etafedrina * } \\
\text { Ambroxol } \\
\text { Bromexina }\end{array}$ & $\begin{array}{l}2 \\
1 \\
2 \\
2\end{array}$ & $\begin{array}{l}0,7 \\
0,4 \\
0,7 \\
0,7\end{array}$ \\
\hline & & lodeto de potássio * & 3 & 1,1 \\
\hline \multirow{2}{*}{$\begin{array}{l}\text { Medicamentos que } \\
\text { atuam sobre o } \\
\text { sistema endócrino } \\
\text { reprodutor e } \\
\text { produtos } \\
\text { farmacêuticos } \\
\text { correlatos }\end{array}$} & \multirow{2}{*}{$\begin{array}{l}\text { Medicamentos que } \\
\text { atuam na motilidade } \\
\text { uterina }\end{array}$} & Hesperidina * & 8 & 3,0 \\
\hline & & Isoxsuprina & 1 & 0,4 \\
\hline $\begin{array}{l}\text { Medicamentos que } \\
\text { atuam sobre o } \\
\text { sistema } \\
\text { hemocitopoiético }\end{array}$ & Antianêmicos & $\begin{array}{l}\text { Ácido fólico } \\
\text { Ácido fólico * } \\
\text { Sulfato ferroso } \\
\text { Ferro * }\end{array}$ & $\begin{array}{r}5 \\
2 \\
60 \\
27 \\
\end{array}$ & $\begin{array}{r}1,8 \\
0,7 \\
22,3 \\
10,0 \\
\end{array}$ \\
\hline \multirow{4}{*}{$\begin{array}{l}\text { Medicamentos que } \\
\text { atuam sobre o } \\
\text { sistema digestivo }\end{array}$} & $\begin{array}{l}\text { Antiulcerosos } \\
\text { Antiácidos }\end{array}$ & $\begin{array}{l}\text { Cimetidina } \\
\text { Hidróxido de Alumínio * } \\
\text { Hidróxido de Alumínio }\end{array}$ & $\begin{array}{r}2 \\
11 \\
3\end{array}$ & $\begin{array}{l}0,7 \\
4,1 \\
1,1\end{array}$ \\
\hline & $\begin{array}{l}\text { Antieméticos e agentes } \\
\text { pró cinéticos }\end{array}$ & $\begin{array}{l}\text { Metoclopromida } \\
\text { Dimenidrato } \\
\text { Bromoprida }\end{array}$ & $\begin{array}{l}2 \\
2 \\
3\end{array}$ & $\begin{array}{l}0,7 \\
0,7 \\
1,1\end{array}$ \\
\hline & $\begin{array}{l}\text { Antidiarreicos } \\
\text { sintomáticos } \\
\text { Antiespasmódicos e } \\
\text { correlatos }\end{array}$ & Hioscina & 18 & 6,7 \\
\hline & Laxativos & Bisacodil & 1 & 0,4 \\
\hline \multirow{2}{*}{$\begin{array}{l}\text { Outros } \\
\text { (Medicamentos } \\
\text { que não se } \\
\text { enquadram em } \\
\text { nenhum grupo }\end{array}$} & & Dexpantenol & 1 & 0,4 \\
\hline & & $\begin{array}{l}\text { Dimeticona } \\
\text { Nafazolina * } \\
\text { Passiflora * }\end{array}$ & $\begin{array}{l}1 \\
2 \\
1\end{array}$ & $\begin{array}{l}0,4 \\
0,7 \\
0,4\end{array}$ \\
\hline Total & & & 269 & 100,0 \\
\hline
\end{tabular}

* em associação com outras substâncias

No primeiro trimestre de gestação os grupos farmacológicos mais utilizados foram:

1. medicamentos que atuam sobre o sistema hematopoiético - $37,5 \%$ (sulfato ferroso, $56,7 \%$; sais de ferro associados com uma ou mais vitaminas, $30,3 \%$ e ácido fólico, $12,1 \%$ ); 
2. medicamentos que atuam sobre o sistema digestivo - $26,1 \%$ (hioscina (monodroga ou associação), 34,8\%; dimenidrato (monodroga ou associação), 26,1\% e hidróxido de aluminio (em associação), 17,4\%);

3. antiinfecciosos - 18,2\% (cefalexina, 31,2\%; nistatina, $25,0 \%$ e ampicilina, $18,7 \%)$.

No segundo trimestre de gestação os grupos farmacológicos mais utilizados foram:

1. medicamentos que atuam sobre o sistema hematopoiético - $44,0 \%$ (sulfato ferroso, $68,6 \%$ e sais de ferro associados com uma ou mais vitaminas, 31,4\%);

2. antiinfecciosos - 19,8\% (nistatina, 34,8\%; cefalexina, $21,7 \%$ e metronidazol, 13,0\%);

3. medicamentos que atuam sobre o sistema digestivo $-13,8 \%$ (hioscina (monodroga ou associação), 37,5\%; hidróxido de alumínio (monodroga ou associação), 25,0\%); Dimeticona, $12,5 \%$ e Dimenidrato, 12,5\%).

No terceiro trimestre de gestação os grupos farmacológicos mais utilizados foram:

1. medicamentos que atuam sobre o sistema hematopoiético - $24,6 \%$ (sulfato ferroso, $37,5 \%$; sais de ferro associados com uma ou mais vitaminas, $56,2 \%$ e ácido fólico, $6,3 \%)$;

2. antiinfecciosos - 23,1\% (cefalexina, 26,7\%; nistatina, 26,7\%; nitrofurantoína, $23,3 \%$ e metronidazol, $23,3 \%$ );

3. medicamentos que atuam sobre o sistema digestivo - $13,8 \%$ (hioscina (monodroga ou associação), 41,7\%; hidróxido de alumínio (monodroga ou associação), 41,7\%); Cimetidina, 8,3, \% e Bromoprida, 8,3\%).

Em relação a prescrição de medicamentos pelo nome genérico, $49,4 \%$ do total estavam pelo nome genérico. A maior freqüência de prescrição com nome genérico se deu no $2^{\circ}$. trimestre de gestação, o que pode ser verificado na Tabela 22. 
Tabela 22: Prescrição de medicamentos em consultas de pré-natal (SUS) segundo nome genérico e trimestre de gestação. Piracicaba - SP, 2001.

\begin{tabular}{ccccc}
\hline Genérico & $1^{\mathbf{0}}$ & $\begin{array}{c}\text { Trimestre } \\
2^{\mathbf{0}}\end{array}$ & $3^{\mathbf{0}}$ & Total \\
& 42 & 60 & 31 & 133 \\
Sim & 46 & 54 & 36 & 136 \\
Não & 88 & 114 & 67 & 269 \\
\hline Total & & &
\end{tabular}

A prescrição de medicamentos padronizados pelo município foi de $53,5 \%$ do total prescrito (Figura 5):

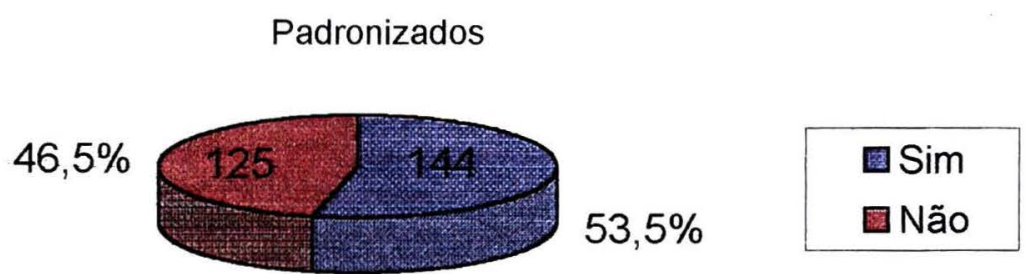

Figura 5 - Distribuição das prescrições de medicamentos em consultas de prénatal (SUS) em relação a Lista de Medicamentos Padronizados pelo município. Piracicaba - SP, 2001.

Das 191 gestantes com prescrição medicamentosa, 12,6\% tiveram antibióticos prescritos e 1,6\% tiveram algum tipo de medicamento injetável prescrito. Nenhuma das gestantes teve ambas as prescrições. 


\section{4 - INDICADORES BÁSICOS DE UTILIZAÇÃO DE MEDICAMENTOS (OMS): INDICADORES DE PRESCRIÇÃO}

Foram obtidos os seguintes valores para os indicadores de prescrição:

. número médio de medicamentos por consulta - 0,6

porcentagem de medicamentos prescritos pelo nome genérico - 49,4\%

porcentagem de consultas em que foram prescritos antibióticos $-5,6 \%$

porcentagem de consultas em que foram prescritos medicamentos injetáveis $0,7 \%$

. porcentagem de medicamentos prescritos que constavam na lista de medicamentos padronizados pelo municipio - 53,5\%

\section{5 - CLASSIFICAÇÃO DOS MEDICAMENTOS PRESCRITOS NAS CATEGORIAS DE RISCO AO FETO (FDA)}

Na tabela 23 estão apresentadas as freqüências dos medicamentos prescritos segundo a classificação de risco ao feto do FDA, seguida dos três medicamentos mais prescritos dentro de cada uma delas. 
TABELA 23 - Distribuição dos medicamentos prescritos em consultas de prénatal (SUS), segundo categorias de risco ao feto (FDA), e os três mais freqüentes (por nome genérico) dentro de cada categoria. Piracicaba - SP, 2001.

\begin{tabular}{|c|c|c|c|c|c|}
\hline Categorias & Freq. & $\%$ & Medicamentos & Freq. & $\%$ \\
\hline A & 96 & 35,7 & $\begin{array}{l}\text { Sulfato ferroso } \\
\text { Ferro (Assoc.) } \\
\text { Vitamina A (Assoc.) }\end{array}$ & $\begin{array}{r}60 \\
27 \\
3\end{array}$ & $\begin{array}{r}62,5 \\
23,1 \\
3,1\end{array}$ \\
\hline$B$ & 74 & 27,5 & $\begin{array}{l}\text { Paracetamol } \\
\text { Nistatina } \\
\text { Cefalexina }\end{array}$ & $\begin{array}{l}17 \\
16 \\
14\end{array}$ & $\begin{array}{l}23,9 \\
22,5 \\
19,7\end{array}$ \\
\hline C & 70 & 26,0 & $\begin{array}{l}\text { Hioscina } \\
\text { Hidróxido de alumínio (Assoc.) } \\
\text { Vitamina B6* }\end{array}$ & $\begin{array}{r}18 \\
11 \\
7\end{array}$ & $\begin{array}{l}25,1 \\
15,7 \\
10,0\end{array}$ \\
\hline$D$ & 5 & 1,5 & $\begin{array}{l}\text { lodeto de potássio (Assoc.) } \\
\text { Tetraciclina (Assoc.) } \\
\text { Indometacina }{ }^{\star \star}\end{array}$ & $\begin{array}{l}3 \\
1 \\
1\end{array}$ & $\begin{array}{l}60,0 \\
20,0 \\
20,0\end{array}$ \\
\hline$E$ & 4 & 1,5 & $\begin{array}{l}\text { Vitamina A (Assoc.) } \\
\text { (acima de } 3.000 \text { UI) }\end{array}$ & 4 & 100,0 \\
\hline $\begin{array}{c}\text { Sem } \\
\text { informações }\end{array}$ & 20 & 7,3 & $\begin{array}{l}\text { hesperidina (Assoc.) } \\
\text { Bromoprida } \\
\text { Ambroxol } \\
\text { Isoconazol }\end{array}$ & $\begin{array}{l}8 \\
3 \\
2 \\
2\end{array}$ & $\begin{array}{l}40,0 \\
15,0 \\
10,0 \\
10,0\end{array}$ \\
\hline
\end{tabular}

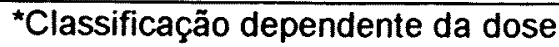

** Quando utilizado no $3^{\circ}$ trimestre de gestação

\section{6 - ANÁlISE DA DOSE E ESQUEMA TERAPÊUTICO DOS MEDICAMENTOS PRESCRITOS}

Levando-se em consideração as doses terapêuticas e doses tóxicas de cada um dos medicamentos receitados (doses máximas e mínimas), com a respectiva posologia estabelecida (intervalo entre as doses) e as doses recomendadas na gestação, encontrou-se a seguinte situação: 
TABELA 24 - Distribuição dos medicamentos prescritos em consultas de prénatal (SUS) segundo adequação de dose. Piracicaba - SP, 2001.

\begin{tabular}{lcc}
\hline Dose & número & freqüência (\%) \\
\hline terapêutica & 244 & 90,7 \\
subterapêutica & 2 & 0,7 \\
supraterapêutica & 4 & 1,5 \\
Sem informação na prescrição & 6 & 2,2 \\
Sem informação científica sobre dose terapêutica & 13 & 4,9 \\
\hline Total & 269 & 100,0 \\
\hline
\end{tabular}

TABELA 25 - Distribuição dos medicamentos prescritos dentro da dose terapêutica nas consultas de pré-natal (SUS) segundo adequação da posologia. Piracicaba - SP, 2001.

\begin{tabular}{lrr}
\hline Posologia & número & freqüência (\%) \\
\hline adequada & 182 & 74,6 \\
inadequada & 62 & 25,4 \\
\hline Total & 244 & 100,0 \\
\hline
\end{tabular}

Figura 6 - Distribuição dos medicamentos prescritos dentro da dose terapêutica nas em consultas de pré-natal (SUS), segundo a dose recomendada na gravidez. Piracicaba - SP, 2001. 


\section{5 - DISCUSSÃO}

\section{1 - PERFIL DA GESTANTE E DO CONSUMO DE MEDICAMENTO}

O perfil de gestante encontrado foi o de uma mulher com idade média aproximada de 24 anos, com um filho ou mais, dona de casa sem atividade remunerada, que estudou até $\circ 1^{\circ}$. grau (Ensino Fundamental), residente em domicílio com mais duas pessoas, com uma renda per capita menor do que um salário mínimo e no terceiro trimestre de gravidez.

Comparando-se com a literatura, percebe-se que se trata de um perfil com aspectos semelhantes aos encontrados por GOMES et al. (1999) para a cidade de São Paulo: predominância de gestantes na faixa etária de 20 - 29 anos, com $1^{\circ}$. grau completo, exercendo ou não atividade remunerada. Vale ressaltar, entretanto, o baixo índice de analfabetismo encontrado na amostra estudada em Piracicaba (0,9\%) (GOMES et al. descrevem um índice de 3,0\%).

As características descritas sugerem uma gestante que tem pouco acesso a informaçōes, serviços e bens de consumo. Pode-se levantar esta hipótese considerando como principal variável o grau de escolaridade da amostra $(0,9 \%$ de analfabetas; $15,7 \%$ de mulheres que pararam de estudar entre a $1^{\mathrm{a}}$. e a $4^{\mathrm{a}}$. série do Ensino Fundamental e, $50,8 \%$ entre a $5^{\mathrm{a}}$ e a $8^{\mathrm{a}}$. série). Segundo GOMES et al. (1999), mais do que a renda per capita familiar, o grau de escolaridade reflete o nivel social dos indivíduos, pois a educação possibilita o exercício de determinadas ocupações, consequentemente a obtenção de um nível diferenciado de renda, que por sua vez, facilita o acesso a diferentes condutas e serviços para a promoção da saúde, mais escolaridade e maior renda. Nesta perspectiva o grau de escolaridade pode ser considerado causa e efeito da desigualdade social. 
Na realidade este era um quadro esperado já que, conforme CARVALHO (1997), as políticas sociais no Brasil não têm conseguido alterar o quadro de pobreza da população, agravando cada vez mais as desigualdades.

Especificamente em relação ao uso de medicamentos, o perfil encontrado pode comprometer o que se preconiza como uso racional ${ }^{28}$ ao dificultar o acesso da gestante ao serviço de saúde, ao medicamento seguro e eficiente, bem como as informações necessárias para uma utilização adequada.

Isto pode ser sugerido também pelas características da automedicação, pois $18,6 \%$ das mulheres tomaram medicamento sem acompanhamento médico na semana anterior a entrevista, sendo que destas $76,7 \%$ tinham renda per capita inferior a um salário mínimo.

Segundo VILARINO et al. (1998), a automedicação pode ser definida como o uso de medicamentos sem prescrição médica, onde o próprio paciente decide qual fármaco utilizar. Pode ser por iniciativa do próprio paciente, por orientação de pessoas não habilitadas, tais como amigos, familiares ou balconistas de farmácia, ou o que se conhece por automedicação orientada, ou seja, a reutilização de receitas médicas anteriores sem indicação de uso contínuo.

Pelas informações obtidas, $58,0 \%$ dos medicamentos utilizados dentro dos parâmetros acima citados eram direcionados a sintomas, vinculados ou não a gravidez, principalmente anitiespasmódicos e relaxantes uterinos $(26,1 \%)$, medicamentos utilizados para dor, tosse, gripes e resfriados $(21,8 \%)$ e antiácidos $(7,3 \%)$.

Os resultados sugerem algumas situações onde a atitude mais adequada seria a procura dos serviços de saúde na busca de avaliação e orientação médica, tais como cólicas e espasmos uterinos, mas a gestante tomou a

\footnotetext{
28 A Política Nacional de Medicamentos (Portaria no. 3916 / 30/10/98 - MS) define o Uso Racional de Medicamentos como um processo que compreende a prescrição apropriada, a disponibilidade dos medicamentos a preços acessiveis, a dispensação em condições adequadas e por profissionais habilitados, o consumo nas doses, periodo de tempo e intervalos definidos de medicamentos eficazes, seguros e de qualidade.
} 
iniciativa de se automedicar.

O maior consumo de medicamentos por automedicação anterior a ocorreu no terceiro trimestre de gestação $(51,8 \%)$, período considerado mais seguro em relação a ocorrência de má-formações congênitas decorrente do uso de medicamentos, mas no qual o feto ainda se encontra vulnerável a alterações no Sistema Nervoso Central e a interferências no seu crescimento (SCHULER et al., 1998).

Em comparação a pesquisa realizada em países europeus, conduzida pelo CGDUP (1992), a prevalência da automedicação aqui observada $(18,6 \%)$ pode ser considerada significativa já que o referido estudo encontrou uma taxa de $6,0 \%$. Entretanto, em relação a pesquisa realizada na cidade de São Paulo, pode-se considerar um resultado mais positivo, já que o descrito por GOMES et al. (1999) foi um indice de $33,5 \%$ e o desejado seria a não utilização de medicamentos sem orientação médica durante a gestação.

Quanto a comparação de dados obtidos nesta pesquisa em relação a outros, relatados na literatura cientifica e aqui referenciados, é importante fazer a seguinte ressalva: na sua totalidade os trabalhos consultados são retrospectivos apresentando resultados decorrentes da utilização de medicamentos durante toda a gravidez, obtidos a partir de entrevistas às mães até 30 dias após o parto e ou através de levantamento de informações nos prontuários médicos ou registros dos serviços de saúde responsáveis pelo atendimento do pré-natal e do parto.

O presente trabalho constitui-se, como já foi explicitado no capitulo Metodologia, num estudo transversal. As informações obtidas refletem portanto um momento específico, fornecendo um panorama focado no periodo estudado (ALMEIDA FILHO \& ROUQUAYROL, 1992). Entretanto, ao fazer um corte aleatório na população, proporciona uma visão geral que pode ser inferida e utilizada para comparações, até porque percebe-se, analisando-se a 
composição da amostra selecionada, que todos os estágios da gestação estão nela representados (primeiro, segundo e terceiro trimestres).

Neste sentido, acredita-se que o dado que não pode ser comparado, ou inferido, é o número total de medicamentos ingeridos pelas mulheres durante toda a gravidez, informação não buscada neste trabalho. As demais informações podem servir de referências para discussão.

Os medicamentos mais utilizados por automedicação foram, com exceção dos antiespasmódicos e relaxantes uterinos, semelhantes aos encontrados no estudo do CGDUP (1992).

Alguns deles, tais como os antibióticos, os medicamentos a base de ácido acetil salicílico (antiinflamatórios, antigripais e antiácidos), os antitussigenos contendo iodeto de potássio e os suplementos vitamínicos, merecem destaque.

Os antibióticos porque, apesar da ampicilina e da cefalexina (medicamentos relatados nas entrevistas) serem considerados relativamente seguros quanto ao uso na gravidez ${ }^{29}$, deve-se considerar que constituem, de uma forma geral, um grupo farmacológico que possui diferentes estruturas quimicas, diferentes indicações terapêuticas e diferentes implicações em relação a teratogenicidade (CZEIZEL \& OLSEN, 1998). Tais aspectos, além da relação risco-benefício, só podem ser devidamente avaliados num processo de acompanhamento e diagnóstico médico. Mesmo assim, CHETLEY (1994) ressalta que nos paises de terceiro mundo o uso dos antibióticos ocorre geralmente de forma inadequada, havendo disponibilização dos mesmos sem receita médica e consequentemente uso indevido, processo este que pode também ser observado a partir dos dados relatados neste trabalho.

Em relação ao ácido acetil salicílico, CHETLEY (1994) afirma que apesar de não haver evidências conclusivas sobre seus efeitos sobre a formação fetal,

29 Segundo BRIGGS et al. (1987), tanto a ampicilina quanto a cefalexina podem ser classificadas na categoria $B$ de risco ao feto (de acordo com proposição do FDA). CZEIZEL et al. (2001) afirmam não haver evidências de que a ampicilina seja teratogênica. 
sabe-se que quando utilizado no final da gravidez $\left(3^{\circ}\right.$. trimestre) pode deter a contração uterina, levar a complicações durante o parto e causar hemorragias na mãe e no recém-nascido. FUCHS \& WANNMACHER (1998) corroboram estas afirmações, observando que os efeitos do ácido acetil salicílico sobre o feto são controversos. Além disso a utilização de medicamentos contendo este fármaco podem provocar efeitos adversos sistêmicos, principalmente gastrointestinais. Partindo destas informações pode-se sugerir o não uso destes medicamentos durante a gravidez.

Já o iodeto de potássio, classificado na categoria $\mathrm{D}$ de risco ao feto, está associado a ocorrência de bócio congênito e portanto deve ter sua relação risco - benefício muito bem avaliada durante a gravidez (BRIGGS et al., 1987).

Em relação ao uso de suplementos vitamínicos, CHETLEY (1994) enfatiza que apesar de não haver evidências sobre as vantagens de sua administração rotineira para gestantes saudáveis, o uso desta classe de medicamentos é bastante comum. Como trata-se de assunto controverso e merecer maior detalhamento, este procedimento será discutido posteriormente. Por ora, é importante ressaltar que um dos medicamentos referidos pelas mulheres entrevistadas contém (segundo informações do fabricante) 25.000 UI de Vitamina A por comprimido, dose 2,5 vezes acima da dose máxima permitida no período gestacional (10.000 UI) e concentração considerada categoria $X$ de risco ao feto (pela sua teratogenicidade conhecida) e, portanto contra-indicado na gravidez (BRIGGS et al., 1987).

Analisando-se as informações sobre o consumo de medicamentos na semana anterior à entrevista, tem-se que o total de mulheres que tomaram pelo menos um medicamento foi de $61,6 \%$. Destas $80,2 \%$ referiram que o fizeram por indicação médica e, 50,6\% informaram ter uma renda per capita familiar inferior a um salário mínimo.

Como mencionado anteriormente, não há como comparar tais dados de maneira categórica com os relatados na literatura científica, devido a diferenças metodológicas. Entretanto, considerando-se que se tratam de valores pontuais, 
mas inseridos em um comportamento (uso de medicamentos) constante no tempo e espaço estudado, pode-se dizer em relação a porcentagem de mulheres que utilizaram pelo menos um medicamento na semana anterior a pesquisa que no geral trata-se de um valor menor do que o encontrado por outros autores sobre a porcentagem de mulheres que usaram pelo menos um medicamento durante a gravidez: CGDUP (1992) para países europeus - $86,0 \%$; por GOMES et al. (1999) na cidade de São Paulo - 94,9\% e por SOTERO et al. (2001) em seis capitais brasileiras - 83,8\%. A exceção é o trabalho relatado por DE VIGAN et al. (1999) em levantamento realizado em 4 paises europeus $64,1 \%$, com valor semelhante.

Todos estes dados, incluindo o deste trabalho, demonstram claramente o processo de medicalização da gestação descrito por BARROS (1995), onde a gravidez, de um processo fisiológico normal, passou a ser considerada uma doença, ou melhor, um agravo à saúde e portanto passivel de tratamento medicamentoso.

Tanto é que os medicamentos mais consumidos pelas gestantes entrevistadas (antianêmicos, antiespasmódicos e vitaminas e minerais) são semelhantes aos descritos nos trabalhos acima citados, refletindo um procedimento comum e esperado na gravidez.

Diversos autores ${ }^{30}$ ressaltam que existem diferenças regionais e locais em relação ao uso de medicamentos, em decorrência de um conjunto de fatores que abarcam questōes médicas (perfil epidemiológico), sociais (religiosas, culturais e disponibilidade de serviços de saúde) e econômicas (custo do tratamento, interesses financeiros, regulamentação da propaganda, produção e comercialização dos medicamentos, entre outros).

De fato, LEFÈVRE (1991) afirma que o medicamento é utilizado nas sociedades contemporâneas por duas funções complementares que determinam o perfil de consumo de uma da população: a função terapêutica (decorrente da

30 OMS (1986), ROZENFELD (1989), LEFÈVRE (1991), CGDUP (1992), LEE \& BERGMAN (1994) e DE VIGAN (1999) 
estrutura química e da ação farmacológica) e a função simbólica ( conseqüência das representações sociais que envolvem o processo saúde - doença). A primeira pode ser considera um aspecto universal, pois trata-se de um dado científico. A segunda, a função simbólica, é construída em contextos específicos, dentro das relações e da estrutura que se estabelece no interior das comunidades e interfere de maneira incisiva na definição de padrões de consumo diferenciados.

Entretanto, apesar da existência de diferentes índices de prevalência de utilização de medicamentos na gravidez, percebe-se que existe um perfil de consumo comum nos trabalhos consultados. Além do alto grau de medicalização encontrado, os medicamentos que geralmente compõe o perfil de utilização são os antianêmicos (suplementos de ferro e ácido fólico), os suplementos vitamínicos, os antiinfecciosos (antibacterianos e antifúngicos), os AAA (antiinflamatórios, analgésicos e antipiréticos e os medicamentos para sintomas gastrintestinais (antiácidos, antiespasmódicos e antieméticos). Outros medicamentos também constituem este perfil, mas de uma forma variável nas diferentes localidades pesquisadas.

\section{2 - PERFIL DA PRESCRIÇÃO}

Após passarem pela consulta médica de pré-natal, $44,7 \%$ das mulheres receberam prescrição medicamentosa, sendo que o maior número de prescrições $(43,5 \%)$ ocorreu para aquelas que estavam no segundo trimestre de gestação.

Nos artigos científicos consultados não foram encontrados parâmetros para inferir sobre a qualificação destes valores. Não é possível dizer se são adequados ou não.

No entanto, acredita-se que após a análise das prescrições considerando-se os Indicadores Básicos de Utilização de Medicamentos da 
OMS, o risco de teratogenicidade e o esquema terapêutico adotado, ter-se-á elementos indicativos para uma avaliação.

De qualquer modo, discutir a qualidade das prescrições é aspecto fundamental para buscar uma utilização racional de medicamentos. Segundo a OMS (1986), os dados disponíveis mostram que de uma forma geral o pessoal médico e outros profissionais que formulam prescrições estão muito distantes de utilizar os medicamentos racionalmente. Na realidade, a prescrição medicamentosa constitui-se em um prática definida em um contexto maior e mais complexo, que é o processo saúde - doença como um todo, refletindo as concepções existentes na comunidade na qual está inserida.

Quando um médico prescreve um medicamento a um paciente, além das propriedades bioquímicas que o produto possa ter, se articulam muito outros fatores que constituem, de acordo com a OMS (1986), um processo denominado de "as bases não farmacológicas da terapêutica". O prescritor sofre influências:

. da formação profissional que recebeu (na graduação) e têm recebido (educação continuada) em terapêutica;

. da indústria farmacêutica (estratégias de promoção e marketing com o fornecimento de informações farmacologicamente não científicas);

- da disponibilidade das formulações colocadas no mercado;

. dos aspectos culturais da comunidade em que está inserido (efeito "simbólico" do medicamento);

. das regulamentações governamentais.

Ora, se no Brasil o quadro conhecido é o da má utilização de medicamentos, com a existência de produtos desnecessários, prescrição irracional, automedicação e deficiências na regulamentação e controle do mercado farmacêutico (ROZENFELD, 1989), aliado a uma concepção de que a "Saúde" é um bem de consumo que pode ser alcançada por meio da aquisição de produtos (medicamentos entre outros) e serviços (LEFÈVRE, 1991), o comportamento médico esperado é o da prescrição de medicamentos. 
Até porque, de acordo com LEFĖVRE (1991), se o medicamento é percebido como um produto fundamental para se garantir a Saúde, consequentemente deve estar presente quando se trata de enfrentar uma enfermidade. O prescritor sente-se, neste contexto, compelido a indicar necessariamente um medicamento, até para finalizar um processo diagnóstico atendendo à expectativa do paciente.

Estes pressupostos ajudam a compreender tanto hábitos de prescrição, quanto de consumo de medicamentos.

Acredita-se então, que através da análise das prescrições alguns aspectos interferentes possam ser explicitados e a partir dai propor-se medidas de intervenção. É o que se pretende a seguir.

De acordo com os dados obtidos, os grupos farmacológicos mais prescritos foram:

medicamentos que atuam sobre o sistema hematopoiético - 34,9\%;

antiinfecciosos - $21,2 \%$;

medicamentos que atuam sobre o sistema digestivo $-15,6 \%$.

Tais informações são compatíveis com os artigos científicos já citados. $O$ interessante é que não houve variabilidade destes grupos em função do trimestre de gestação. Encontrou-se diferenças na freqüência de prescrição, mas não dos medicamentos prescritos.

\section{2. 1 - Medicamentos que atuam sobre o sistema hematopoiético}

Em relação aos medicamentos que atuam sobre o sistema hematopoiético, os produtos prescritos tinham como princípio ativo: sulfato ferroso (monodroga), compostos de ferro associados a suplementos vitamínicos, ácido fólico (monodroga) e ácido fólico associado em suplementos vitamínicos.

Quanto ao uso de sais de ferro na gestação, MENGUE et al. (2001) salientam que trata-se de uma intervenção de rotina. Relatam uma prevalência de uso de $33,5 \%$ de vitaminas associadas a antianêmicos entre as gestantes 
pesquisadas por eles, indice bastante semelhante ao do presente trabalho (34,9\%). Na pesquisa realizada pelo CGDUP (1992), a prevalência de uso teve uma grande variação entre os países estudados. Foram relatados índices que variaram de $4 \%$ a $94 \%$ de gestantes que utilizaram tais medicamentos. FORFAR \& NELSON (1991) descrevem um consumo de sais de ferro por $82,0 \%$ das gestantes na cidade de Edimburgo.

Apesar de ser uma prática disseminada, MENGUE et al. (2001) ressaltam que vários autores admitem que as evidências que sustentam esta conduta são fracas e os benefícios do tratamento não são claramente definidos.

A favor da prescrição de suplementos de ferro, está a recomendação da OMS de que devido as altas taxas de anemia nos paises de terceiro mundo, deve-se ministrar tais medicamentos a todas as mulheres nos últimos quatro a cinco meses de gravidez (CHETLEY, 1994).

De fato, é consenso que as anemias constituem o maior problema nutricional da atualidade, sendo que a deficiência de ferro é considerada a principal responsável por esta condição. Estima-se que nos países latinoamericanos $48,0 \%$ das gestantes sejam anêmicas e o Brasil, existem trabalhos que relatam uma prevalência de anemia em gestantes de 30,3\% (Pernambuco) a $52,1 \%$ (São Paulo) (LOPES et al., 1996).

Segundo FREIRE (1998), a anemia na gravidez está associada com baixo peso do recém-nascido e a um aumento da mortalidade materna e infantil. A deficiência de ferro inibe a capacidade corporal de regulação de temperatura (alterando a produção de hormônios e o metabolismo basal) e afeta o desenvolvimento cognitivo da criança, problema este irreversível.

Devido as conseqüências da doença, desde 1996 a Organização Mundial de Saúde / Organização Pan-americana de Saúde (OPS) vem propondo uma série de atividades regionais, nacionais e locais visando a reduzir a prevalência de anemias ferroprivas, e entre elas, está a disponibilização de suplementos de ferro às gestantes (FREIRE, 1998). 
Contra a prescrição de suplementos de ferro de maneira generalizada, está o fato de que somente 5 a $10 \%$ do ferro ingerido é absorvido em condições normais. O organismo humano só absorve ferro em proporções maiores (25\%) em situações de deficiência (FUCCHS \& WANNMACHER, 1998). Deste modo, a ingestão diária através da dieta é geralmente suficiente para manter os niveis adequados de ferro no organismo, justificando-se a utilização de medicamentos com fero somente em casos de anemia diagnosticada (CHETLEY, 1994).

Além disto (devido a má absorção do sal), as preparações de ferro freqüentemente podem causar alterações gastrointestinais (náuseas, cólicas, constipação intestinal, vômitos e diarréia) ${ }^{31}$ e existem trabalhos sugerindo propriedades teratogênicas quando da sua ingestão no primeiro trimestre de gravidez $^{32}$.

De todo modo, deve-se considerar que o uso de medicamentos contendo ferro corresponde a um enfoque curativo e que para combater a anemia a e suas conseqüências são necessárias medidas que intervenham nas causas do problema decorrentes principalmente das desigualdades sociais observadas nos paises de terceiro mundo.

De acordo com MATHIAS \& NOBILE (1981), as preparações de ferro mais freqüentemente prescritas são: sulfato, succinato, carbonato, fumarato $e$ succinato ferroso. Na pesquisa realizada em Piracicaba, o mais prescrito foi o Sulfato Ferroso, até porque trata-se de medicamento padronizado pelo Serviço Municipal de Saúde.

$\mathrm{Na}$ figura 7, estão listados os sais ferrosos com suas respectivas concentrações do elemento ferro.

\footnotetext{
${ }^{31}$ LOPES et al. (1999), FORFAR \& NELSON (1991), CHETLEY (1994)

${ }^{32}$ CHETLEY (1994) e FREIRE (1998)
} 


\begin{tabular}{|ll|}
\hline Sal de Ferro & Elemento Ferro / mg de sal \\
\hline Sulfato ferroso & $60 \mathrm{mg} / 300 \mathrm{mg}$ \\
Gluconato Ferroso & $36 \mathrm{mg} / 300 \mathrm{mg}$ \\
Succinato Ferroso & $70 \mathrm{mg} / 300 \mathrm{mg}$ \\
Fumarato Ferroso & $65 \mathrm{mg} / 200 \mathrm{mg}$ \\
Complexo polissacarídeo - ferro & $40 \mathrm{mg} / 330 \mathrm{mg}$ \\
\hline
\end{tabular}

FONTE: FUCHS \& WANNMACHER, 1998

FIGURA 7: Sais de ferro e concentraçōes do elemento ferro

A dose profilática preconizada na gestação vai de 25 a $30 \mathrm{mg} / \mathrm{dia}^{33}$.

Neste sentido, vale destacar que nas prescrições analisadas $94,8 \%$ dos medicamentos com ferro estavam em concentrações acima da dose recomendada, embora ainda dentro da faixa terapêutica (180 mg / dia). Esta informação é importante porque sabe-se que os efeitos adversos do ferro oral são geralmente dose - dependente e a dos tóxica é muito próxima da dos terapêutica (FUCHS \& WANNMACHER, 1998).

Estes dados sugerem um uso inadequado dos suplementos de ferro, sujeitando as gestantes e seus fetos a efeitos adversos desnecessário.

Nesta perspectiva ressalta-se o trabalho de LOPES et al. (1999) que em ensaio terapêutico conduzido em Recife, concluiu que um esquema terapêutico alternativo, onde foi utilizada apenas uma dose semanal de suplemento de feto (contendo $60 \mathrm{mg}$ de ferro elementar), propiciou um percentual de cura da anemia maior que o esquema terapêutico diário tradicional (com os mesmos 60 $\mathrm{mg}$ de ferro por dose). A hipóteses levantada pelos autores é de que a absorção do ferro no esquema alternativo é melhorada pelo aumento de sua absorção pela através da mucosa intestinal. Além disto, com a melhora da absorção de ferro, amenizam-se os efeitos colaterais, propiciando uma maior adesão ao tratamento.

\footnotetext{
${ }^{33}$ FUCHS \& WANNMACHER (1998) e ZANINI et al. (1998)
} 
Estas informações podem subsidiar mudanças nas práticas de prescrição, racionalizando o uso, diminuindo os efeitos adversos, diminuindo o custo do tratamento, minimizando os riscos desnecessários, aumentando a adesão ao tratamento e otimizando os resultados terapêuticos.

Em relação ao ácido fólico, vitamina hidrossolúvel do complexo $\mathrm{B}$, sabese que a deficiência materna ou a utilização de medicamentos antagonistas do seu metabolismo ${ }^{34}$ no periodo periconcepcional (de um a dois meses antes do último periodo menstrual) estão associados a um aumento do risco de defeitos no tubo neural (DTN), principalmente o aparecimento de espinha bifida, bem como de fendas labiais na criança ${ }^{35}$.

Nesta perspectiva, pesquisas têm sido realizadas ${ }^{36}$ para verificar se o uso de suplementos de ácido fólico na gestação têm um efeito protetor, diminuindo o risco de má-formações congênitas. WERLER et al. (1999) descrevem estudo caso - controle realizado entre 1993 e 1996 nas cidades de Boston, Filadélfia e Toronto, onde os resultados obtidos sugerem que uma suplementação diária de 0,4 mg entre os dois meses antes da concepção e o início da gestação reduz os riscos de má-formações, entre elas a ocorrência de espinha bífida, defeito nos lábios e no palato, má-formação do coração, membros, trato urinário e cérebro.

Na mesma direção, CHETLEY (1994), recomenda a suplementação de 0,4 mg de ácido fólico do período perinatal até a décima segunda semana de gravidez.

Além dos efeitos sobre o feto, a deficiência de ácido fólico pode trazer consequências à gestante. A complicação mais comum é a anemia megaloblástica (BRIGGS, 1987).

De fato, o relato do uso de ácido fólico por gestantes é comum tanto nos artigos consultados ${ }^{37}$ quanto no presente trabalho. Entretanto, assim como em relação aos suplementos de ferro, o que chama a atenção é a concentração dos

\footnotetext{
${ }^{34}$ carbamazepina, fenobarbital, fenitoina, sulfasalazina e trimetropin (HERNANDEZ-DIAS et al. (2001)

${ }_{35}^{35} \mathrm{KING}$ et al. (1996); HERNANDEZ-DIAS et al. (2001) e WERLER et al. (1999)

${ }^{36}$ WERLER et al. (1999) \& BRIGGS et al. (1987)
} 
medicamentos utilizados. Do total de prescrições de medicamentos contendo ácido fólico, 47,9\% estavam acima da dose diária recomendada (0,8 mg). Até esta concentração, o ácido fólico é considerado categoria $A$ de risco ao feto. Acima deste valor, segundo BRIGGS et al. (1987), passa a ser categoria C, ou seja, existe a suspeita de que este medicamento esteja associado a problemas no desenvolvimento fetal (BERGLUND et al., 1984).

Outro aspecto a ser destacado é a prescrição de ácido fólico para mulheres no segundo e no terceiro trimestre de gravidez, quando já não ocorre seu efeito protetor contra má-formações congênitas.

Levando-se em consideração que os suplementos de ácido fólico também podem causar efeitos colaterais tais como: choque anafilático, prurido, erupção na pele, estreitamento dos brônquios e mal estar (BPR, 1999), os dados obtidos sugerem a necessidade de adequação de quase metade das prescrições, na busca de minimizar os problemas decorrentes da utilização de tais medicamentos, cujo uso é desejável no primeiro trimestre de gestação.

Quanto a utilização do sulfato ferroso e do ácido fólico em associação a outras vitaminas, os resultados são bastantes controversos. Segundo CHETLEY (1994), não há justificativa para o uso de tais medicamentos. Por outro lado, SCHOLL et al. (1997) relatam estudo realizado no período de 1985 a $1995 \mathrm{em}$ Candem, Estados Unidos, com mulheres de baixa renda, onde a ingestão de multivitaminicos contribuiu para um ganho de peso adequado das gestantes e uma diminuição de partos prematuros.

DINIZ (2001) ressalta que a deficiência de Vitamina A é também um dos mais importantes problemas nutricionais dos paises em desenvolvimento. $E$, parece estar relacionada com o aparecimento de má-formações congênitas.

Entretanto, destaca que altas doses de Vitamina A podem ser teratogênicas, principalmente quando administradas no início da gravidez. Por isso a suplementação indiscriminada não é recomendada. O mais adequado seria o fornecimento de suplementos de vitamina A no pós-parto para suprir as

${ }^{37}$ MENGUE et al. (1999); PIPER et al. (1987), CGDUP (1992), FORFAR \& NELSON (1991) 
necessidades do recém-nascido, pois tratando-se de uma vitamina lipossolúvel ela vai ser consequentemente secretada no leite materno.

A OMS (1990) corrobora a recomendação da não utilização durante a gravidez, sugerindo até mesmo a retirada de alimentos ricos em vitamina $A$ da dieta das mulheres em início de gestação.

De fato, doses acima de 10.000 UI de Vitamina A diárias são consideradas categoria $X$ de risco ao feto (BRIGGS, 1987), ou seja, possuem teratogenicidade confirmada e não devem ser usadas na gestação. BERGLUND (1984) cita a associação de má-formações ósseas e cranianas em crianças a doses excessivas da Vitamina a e seus derivados.

Vale destacar que cinco das prescrições contendo polivitamínicos, continham doses acima da considerada segura: quatro delas referiam-se a especialidade farmacêutica contendo 25.000 UI de vitamina A e a outra, apesar de indicar medicamento em concentração adequada (5.000 UI), prescrevia três tomadas diárias, o que corresponde a 15.000 UI.

Considerando-se que o excesso de outras vitaminas também podem causar efeitos colaterais ${ }^{38}$, pode-se levantar a hipótese de que a utilização maciça e indiscriminada de suplementos vitamínicos, apesar de prática comum, não deveria ocorrer na gestação. O mais adequado seria a prescrição destes medicamentos apenas em casos de deficiências diagnosticadas ou quando se tratam de gestantes desnutridas.

\section{2. 2 - Antiinfecciosos}

Em relação aos antiinfecciosos, CHETLEY (1994) afirma que estes medicamentos estão entre aqueles freqüentemente prescritos ou usados para condições agudas na gravidez.

\footnotetext{
${ }^{38}$ Segundo FUCHS \& WANNMACHER (1998), podem ocorrer vertigens, náuseas (com excesso de vitamina $A$ ), vômitos, polidpsia, nefrotoxicidade (com vitamina $D$ ), diarréia, uretrites (com megadoses de Vitamina $\mathrm{C}$ ) entre outras alterações.
} 
No presente trabalho, a prevalência de prescrição encontrada (considerando-se os antibacterianos, antifúngicos, antiparasitários e antisépticos) foi de $21,2 \%$, constituindo-se no segundo grupo farmacológico mais prescrito. Esta situação é semelhante a descrita pelo CGDUP (1992), que também relata esta classe de medicamentos como a segunda mais largamente utilizada.

Trata-se, porém, de valor mais alto do que os encontrados por DE VIGAN et al. (1999) - 12,3\%, pelo próprio CDGUP (1992) - 8,3\% em países europeus, e por MENGUE et al. (2001) - 15,4\% e inferior aos de GOMES et al. (1999) $39,3 \%$, em cidades brasileiras.

Especificamente em relação aos antibióticos, CZEIZEL et al. (1998) destacam situações em que a utilização destes medicamentos é necessária na gravidez: infecções agudas no sistema respiratório, no trato urinário e nos órgãos genitais. Segundo os autores, além de problemas para a gestante, estas infecções podem causar sérios prejuizos ao feto, tais como parto prematuro, depressão respiratória, perda de reflexos e paralisia cerebral.

Como a maioria dos antibióticos pode ser usada com segurança na gestação (GOMES et al., 2001), pode-se inferir que a utilização adequada destes medicamentos tem relação risco - benefício favorável.

O antibiótico mais prescrito foi a cefalexina $(53,8 \%$ do total de antibióticos), seguido pela ampicilina (23,1\%). Como já mencionado anteriormente, ambos são considerados medicamentos seguros em relação ao risco para o feto. De acordo com CHETLEY (1994), as penicilinas e as cefalosporinas são os antibióticos de escolha durante a gravidez.

Vale ressaltar porém, a prescrição de quatro especialidades farmacêuticas que podem ser consideradas problemas. A primeira é um creme vaginal contendo entre seus componentes a tetraciclina, classificada como categoria D de risco ao feto e que, segundo BRIGGS et al. 91987), só deve ser utilizada quando não houver outra possibilidade terapêtica, já que existem 
evidencias associando seu uso com problemas na formação de ossos e dentes da criança e ocorrência de toxicidade hepática materna.

As demais continham nitrofurantoína, classificada na categoria $B$ de risco (BRIGGS et al., 1987), mas associada a ocorrência de anemia megaloblástica no feto e no recém-nascido (FORFAR \& NELSON, 1990). Sugere-se então a prescrição de medicamentos alternativos no caso de infecções genito - urinárias (indicação terapêutica da Nitrofurantoina - FUCHS \& WANNMACHER, 1998).

Segundo PIPER et al. (1987), outro grupo de medicamentos bastante usado na gravidez é o constituido por antifúngicos na forma tópica, refletindo fenômeno conhecido de aumento da incidência de infecções fúngicas vaginais de maneira progressiva durante o decorrer da gestação. MENGUE et al. (2001) descrevem uma taxa de $4,7 \%$ de utilização destes medicamentos. No presente trabalho encontrou-se uma prevalência de $7,7 \%$ de antifúngicos no total das prescrições.

De uma forma geral são considerados medicamentos relativamente seguros para serem utilizados na gravidez. A nistatina, medicamento mais prescrito dentro da classe $(57,1 \%$, é enquadrada na categoria B de riso ao feto (BRIGGS, 1987). O cetoconazol e o terconazol, antifúngicos imidazólicos também indicados nas receitas médicas, são considerados categoria $\mathrm{C}$ de risco, sendo a restrição para o terconazol seu uso durante o primeiro trimestre de gestação (ZANINI, 1998).

Entretanto, para o isoconazol, outro antifúngico imidazólico de uso tópico, não foram encontradas informações nem sobre sua segurança, nem sobre possiveis riscos. Pode-se recomendar, então, sua substituição por similar terapêutico com efeitos colaterais já bem conhecidos e relatados na literatura científica.

Os antiparasitários representaram 3,0\% do total de prescrições. PIPER et al. (1987) e MENGUE et al. (2001) também relatam o uso de tais medicamentos, este último numa porcentagem semelhante ao deste trabalho $(3,8 \%)$. 
Todos os antiparasitários prescritos são considerados seguros quanto a sua utilização na gravidez: a espiramicina é classificada na categoria a de risco ao feto BERGLUND, 1984) e tanto o metronidazol quanto o tinidazol na categoria $\mathrm{B}^{39}$. Porém, o uso de metronidazol é contra-indicado no primeiro trimestre de gestação, pois estudos em animais de laboratório sugerem uma associação com o desenvolvimento de câncer no feto ${ }^{40}$. Vale ressaltar que este procedimento não foi encontrado entre as prescrições analisadas.

Já a utilização de espiramicina no primeiro trimestre diminui em $60 \%$ o risco de toxoplasmose congênita, tendo uma relação risco - benefício favorável (FUCHS \& WANNMACHER, 1998) e seu uso plenamente no caso de infecção materna.

\section{2. 3 - Medicamentos que atuam sobre o sistema digestivo}

O terceiro grupo farmacológico mais prescrito foi o dos medicamentos que atuam sobre o sistema digestivo (15,5\%).

MENGUE et al. (2001), CGDUP (1992), PIPER et al. (1987) e GOMES et al. (1999) também relatam a utilização destes medicamentos.

Segundo CHETLEY (1994) são medicamentos utilizados para sintomas comuns na gravidez: náusea matinais, acidez, indigestão e constipação, e, que podem ser melhorados na maioria dos casos com mudanças de hábitos alimentares (dieta rica em fibras e aumento da ingestão de líquidos), exercícios físicos e sono em quantidade adequada (medidas sem riscos para a mãe ou para a criança).

Entretanto, quanto aos antiulcerosos e antiácidos, RUIGOMEZ et al. (1999) afirmam ser seu uso freqüentemente necessário devido a ocorrência comum de refluxo gástrico ma gravidez.

\footnotetext{
${ }^{39}$ BRIGGS et al. (1987) e BERGLUND ET AL. (1984)

${ }^{40}$ BRIGGS et al. (1987) e CHETLEY (1994)
} 
Nesta categoria, os medicamentos prescritos nas consultas de pré-natal foram a cimetidina, hidróxido de alumínio (monodroga) e hidróxido de alumínio em associação.

A cimetidina é classificada na categoria B de risco ao feto (BRIGGS et al. 1987). De fato, RUIGOMEZ et al. (1999) após estudo caso - controle realizado entre 1991 e 1996 na Inglaterra e Itália, não encontraram evidências de associação do uso de bloqueadores $\mathrm{H} 2$ (cimetidina, omeprazol e ranitidina) e ocorrência de má-formações congênitas, sendo sua utilização, portanto, considerada relativamente segura.

Já os medicamentos contendo hidróxido de alumínio em sua formulação são classificados na categoria de riso C (BPR, 1999) e por isto devem ter sua relação risco beneficio avaliada antes de sua prescrição.

MATHIAS \& NOBILE (1981), ressaltam ainda que na maioria das especialidades farmacêuticas comercializadas, o hidróxido de alumínio aparece em associação com sais de magnésio, na tentativa de minimizar principalmente seus efeitos colaterais, especialmente a constipação intestinal. Nestes casos os antiácidos devem ser considerados possivelmente teratogênicos, pois não existem estudos que subsidiem seu uso com segurança. Mesmo assim, relatam que este grupo de medicamentos tem sido utilizado de forma abusiva.

De fato, o presente trabalho encontrou uma taxa de $78,6 \%$ de antiácidos compostos de associações, dado que pode ser considerado preocupante a partir das informações relatadas.

Em relação aos anti-eméticos, sua prescrição e utilização já era esperada. Como mencionado anteriormente, náuseas e vômitos matinais são sintomas muito comuns, principalmente no primeiro trimestre da gravidez. Todos os artigos científicos consultados descrevem seu uso pelas gestantes.

Dos medicamentos prescritos nesta categoria, $57,1 \%$ podem ser incluidos na categoria $\mathrm{B}$ de risco ao feto: são aqueles contendo metoclopramida e dimenidrato ${ }^{41}$.

\footnotetext{
${ }^{41}$ BRIGGS et al. (1987) e ZANINI et al. (1998)
} 
Já o restante, continha como princípio ativo a bromoprida, substância para a qual não foi encontrada nenhuma informação científica em relação a sua utilização na gravidez e portanto devendo ser evitada.

Neste sentido, FUCHS \& WANNMACHER (1998) afirmam que apesar da emese ser um fenômeno que deva ser controlado, pois além do desconforto pode trazer complicações sistêmicas como desidratação, desequilíbrio eletrolítico e pneumonia aspirativa, na gravidez ela só deve ser medicalizada quando medidas não -farmacológicas não forem suficientes para amenizar o problema.

Quanto aos antiespasmódicos, o representante desta classe foi a hioscina (metilescopolamina) com $100 \%$ das prescrições. É considerada categoria B de risco ao feto (BPR, 1999), podendo ser utilizada com relativa segurança na gravidez. Porem, seu uso deve ser acompanhado pelo médico devido aos efeitos colaterais que podem ocorrer na mulher: alucinações, confusão mental, boca seca, hipotensão ortostática, irritabilidade, sonolência, diminuição da freqüência cardíaca, entre outros.

Outro medicamento que atua sobre o sistema gastrointestinal encontrado nas receitas é o bisacodil, laxante que age irritando a mucosa e aumentado a motilidade intestinal, prescrito apenas uma vez ( $0,4 \%$ do total de prescrições). É classificado na categoria $C$ de risco ao feto (BPR, 1999) e por isso deve ser usado com cautela durante a gravidez.

Corroborando esta afirmação, FUCHS \& WANNMACHER (1998), afirmam que nos últimos 50 anos pouco se evoluiu em relação a informações sobre os laxantes, quase não havendo ensaios clínicos bem conduzidos nesta área, o que torna sua prescrição empírica e pouco segura na gravidez. 


\section{2. 4 - Classificação dos medicamentos prescritos por categoria de risco ao feto (FDA)}

Dos medicamentos prescritos, $35,7 \%$ foram classificados na categoria $A$ de risco ao feto; $27,5 \%$ na categoria $B ; 26,0 \%$ na categoria $C ; 1,5 \%$ na categoria $D ; 1,5 \%$ na categoria $E$ e, para $7,3 \%$ do total de medicamentos não foram encontrados nenhuma informação sobre seu uso durante a gravidez.

Revisando-se a literatura científica, não encontrou-se artigos com metodologia semelhante a deste trabalho para propiciar uma comparação direta entre valores. MENGUE et al. (2001), por exemplo, utilizam-se das categorias de risco do FDA para classificar todos os medicamentos utilizados durante a gravidez, independente da fonte de indicação (automedicação ou prescrição médica). Entretanto, quando confrontam-se os valores encontrados nos dois trabalhos (Tabela 27) verifica-se que são bastante semelhantes, sugerindo que o consumo de medicamentos segue uma padrão comum, incluindo-se nele a automedicação ou não. Isto pode estar evidenciando um automedicação orientada (influenciada por prescrições médicas anteriores) ou até mesmo, a interferência de fatores outros além da questão terapêutica na utilização dos medicamentos, tais como: propagandas, disponibilidade de medicamentos no mercado, hábitos de consumo, custo do tratamento, entre outros já discutidos anteriormente. 


\begin{tabular}{|ccc|}
\hline CATEGORIAS & MENGUE et al. (1999) & Piracicaba \\
\hline A & $34,0 \%$ & $35,7 \%$ \\
B & $22,6 \%$ & $27,5 \%$ \\
C & $26,8 \%$ & $26,0 \%$ \\
D & $3,0 \%$ & $1,5 \%$ \\
E & $0,6 \%$ & $1,5 \%$ \\
sem informação disponivel & $12,9 \%$ & $7,3 \%$ \\
\hline Total & $100,0 \%$ & $100,0 \%$ \\
\hline
\end{tabular}

FIGURA 8: Quadro comparativo entre a distribuição dos medicamentos encontrados por GOMES et al. (1999) e os obtidos no presente trabalho (Piracicaba) nas categorias de risco ao feto (FDA)

Analisando-se os resultados obtidos, a partir da classificação do FDA ${ }^{42}$, pode-se dizer que do total de medicamentos prescritos:

. 35,7\% são considerados seguros para serem utilizados na gestação, pois existem informações científicas suficientes para que os profissionais de saúde e as gestantes sintam-se confiantes quanto à sua utilização (categoria $\mathrm{A}$ );

. $27,5 \%$ devem ser considerados relativamente seguros quanto a sua utilização na gravidez, pois apesar de não haver ensaios clínicos em humanos, estudos em animais não evidenciaram risco ao feto. Entretanto, sua utilização deve ser acompanhada pois sempre existe a possibilidade de ocorrerem efeitos adversos (Categoria B);

. 26,0\% são medicamentos sem prova de segurança para utilização na gestação. Pode-se dizer que seus efeitos sobre a gravidez humana são desconhecidos. São aqueles para os quais não existem estudos em animais ou em seres humanos ou, cujos estudos pré-clínicos sugerem má-formaçōes

\footnotetext{
${ }^{42}$ UNICEF (1992, BERGLUND et al. (1984), MENGUE et al. (2001) e MEADOWS (2001)
} 
congênitas em animais mas que não foram evidenciadas em humanos. Porém, quando forem realmente necessários, a relação risco - benefício pode ser avaliada pelo médico e pela gestante e seu uso realizado com cautela (Categoria C);

. 3,0\% são medicamentos de risco comprovado para o feto. São aqueles que efetivamente afetam a formação da criança ou então, estão fortemente associados a ocorrência de má-formações congênitas. Destes 50,0\% são totalmente contra-indicados na gestação, seja qual for a situação (Categoria $\mathrm{X}$ ) e 50,0\% podem ser utilizados desde que haja risco de vida da mãe ou que as vantagens de sua utilização superem os potenciais riscos ao feto (Categoria D);

$7,3 \%$ são medicamentos para os quais não foram encontradas nenhuma informação na literatura científica, a favor ou contra sua utilização na gravidez.

A partir da análise realizada, sugere-se que cerca de 40,0\% dos medicamentos prescritos às gestantes foram de medicamentos cuja segurança de uso na gravidez pode ser questionada, pois coloca em risco a formação das futuras crianças. O mais grave, porém, é a prescrição de medicamentos sabidamente teratogênicos, os suplementos vitamínicos contendo Vitamina $A$ em dose excessiva, sem justificativa para tal procedimento.

Estes dados sugerem algumas reflexões sobre as prescrições médicas. A primeira e a mais importante delas é: será que a utilização de medicamentos sem segurança confirmada com potenciais riscos ao feto eram realmente necessárias?

Como não se tem o diagnóstico médico que resultou nas prescrições analisadas, não se pode responder esta pergunta de forma conclusiva. Mas, levando-se em consideração a prescrição de suplementos vitaminicos em dose inadequada, de expectorantes contendo iodeto de potássio e de medicamentos para os quais não existem informações científicas sobre a segurança de utilização na gravidez, pode-se sugerir que deva haver mais cautela na escolha de medicamentos durante o pré-natal, com adequada avaliação de riscobenefício. Esta decisão deve envolver tanto o prescritor quanto a gestante, pois 
entende-se que a mulher tem o direito de saber as implicações da decisão de utilizar ou não certos medicamentos em determinadas situações.

\section{2. 5 - Análise da dose e do esquema terapêutico dos medicamentos prescritos}

A partir da dose terapêutica estabelecida para cada medicamento ${ }^{43}$, chegou-se a informação de que $90,7 \%$ do total de medicamentos prescritos estavam dentro da dose adequada; $0,7 \%$ estavam abaixo da dose terapêutica $e$ $1,5 \%$ foram prescrito em sobredose.

Levando-se em consideração as prescrições que não continham dose e esquema terapêtico indicados $(2,2 \%)$ e aqueles medicamentos para os quis não se encontrou, na literatura científica consultada, informações sobre a faixa de dosagem adequada (doses mínima e máximas), tem-se que cerca de uma em cada 10 gestantes que receberam prescrição de medicamentos a tiveram de forma inadequada.

Considerando-se também que dos medicamentos prescritos dentro da dose terapêutica, $25,4 \%$ estavam em esquema terapêutico fora das recomendações, contendo intervalos entre as doses maiores do que os estabelecidos (em função da meia-vida dos medicamentos) ou sem especificação de posologia, a porcentagem de medicamentos prescritos de forma inadequada sobe de $9,3 \%$ para $33,2 \%$.

Outra questão importante, é que do total de medicamentos prescritos dentro da dose terapêutica, $37,7 \%$ estavam acima da dose recomendada para gestantes, aumentando os potenciais riscos de efeitos adversos.

Este aspecto eleva para $77,7 \%$ as prescrições inadequadas, comprometendo de forma desnecessária a saúde das gestantes e das crianças em formação.

\footnotetext{
${ }^{43}$ FUCHS \& WANNMACHER (1998); ZANINI et al. (1998); BPR (1999) E BRIGGS et al. (1987)
} 


\section{2. 6 - Indicadores Básicos de Utilização de Medicamentos (OMS)}

Para se avaliar de forma adequada os indicadores básicos de utilização de medicamentos construídos no presente trabalho, é importante salientar que, segundo HOGERZEIL et al. (1993), para três dos indicadores de prescrição utilizados é muito difícil definir valores ótimos. São eles: o número médio de medicamentos por consulta, porcentagem de consultas em que se prescrevem antibióticos e porcentagem de consultas em que se prescrevem injetáveis.

De acordo com SANTOS (1999), isto ocorre pois tais indicadores sofrem influência de diferentes fatores fortemente dependentes de características regionais e locais (perfil de morbidade, características dos serviços de saúde, existência de lista de medicamentos padronizados, entre outros).

Entretanto, os valores obtidos podem servir de base para pesquisas subseqüentes e posterior aprofundamento da avaliação das prescrições ${ }^{44}$. Sugere-se, por exemplo, a análise dos esquemas terapêuticos prescritos, parâmetro que foi utilizado e já mencionado neste trabalho.

Além desses fatores, outro aspecto dificulta a compara e a avaliação dos fatores obtidos. Em todos os artigos científicos consultados, os indicadores foram construídos levando-se em consideração as prescrições totais dos serviços de atenção primária, o que inclui as prescrições de pediatria, ginecologia e clínica geral.

O presente trabalho envolveu uma população específica, gestantes, que por tudo que foi discutido anteriormente, possui características muito particulares em relação a prescrição medicamentosa.

Por outro lado, para os indicadores que medem a porcentagem de medicamentos prescritos pelo nome genérico e a porcentagem dos medicamentos prescritos que constam da lista de medicamentos padronizados, 
os valores são óbvios: eles devem ser o mais alto possivel, considerando-se que:

se existe uma lista de medicamentos padronizados, ela deve ser constituída pelos medicamentos essenciais àquela localidade ou serviço e, portanto, deve ser seguida, a menos que não reflita as demandas existentes (nestes casos valores baixos podem indicar necessidade de sua revisão);

. a prescrição por nome genérico, faz parte das estratégias da OMS para se aumentar o acesso da população ao medicamento e promover a utilização racional dos mesmos ${ }^{45}$. No Brasil, seguindo esta recomendação, a RDC n 10 , de 02 de janeiro de 2001, da Agência nacional de Vigilância Sanitária do Ministério da Saúde, determina que "... no âmbito do Sistema Único de Saúde (SUS), as prescrições pelo profissional responsável adotarão obrigatoriamente a DCB, ou, na sua falta a DCl".

A partir dos pressupostos levantados, os três indicadores abaixo não podem ser avaliados como adequados ou não e devem ser analisados juntamente com as demais observações sobre a prescrição feitas neste capitulo:

número médio de medicamentos por consulta $=0,6$;

porcentagem de consultas em que se prescreveram antibióticos $=5,6$;

porcentagem de consultas em que se prescreveram injetáveis $=0,7$.

A princípio parecem valores baixos se comparados com os relatados em outros trabalhos (Figuras 9 e 10), entretanto, frente a observação de que cerca de $77 \%$ das prescrições avaliadas neste trabalho apresentavam algum tipo de problema (risco potencial ao feto e ou dose ou posologia inadequadas) constituem-se apenas em dados descritivos não devendo ser agregados a nenhum juizo de valor.

\footnotetext{
${ }^{44}$ HOGERZEIL et al. (1993) e OMS (1993)

${ }^{45}$ OMS (1993), JARAMILLO E ROJAS (1994), Política Nacional de Medicamentos - Brasil (1998)
} 
Quanto aos demais indicadores, pode-se fazer as seguintes inferências:

a porcentagem de medicamentos prescritos pelo nome genérico $(49,4 \%)$, como pode ser observado na Figura 9, é menor do que os encontrados no Sudão, na Indonésia, em Bangladesh, no Zimbabwe, na Tanzânia, na Nigéria e na Guatemala. Ficando acima apenas dos relatados no Equador e no Nepal. Em relação aos trabalhos brasileiros, fica abaixo do valor encontrado em Ribeirão Preto por SIMÕES \& MOTA (1996), mas acima do valor relatado por Santos (1999); abaixo dos valores encontrados em Fortaleza e Campo Grande, mas acima dos descritos em Araraquara e Tabatinga (Figura 10);

- quanto a porcentagem de medicamentos prescritos constantes da LMP $(53,5 \%)$ é menor do que os relatados em Bangladesh, na Tanzania e no Nepal (únicos países para os quais existem tal indicador) e, no Brasil, abaixo dos descritos para Ribeirão Preto, Fortaleza e Campo Grande, mas acima dos encontrados em Araraquara e Tabatinga.

De uma forma geral, pode-se dizer que os valores desses dois indicadores são baixos, sugerindo a necessidade de discussão das práticas de prescrição. Primeiro, porque parece haver desconhecimento da legislação por parte dos prescritores: a metade dos medicamentos prescritos não estava grafada pelo por nome genérico. Segundo, porque estes dados revelam a não adesão dos profissionais ás políticas nacional e local de medicamentos e consequentemente à Política de Saúde.

Além disso, ao não adotarem a Lista de Medicamentos Padronizados do município, dificultam o acesso dos pacientes aos medicamentos prescritos, comprometendo a resolutividade dos serviços em que atuam, Por outro lado, a alta prescrição de medicamentos não considerados essenciais e portanto não padronizados, sugere a necessidade de revisão da LMP e talvez uma adequação e posterior divulgação da lista existente entre os prescritores.

Considerando-se que um dos objetivos dos Indicadores Básicos de Utilização de medicamentos é identificar prioridades para ação (HOGERZEIL, 1993), sugere-se que: 
seja feita um programa de conscientização dos prescritores sobre a importância da prescrição por nome genérico, tanto em relação a questão legal, quanto em relação a otimização do seu trabalho e dos serviços de saúde que integra;

seja discutida e, se necessário, revista a LMP;

seja divulgada a LMP existente e paralelamente seja realizada uma campanha de conscientização dos médicos sobre as vantagens da adoção de uma padronização municipal. 


\begin{tabular}{|lccccc|}
\hline & $\begin{array}{c}\text { no. médio de } \\
\text { medicamentos } \\
\text { por receita }\end{array}$ & $\begin{array}{c}\text { \% de } \\
\text { prescrição por } \\
\text { nome genérico }\end{array}$ & $\begin{array}{c}\text { \% de } \\
\text { consultas com } \\
\text { antibiótico }\end{array}$ & $\begin{array}{c}\% \text { de } \\
\text { consultas } \\
\text { com } \\
\text { injetável }\end{array}$ & $\begin{array}{c}\% \\
\text { prescrição } \\
\text { pela LMP }\end{array}$ \\
\hline Yemem & 1,5 & $\ldots$ & 46 & 25 & $\ldots$ \\
Uganda & 1,9 & $\ldots$ & 56 & 48 & $\ldots$ \\
Sudão & 1,4 & 63 & 63 & 36 & $\ldots$ \\
Malawi & 1,8 & $\ldots$ & 34 & 19 & $\ldots$ \\
Indonésia & 3,3 & 59 & 43 & 17 & $\ldots$ \\
Bangladesh & 1,4 & 78 & 25 & $\ldots$ & 85 \\
Zimbabwe & 1,3 & 94 & 29 & 11 & $\ldots$ \\
Tanzania & 2,2 & 82 & 39 & 29 & 88 \\
Nigéria & 3,8 & 58 & 48 & 37 & $\ldots$ \\
Nepal & 2,1 & 44 & 43 & 5 & 86 \\
Equador & 1,3 & 37 & 27 & 19 & $\ldots$ \\
Guatemala & 1,4 & 72 & 27 & 13 & $\ldots$ \\
Piracicaba & 0,6 & 49 & 6 & 1 & 53 \\
\hline
\end{tabular}

FIGURA 9: Quadro comparativo entre os indicadores de prescrição relatados por HOGERZEIL (1993) e os obtidos no presente trabalho (Piracicaba). 


\begin{tabular}{|lccccccc|}
\hline & $\begin{array}{c}\text { Ribeirão } \\
\text { Preto }\end{array}$ & Araraquara & Fortaleza & Tabatinga & $\begin{array}{c}\text { Campo } \\
\text { Grande }\end{array}$ & $\begin{array}{c}\text { Ribeirão } \\
\text { Preto * }\end{array}$ & Piracicaba \\
\hline $\begin{array}{l}\text { no. médio de } \\
\text { medicamentos } \\
\text { por receita }\end{array}$ & 1,9 & 1,8 & 2,2 & 2,5 & 2,0 & 2,4 & 0,6 \\
$\begin{array}{l}\text { \% de } \\
\text { prescrição por } \\
\text { nome genérico }\end{array}$ & 72,0 & 43,7 & 74,0 & 32,7 & 81,0 & 30,5 & 49,4 \\
$\begin{array}{l}\text { \% de receitas } \\
\text { com antibiótico }\end{array}$ & 10,1 & 15,1 & 37,0 & 2,7 & 34,8 & 21,3 & 5,6 \\
$\begin{array}{l}\text { \% de receitas } \\
\text { com injetável }\end{array}$ & 12,2 & 7,4 & 11,0 & 5,7 & 15,7 & 8,2 & 0,7 \\
\% prescrição & 88,1 & 47,2 & 78,0 & 44,8 & 89,5 & 80,1 & 53,5 \\
pela LMP & 88,1 & & & & & & \\
\hline
\end{tabular}

FIGURA 10 - Quadro comparativo entre indicadores de prescrição relatados em artigos referenciados e os obtidos no presente trabalho (Piracicaba). 


\section{6 - CONCLUSÃO}

Considerando-se que:

o perfil encontrado foi o de gestantes com pouco acesso a informações, serviços e bens de consumo;

$61,6 \%$ das gestantes afirmou ter utilizado algum medicamentos na semana anterior a pesquisa;

$18,6 \%$ das gestantes que utilizaram pelo menos um medicamento o fizeram por automedicação;

$44,7 \%$ das gestantes receberam prescrição medicamentosa na consulta de pré-natal;

$.77,7 \%$ das prescrições de medicamentos apresentaram algum tipo de irregularidade (medicamentos contra-indicados, dose e posologia incorretas, medicamentos grafados pelo nome comercial e ou fora da lista de medicamentos padronizados pelo município),

os grupos de medicamentos mais prescritos foram aqueles que atuam sobre o sistema hematopoiético $(34,9 \%)$, os antiinfecciosos $(21,2 \%)$ e os que atuam sobre o sistema digestivo $(15,6 \%)$.

Conclui-se que o padrão de consumo de medicamentos pelas gestantes atendidas na atenção primária de Piracicaba sugere um processo de medicalização da gravidez, muitas vezes de forma inadequada e sem respaldo técnico, colocando as mulheres e seus futuros bebês frente a riscos de efeitos adversos desnecessários e comprometendo os resultados do atendimento de pré-natal oferecido. 
utilização racional dos medicamentos e a otimização dos recursos disponiveis, tais como:

estabelecimento de programas de educação em saúde visando conscientização das gestantes sobre os riscos da automedicação;

orientação sobre medidas não farmacológicas que podem ser adotadas pelas mulheres para controlar sintomas comuns na gravidez (como náuseas, vômitos e constipação), diminuindo a necessidade da utilização de medicamentos;

estímulo à educação continuada dos profissionais de saúde envolvidos com o pré-natal, visando uma melhoria da qualidade das prescrições e consequentemente da atenção à gestante;

avaliação e restruturação dos serviços de atendimento de pré-natal com o objetivo de estabelecer vínculo das gestantes com as Unidades Básicas de saúde do seu bairro, facilitando o acesso ao SUS;

revisão e posterior divulgação da lista de medicamentos padronizados do municipio;

desenvolvimento de um trabalho multiprofissional e interdisciplinar, baseado em critérios técnicos e científicos, para garantir à gestante uma atenção integral à saúde, com enfoque preventivo, de qualidade, que realmente atenda suas necessidades.

discutir com todos os sujeitos do processo a concepção de saúdedoença que norteia as práticas do serviço e da comunidade, visando resgatar a representação da gestação como um processo fisiológico normal, que exige cuidados, mas que não é patológico e portanto não implica necessariamente em intervenções curativas, entre elas a prescrição de medicamentos. 


\section{7 - REFERÊNCIAS BIBLIOGRÁFICAS}

1. Almeida Filho, $N \&$ Rouquayrol, $M Z$ Introdução à epidemiologia moderna. $2^{a}$. ed., Belo Horizonte / Salvador / Rio, COOPMED / APCE / ABRASCO, 1992

2. Barros, JAC Importância dos sistemas de Farmacovigilância. Saúde em debate, 1992; 36: 76-80.

3. BARROS, JAC Propaganda de medicamentos. Atentado à Saúde? São Paulo, Hucitec, 1995. p. 21 - 74.

4. Berglund, F; Frodh, H; Lundborg, P; Prame, B \& Sannerstedt; R Drug use during pregnancy and breast-feeding. Acta Obstet. Gynecol. Scand., 1984; suppl. 126.

5. Boobis, AR \& Lewis, $P$ Drugs in pregnancy: altered pharmacokinetics. British journal of hospital medicine, 1982; $566-573$.

6. BPR Guia de remédios. São Paulo, BPR, 1999.

7. Brasil. Ministério da Saúde. Portaria n 1179 de 17 de junho de 1996. Aprova as denominações comuns brasileiras, DCB. Disponivel em URL: http: llwww.saude.gov.br

8. Brasil. Ministério da Saúde. Portaria GM - 3916 de 30 de outubro de 1998: aprova a Politica Nacional de Medicamentos. Disponivel em URL: http: II www. saude.gov.br

9. Brasil. Agência Nacional de Vigilância Sanitária. Resolução - RDC $n^{\circ} 10$ de 02 de janeiro de 2001. Aprova o Regulamento Técnico para Medicamentos Genéricos e dá outras providências. Diário Oficial da União, Brasília, 15 de janeiro de 2001.

10. Briggs, GG; Freeman, RK \& Yaffe, SJ Drogas na gravidez e na lactação. Trad.: Ramos, SRTS, 2a. ed., São Paulo, Livraria Roca Ltda., 1987.

11. Cárdenas, EF-V \& Obregón, L S Algunas consideraciones sobre os Estudios del Uso de los Medicamentos. Rev. Cubana Invest. Biomed., 1997; 16(2): 156-158. 
12. Carvalho, MCB A priorização da família na agenda da política social. In: CARVALHO, MCB, organizadora. A família contemporânea em debate. $2^{\mathrm{a}}$. ed. São Paulo: EDUC - Cortez Editora; 1997. p 11 - 21.

13. Castro, CGSO Estudos farmacoepidemiológicos: perspectiva para a racionalidade terapêutica pediátrica e perinatal. Bol. Sobravime, 1998; 30:135 .

14. Castro, CGSO Estudos de utilização de medicamentos: noções básicas. Rio de Janeiro, Editora Fiocruz, 2000. p. 15 - 25.

15. CGDUP Medication during pregnancy: na intercontinental cooperative study. Int. J. Gynecol. Obstet., 1992; 39: 185-196.

16. Chetley, A Medicamentos problema. $2^{\text {a }}$. ed., Chimbote, AIS LAC, 1994.

17. Cobert, BL \& Biron, $\mathrm{P}$ Pharmacovigilance from $A$ to $Z$. Massachusetts, Blackwell Science Ltda, 2002.

18. Cunha, MCN \& Castro, LLC An evaluation of drug use quality in the municipal health care public services of Campo Grande, Mato Grosso do Sul State, Brasil. Bol. Chim. Farm., 1999; 138 (2).

19. Czeizel, A E; Rockenbauer, M; Sorensen, HT \& Olsen, J A population-based case-control teratologic study of ampicillin treatment during pregnancy. Am. J. Obster. Gynecol., 2001; 185 (1): $140-147$.

20. De Vigan, CD; De Walle, HEK; Cordier, S; Goujard, J; Knill-Jones, R; Ayme, Calzorali, E; Bianchi, F \& OECM WORKING GROUP Therapeutic drug use during prenancy: a comparison in four european countries. J. Clin.Epidemiolog., 1999; 52 (10): 977-982.

21. Dillon, $A E$, Wagner, $C L ;$ Wiest, $D \&$ Newman, RB Drug therapy in the nursing mother. Obstet. Gynecol. Clin. North Am., 1997; 24 (3): 675-96.

22. Dinia, AS Combate à deficiência de vitamina $A$ : linhas de ação e perspectiva. Rev. Bras. Saúde Materno Infantil, 2002; 1(1):31 - 36.

23. Fonseca, MRCC Uso de medicamentos na gravidez: uma abordagem farmacoepidemiológica. Campinas, 1998. [ Dissertação de mestrado, UNICAMP 
24. Forfar, JO \& Nelson, MM Epidemiology of drugs taken by pregnant womem: drugs that may affect the fetus adversely. Clinical Pharmacology and Therapeutics, 1990; 14 (4): 632-642.

25. Freire, WB La anemia por deficiencia de hierro: estrategias de la OPS I OMS para combatila. Salud pública de México, 1998; 40 (2): 199 - 205

26. Fuchs, FD \& Wannmacher, L Farmacologia clínica: fundamentos da terapêutica racional. $2^{\mathrm{a}}$. ed., Rio de Janeiro, Editora Guanabara Koogan SA, 1998.

27. Fundação SEADE. Dados demográficos do municipio de Piracicaba, ano 2000. Disponivel em URL: http://www. seade.gov.br

28. FURP. Memento terapêutico. $2^{\mathrm{a}}$. ed., São Paulo, 1998.

29. Gomes, KRO; Moron, AF; Souza e Silva, R \& Siqueira, AAF Prevalência do uso de medicamentos na gravidez e relações com as caracteristicas maternas. Rev. Saúde Pública, 1999; 33 (3). Disponível em URL: http://unw.scielo.br

30. Hogerzeil, HV Promoting rational prescribing: na international perspective. Br. J. clin. Pharmac., 1995: 39: 1 - 6.

31. Hogerzeil, HV; Bimo; Ross-Degnan, D; Laing, RO; Ofori-Adjei, D; Santoso, B; Chowdhury, AK; Das, AM; Kafle, KK; Mabadeje, AFB \& Massele, AY Field tests for rational drug use in twelve developing countries. Lancet, 1993; 342: $1408-10$.

32. Jaramillo, GGI \& Moreno Rojas, C Condições sócio-sanitárias de uma população. In: OPAS. Curso de administração de sistemas de abastecimento de medicamentos essenciais, $1^{\mathrm{a}}$. ed., Brasilia, 1994. $2 \mathrm{v}$.

33. Joncheere, $\mathrm{K}$. A necessidade e os elementos de uma política nacional de medicamentos. In: Bonfin, JRA \& Mercucci, VL, org. A construção da política de medicamentos. São Paulo, Hucitec, 1997. p. 49 - 63.

34. King, PB; Lie, RT \& Irgens, LM Spina bifida and cleft lip among newborns of norwegian womem with epilepsy: changes related to the use of anticonvulsants. American Journal of Public Health, 1996; 86 (10): 1454 1456.

35. Laporte, JR; Tognoni, G \& Rozenfeld, S Epidemiologia do medicamento. São Paulo / Rio de Janeiro, Hucitec / Abrasco, 1989. 
36. Lee, D \& Bergman, U Studies of drug utilization. In: Strom, BL What is Pharmacoepidemiology? In: Strom, BL Pharmacoepidemiology. $2^{\mathrm{a}}$. ed., Chichester, John Wiley \& Sons, 1994. p. 3 - 11.

37. Lefèvre, F. O medicamento como mercadoria simbólica. São Paulo, Cortez, 1991.

38. Little, BB Pharmacokinetics during pregnancy: evidence-based maternal dose formulation. Obstetrecs \& Gynecology, 1999; 93(5): 858 - 868.

39. Lopes, AEC, Teixeira, ACA, Gurgel, MLF \& Miranda, MCC Drug se of evaluation in health services in Fortaleza, Brasil. INRUD, 1986; 6 (1): 17.

40. Lopes, MCS; Ferreira, LOC \& Batista Filho, M Uso diário e semanal de sulfato ferroso no tratamento de anemia em mulheres no período reprodutivo. Cadernos de Saúde Pública, 1999; 15 (4). Disponivel em URL: http:Illwww.scielo.org

41. Mathias, $L \&$ Nobile, $L$. Medicamentos que podem ser prescritos durante a gravidez. Ginecol. Obstet. Bras., 1981; 4 (4): 37 - 50.

42. Meadows, M. Pregnancy and the drug dilemma. FDA consumer magazine, may-june,2001.Disponivel em URL: http://www.fda.gov.fdac/feature/2001/301preg.html.

43. Mellin, GW \& Katzenstein, $M$ The saga of Thalidomide (conclude): neuropathy to embryopathy, with case reports of congenital anomalies. The New England Journal of Medicine, 1962; dez:: 1238-1244.

44. Mengue, SS; Schenkel, EP; Duncan, BB \& Schmidt, MI Uso de medicamentos por gestantes em seis cidades brasileiras. Rev. Saúde Pública, 2001; 35 (5). Disponível em URL: http:Ilumw.scielo.org

45. Mitchell, AA; Cottler, LB \& Shapiro, S Effect of questionnaire design on recall of drug exposure in pregnancy. American Journal of Epidemiology, 1986; 123 (4): $670-676$.

46. Niebyl, JR Uso de drogas na gravidez. $2^{\mathrm{a}}$. ed., São Paulo, Livraria Roca Ltda., 1989. p. 1 - 11.

47. Nunes, AMC Conceitos básicos de Farmacovigilância. In: Castro, LLC, org. Fundamentos de Farmacologia. Campo Grande, AG Gráfica e Editora Ltda., 2000. p. $106-126$. 
48. OMS. Uso racional de los medicamentos. Informe de la Conferencia de Expertos. OMS, England, 1986.

49. OMS. Investigación del uso de los medicamentos. Boletin de Medicamentos Essenciais, 1993; 14: 1.

50. OMS. Como investigar el uso de medicamentos en los serviços de salud. OMS, Genebra, 1993.

51. PIPER, J. M; BAUM, C. \& KENNEDY, D. L. Prescription drug use before and during pregnancy in a Medicaid population. Am. J. Obstet. Gynecol., 157: 148 $-156,1987$.

52. PORTA, M.; HARTZEMA, A. G. \& TILSON, H. H. The contribution of epidemiology to the study of drug uses and effects. In: HARTZEMA, A . G.; PORTA, M. \& TILSON, H. H. Pharmacoepidemiology: an introduction. $3^{\text {a }}$. ed., Cincinnati, Harvey Whitney Books Company, 1998. p. 1 - 29.

53. PRESCRIRE INTERNATIONAL. Talidomida: usar em indicações bem definidas. Trad.: BONFIM, J. R. de A. Bol. Sobravime, 31: 3-8, 1998.

54. Relação Nacional de Medicamentos Essenciais: RENAME - 2000 / Gerência de Assistência Earmacêutica. Brasília: Ministério da Saúde, Secretaria de Politicas de Saúde, 2000.

55. ROUQUAYROL, M.Z. \& ALMEIDA FILHO, N. Epidemiologia \& Saúde. 5ed., MEDSI, Rio de Janeiro, 1999. P. $149-170$.

56. RUZENFELD, S. O uso de medicamentos no Brasil. In: LAPORTE, J. R. ; TOGNONI, G. \& ROZENFELD, S. Epidemiologia do medicamento. São Paulo / Rio de Janeiro, Hucitec / Abrasco, 1989. P. 21-41.

57. ROZENFELD, V. L. \& PEPE, V.L.E. Guia terapêutico ambulatorial. Porto Alegre, Artes Médicas, 1992/93. P.269 -273.

58. Ruigomez, A; Rodrigues, LAG; Cattaruzzi, C; Troncon, MG; Agostinis, L; Wallander, M-A \& Johanssons, S Use of cimetidine, omeprazole and ranitidine in pregnant women and pregnancy outcomes. Am J Epidemiol, 1999; 150 (5): 476 - 481.

59. SANTOS, V. Indicadores selecionados do uso de medicamentos - OMS, no município de Ribeirão Preto - SP. Tese de Doutorado, FSP - USP, São Paulo, 1999. 
60. Satge, D; Sasco, AJ \& Little, J.. Antenatal therapeutic drug exposure and fetal / neonatal tumours: review of 89 cases. Paediatr. Perinat. Epidemiol., 1998; $12(1): 84-117$.

61. SETO, A; EINARSON, T \& KOREN, G Pregnancy outcome following first trimester exposure to antihistamines: meta-analysis. American Journal of Perinatology, 4(3): $119-124,1997$.

62. School, TO; Hediger, ML; Bendich, A; Schall, JI; Smith, WK \& Krueger, PM. Use of multivitamin mineral prenatal supplements influence on the outcome of pregnancy. Am. J. Epidemiol., 1997; 146 (2): 134 - 141.

63. Schuler, L ; Sanseverino, MTV; Souza, CFM \& Giuliane, Fármacos e Gestação. In: . Fuchs, FD \& Wannmacher, L Farmacologia clínica: fundamentos da terapêutica racional. $2^{a}$. ed., Rio de Janeiro, Editora Guanabara Koogan S. A., 1998.

64. Simões, MJS Estudos de utilização de medicamentos. In: Castro, L.L.C. FUNDAMENTOS DE FARMACOEPIDEMIOLOGIA. Campo Grande, AG Gráfica e Editora Ltda., 2000. p. 106 -126.

65. Simões, MJS \& FEGADOLLI, C Indicadores de prescrição de medicamentos em Araraquara, SP. Seminário de Farmacoepidemiologia. Fortaleza, 1996. p. 33.

66. Simões, MJS \& MOTTA, M Indicadores de prescrição de medicamentos em Ribeirão Preto, SP. Seminário de Farmacoepidemiologia. Fortaleza, 1996. p. 32.

67. Simões, MJS \& Soler, EA Estudo de alguns indicadores do consumo de medicamentos adotados pela OMS e antibioticoterapia em crianças. Tabatinga - SP, 1998. Monografia apresentada ao Curso de especialização em Saúde Pública, 1998. 58p.

68. Simões, MJS \& Carneiro, RM. Determinação de indicadores da avaliação de prescrição de medicamentos selecionados pela Organização Mundial de Saúde em municípios da Divisão Regional de Saúde (DIR XV) de Araraquara - SP, 2000. In: Resumos da 48 . Jornada Farmacêutica UNESP Araraquara, 19 a 23 de agosto de 2001. [ CD-Rom ]. Araraquara, 2001

69. SPITZER, W. Q. Drug as determinants of health and disease in the population: na orientation to the bridge science of Pharmacoepidemiology. J. Clin. Epidemiol., 44 (8): 823-830, 1991. 
70. Strom, BL What is Pharmacoepidemiology? In: Strom, BL Pharmacoepidemiology. 2a . ed., Chichester, John Wiley \& Sons, 1994. p. 3 11.

71. UNICEF. A Prescripção: diretrizes para a utilização racional de medicamentos nos serviços básicos de saúde, 1, UNICEF-USP, 1992. 11p.

72. Vaughan, JP \& Morrow, RH Epidemiologia para os municipios: manual para gerenciamento dos destrittos sanitários. Trad: Dora, C, Hallal, IS \& Victora, CG. São Paulo, Hucitec, 1992.

73. Vilarino, JF; Soares, IC; Silveira, CM; Rodel, APP; Bortoli, R \& Lemos, RR Perfil da automedicação em município do sul do Brasil. Rev. Saúde Pública, 1998, 32 (1). Disponível em URL: http://www. scielo.br

74. Zanini, AC \& Oga, S Guia de medicamentos / Grupo de Trabalho Zanini Oga. $2^{a}$. ed., São Roque, IPEX Editora, 1997.

75. Zenker, M; Klinge, J; Krüger, C; Singer, H \& Scharf, J Severe pulmonary hipertension in a neonate caused by premature closure of the ductus arterious following maternal treatment with diclofen: a case report. J. Perin. Med., 1998; 26(3): 231-4.

76. Werler, MM; Hayes, C; Lovik, C; Shapiro, S \& Mitchell, AA Multivitamin supplementation and risk of birth deffects. Am. J. Epidemiol., 1999; 150 (7): $675-682$.

77. WHO. Vitamin A in pregnacy. Drug information, 1990; 4(3): 130.

778. WHO. How to investigate drug use in communities. WHO, Geneva, 1992. 
ANEXOS 


\section{ANEXO 1}

TABELA : Indicadores de prescrição selecionados pela OMS relatados em artigos referenciados.

\begin{tabular}{lcccccc}
\hline & $\begin{array}{c}\text { Ribeirão } \\
\text { Preto }\end{array}$ & $\begin{array}{c}\text { Araraquara } \\
1996 / 2000\end{array}$ & Fortaleza & Tabatinga & $\begin{array}{c}\text { Campo } \\
\text { Grande }\end{array}$ & $\begin{array}{c}\text { Ribeirão } \\
\text { Preto * }\end{array}$ \\
\hline $\begin{array}{l}\text { no. médio de } \\
\text { medicamentos } \\
\text { por receita }\end{array}$ & 1,9 & $1,8 / 2,2$ & 2,2 & 2,5 & 2,0 & 2,4 \\
$\begin{array}{l}\text { \% de prescrição } \\
\text { por nome } \\
\text { genérico }\end{array}$ & 72,0 & $43,7 / 72,0$ & 74,0 & 32,7 & 81,0 & 30,5 \\
$\begin{array}{l}\text { \% de receitas } \\
\text { com antibiótico }\end{array}$ & 10,1 & $15,1 / 31,0$ & 37,0 & 2,7 & 34,8 & 21,3 \\
$\begin{array}{l}\text { \% de receitas } \\
\text { com injetável }\end{array}$ & 12,2 & $7,4 / 10,0$ & 11,0 & 5,7 & 15,7 & 8,2 \\
$\begin{array}{l}\% \text { prescrição } \\
\text { pela LMP } \\
* *\end{array}$ & 88,1 & $47,2 / 74,5$ & 78,0 & 44,8 & 89,5 & 80,1 \\
\hline
\end{tabular}

* Dados relatados em SANTOS (1999)

* LMP = Lista de Medicamentos Padronizados pelo Município 
ANEXO 2

\section{GESTANTES}

UBS:

DATA:

QUESTIONÁRIO $n^{\circ}$ :

Prontuário $n^{\circ}$

FASE 1 - Pré-consulta

1. Dados relativos ao paciente:

1.1. data de nascimento:

1.2 grau de escolaridade:

analfabeto (....)

$1^{\mathrm{a}}$ a $4^{\mathrm{a}}$ série do $1^{\circ}$ grau (....)

$5^{\mathrm{a}}$ a $6^{\mathrm{a}}$ série do $1^{\circ}$ grau $(. . .$.

$2^{\circ}$ grau incompleto $(. .$.

$2^{\circ}$ grau completo $(. . .$.

superior incompleto (....)

superior completo (....)

não sabe (....)

1.3 ocupação:

1.4. renda familiar: $R \$$

1.5. número de pessoas residentes no domicílio:

1.6. número de filhos:

1.7 mês de gestação: obs. Caso a paciente não saiba informar o tempo de gestação, consultar o prontuário.

2. Você usou algum remédio na última semana (7 dias)?

(.....) não

(....) sim. Qual (is)?

Quem indicou?

FASE 2 - Pós-consulta

Dados relativos à prescrição:

1. O paciente teve prescrição medicamentosa: (....) não sim

2. Em caso afirmativo anotar a prescrição na íntegra (medicamentos, posologia e orientações): 


\section{ANEXO 3}

\section{PERFIL DE UTILIZACÃO DE MEDICAMENTOS NA GESTACÃO UM ESTUDO FARMACOEPIDEMIOLÓGICO}

\section{Responsáveis:}

Prof.a. Thais Adriana do Carmo (Faculdade de Ciências da Saúde - UNIMEP)

Prof.a. Dra. Sandra M. O. de O. Nitrini (Faculdade de Saúde Pública - USP

\section{Termo de consentimento}

$O$ abaixo assinado (nome, idade, RG e endereço) declara que é de livre e expontânea vontade que está participando como voluntário do projeto de pesquisa supra citado, de responsabilidade dos professores acima mencionados. $\mathrm{O}$ abaixo assinado está ciente que:

1. o objetivo da pesquisa é identificar e discutir os medicamentos utilizados por gestantes usuárias do Serviço Municipal de Saúde de Piracicaba;

2. os dados serão colhidos em entrevista realizada por professores e estagiários do Curso de Farmácia da UNIMEP, orientados por questionário previamente elaborado;

3. os resultados obtidos durante este estudo serão mantidos em sigilo e os autores não identificarão os voluntários por ocasião da exposição e/ou publicação dos mesmos

4. poderá contatar a secretaria da Comissão de Ética para apresentar recursos ou reclamações em relação a este estudo.

Declara ainda que obteve todas as informações necessárias para poder decidir conscientemente sobre a participação no referido estudo.

Piracicaba,

de

de

Nome da gestante:

Endereço:

R.G

Assinatura: 
ANEXO 4 
Prefeitura do Município de Piracicaba - Secretaria da Saúde BANCO DE DADOS DA DIVISÃO DE VIGILÂNCIA EPIDEMIOLÓGICA Rua do Trabalho, 634 - V. Independência. Fone: 434-1100 ou 433-1084.

\section{$\underline{\text { Informações sobre o ano } 2.000 \text { - Residentes em Piracicaba }}$}

1. Coeficiente geral de mortalidade: 6.1 por 1.000 habitantes.

2. Mortalidade Infantil: 13.2 por 1.000 nascidos vivos.

3. Mortalidade Materna: 0.4 por 1.000 nascidos vivos.

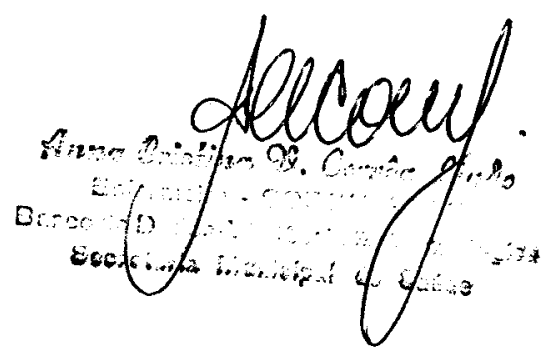


Prefeitura do Município de Piracicaba - Secretaria da Saúde

BANCO DE DADOS DA DIVISÃO DE VIGILÂNCIA EPIDEMIOLÓGICA

Rua do Trabalho, 634 - V. Independência. Fone: 434-1 100 ou 433-1084.

4. Distribuição dos óbitos segundo os grupos de causas (CID $\left.10^{a}\right)$ :

\begin{tabular}{l|c|c}
\hline \multicolumn{1}{c|}{ Grupo de causa } & Frequência & $\%$ \\
\hline Doenças do aparelho circulatório & 437 & 21.7 \\
Mal definidas & 327 & 16.3 \\
Neoplasias & 312 & 15.5 \\
Causas externas & 193 & 9.6 \\
Doenças do aparelho respiratório & 180 & 9.0 \\
Algumas doenças infecciosas e parasitárias & 120 & 6.0 \\
Doenças do aparelho digestivo & 116 & 5.8 \\
Afecções originadas no período perinatal & 109 & 5.4 \\
Doenças endócrinas, nutricionais e metabólicas & 86 & 4.3 \\
Doenças do aparelho geniturinário & 47 & 2.3 \\
Doenças do sistema nervoso & 23 & 1.1 \\
Anomalias congênitas & 21 & 1.0 \\
Doenças do sangue e transtornos imunitários & 16 & 0.8 \\
Transtornos mentais e comprotamentais & 08 & 0.4 \\
Doenças da pele e do tecido subcutâneo & 08 & 0.4 \\
Doenças do sistema osteomuscular & 04 & 0.2 \\
Gravidez, parto e puerpério & 02 & 0.1 \\
Doenças do ouvido e apófise mastóide & 01 & 0.1 \\
Total & 2.010 & 100 \\
\hline \hline
\end{tabular}


ANEXO 5 


\section{Prefeitura do Município de Piracicaba \\ Secretaria Municipal de Saúde \\ Estado de Sảo Paulo}

Medicamentos Padronizados nas Farmácias Regionais e Descentralizadas do Municipio de Piracicaba - Ano 2001

\section{ANALGESIA E DOENCAS INFLAMATÓRIAS}

Analgésicos e Antipiréticos

- ácido acetilsalicílico

- ácido acetilsalićlico

- dipirona

- paracetamol

comp. $100 \mathrm{mg}$

comp. $500 \mathrm{mg}$

gotas, $500 \mathrm{mg} / \mathrm{ml}$

gotas, $200 \mathrm{mg} / \mathrm{ml}$

Antifflamatórios Nāo Hormonais

- ácido acetilsalicilico

- ácido acetilsalicílico

- diclofenaco potássico

- didofenaco sódico

comp. $100 \mathrm{mg}$

gotas, $15 \mathrm{mg} / \mathrm{m}$

comp. $50 \mathrm{mg}$

\section{Antiiflamatórios Hormonais}

- prednisona

comp. $5 \mathrm{mg}$

- prednisona comp. $20 \mathrm{mg}$

- dexametasona creme 1\%

\section{Anti-Hiperuricémicos}

- alopurinol comp. $100 \mathrm{mg}$

\section{SISTEMA CARDIOVASCULAR}

\section{Anti-hipertensivos}

- captopril

- metildopa

- metildopa

- nifedipino

- verapamil

- proprandol

Antianginosos

- isossorbida dinitrato

- isossorbida dinitrato

- verapamil

- nifedipino comp. $25 \mathrm{mg}$

comp. $250 \mathrm{mg}$

comp. $500 \mathrm{mg}$

comp. retard $20 \mathrm{mg}$

comp. $80 \mathrm{mg}$

comp. $40 \mathrm{mg}$

comp. SL $5 \mathrm{mg}$

comp. $10 \mathrm{mg}$

comp. $80 \mathrm{mg}$

comp. retard $20 \mathrm{mg}$

\section{Diuréticos}

- furosemida comp. $40 \mathrm{mg}$

- hidroclorotiazida comp. $50 \mathrm{mg}$

Antiarritmicos

- amiodarona

- metildopa

comp. $200 \mathrm{mg}$

comp. $250 \mathrm{mg}$

- metildopa

Cardiotónicos

- digoxina comp. $500 \mathrm{mg}$

Vasodilatadores Periféricos/Cerebrais

- cinarizina comp. $75 \mathrm{mg}$

\section{SISTEMA ENDÓCRINO}

\section{Diabetes - Hipoglicemiantes Orais e Injetáveis}

- clorpropramida

- glibenclamida

- insulina NPH humana

- insulina NPH suína/bovina comp. $250 \mathrm{mg}$

comp. $5 \mathrm{mg}$

sol. ini. $100 \mathrm{Ul} / \mathrm{ml}$

sol. inj. $100 \mathrm{Ul} / \mathrm{ml}$

\section{Contraceptivos e Repositores Hormonais}

- levonorgestrel + etinilestradiol comp. 0,15 mg +0,03 mg

- levonorgestrel + etinilestradiol comp. 0,25 mg + 0,05 mg

- desogestrel + etinilestradiol comp. 0,15 mg +0,03 mg

- preservativo (condom) unidade

- estrogênios conjugados comp. 0,625 mg

- estrogènios conjugados creme vaginal $0,625 \mathrm{mg}$

- noretindrona (norestisterona) comp. 0,35 mg

\section{SISTEMA RESPIRATÓRIO}

\section{Broncodilatadores}

- aminofilina

- salbutamol

- salbutamo comp. $100 \mathrm{mg}$

comp. $2 \mathrm{mg}$

xarope $2 \mathrm{mg} / 5 \mathrm{~m}$

\section{Anti-séptico Nasal}

- cloreto de benzalcônio (soro fisiológ.) gotas nasais

\section{ANTIALÉRGICOS}

- dexclorfeniramina

comp. $2 \mathrm{mg}$

- dexclorfeniramina

\section{SISTEMA DIGESTIVO}

\section{Antiáciolos Neutralizantes}

- hidróxido de aluminio

Antiulcerosos

- cimetidina

Antieméticos

- metodopramida

- metoclopramida susp. oral $6,2 \%$

comp. $200 \mathrm{mg}$

comp. $10 \mathrm{mg}$

gotas, $4 \mathrm{mg} / \mathrm{ml}$

\section{Antiespasmódicos}

- hioscina (escopolamina) comp. $10 \mathrm{mg}$

Laxantes

- óleo mineral puro liquido oral 


\section{Prefeitura do Município de Piracicaba \\ Secretaria Municipal de Saúde \\ Estado de São Paulo}

Medicamentos Padronizados nas Farmácias Regionais e Descentralizadas do Município de Piracicaba - Ano 2001

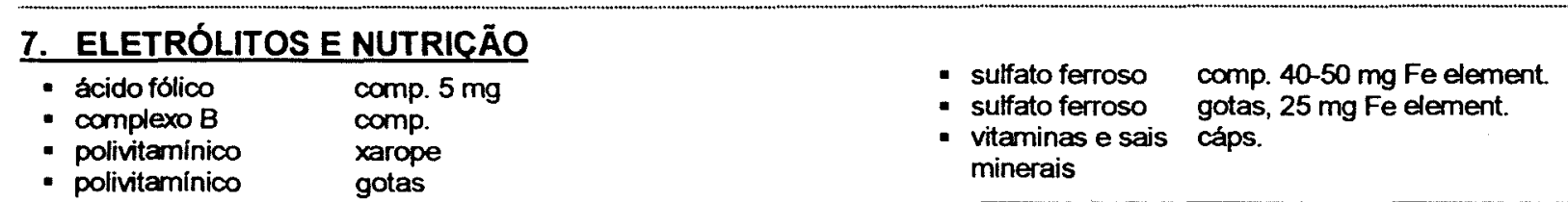

\section{SISTEMA NERVOSO CENTRAL}

\section{Anticonvulsivantes}

- carbamazepina

- carbamazepina

- fenitóna

- fenobarbital

Antidepressivos

- amitriptilina

- imipramina

Antiparkinsonianos

- biperideno

- levodopa + carbidopa

\begin{abstract}
comp. $200 \mathrm{mg}$
susp. oral. $2 \%$

comp. $100 \mathrm{mg}$

comp. $100 \mathrm{mg}$
\end{abstract}

comp. $25 \mathrm{mg}$

comp. $25 \mathrm{mg}$

comp. $2 \mathrm{mg}$

comp. $250 \mathrm{mg}+25 \mathrm{mg}$
Ansioliticos Bensodiazepinicos

- bromazepam

- diazeparn

- nitrazeparn

comp. $3 \mathrm{mg}$

Neurolépticos

- clorpromazina

- clorpromazina

- haloperidol

- haloperidol

- haloperidol comp. $10 \mathrm{mg}$

comp. $5 \mathrm{mg}$

comp. rev. $100 \mathrm{mg}$

comp. $25 \mathrm{mg}$

comp. $1 \mathrm{mg}$

comp. $5 \mathrm{mg}$

sol. oral. $0,2 \%$

\section{ANTIBACTERIANOS}

\section{Anfenicóis}

- cloranfenicol

- cloranfenicol

Penicilinas

- amoxicilina

- ampicilina

- ampicilina

- penicilina $G$ benzatina

- penicilina $G$ benzatina

- penicilina G procaína

Cefalosporinas

- cefalexina

- cefalexina

\author{
comp. $250 \mathrm{mg}$ \\ colírio $0,5 \%$
}

susp. oral $250 \mathrm{mg} / 5 \mathrm{ml}$ susp. oral $250 \mathrm{mg} / 5 \mathrm{ml}$ comp. $500 \mathrm{mg}$

susp. inj. 600.000 Ul/fr.amp

susp. inj. $1.200 .000 \mathrm{Ul} / \mathrm{fr} . \mathrm{amp}$

susp. inj. $400.000 \mathrm{Ul} / \mathrm{fr} . \mathrm{amp}$

cáps. $500 \mathrm{mg}$

susp. oral $125 \mathrm{mg} / 5 \mathrm{ml}$

\section{Macrolideos}

- eritromicina

- eritromicina

comp. $250 \mathrm{mg}$

Quinolonas

- norfloxacino comp. $400 \mathrm{mg}$

Sulfas

- sulfametoxazol + trimetoprima comp. $400 \mathrm{mg}+80 \mathrm{mg}$

- sulfametoxazol + trimetoprima susp. oral $200+40 \mathrm{mg} / 5 \mathrm{ml}$

Tetraciclinas

- tetraciclina

Outros Antimicrobianos

- ácido nalidixico

- metrodinazol

- metrodinazol

- neomicina + bacitracina

cáps. $500 \mathrm{mg}$

susp. oral $250 \mathrm{mg} / 5 \mathrm{ml}$

comp. $250 \mathrm{mg}$

susp. oral $200 \mathrm{mg} / 5 \mathrm{ml}$

pomada, $5 \mathrm{mg}+250 \mathrm{UI}$

\section{ANTIFÚNGICOS}

- nistatina

- nistatina susp. oral $100.000 \mathrm{Ul} / \mathrm{ml}$ creme vaginal 100.000 Ui $/ 40$

\section{ANTIPARASITÁRIOS}

- mebendazol

- mebendazol

- metronidazol comp. $100 \mathrm{mg}$

susp. oral $100 \mathrm{mg} / 5 \mathrm{ml}$

comp. $250 \mathrm{mg}$
- tiabendazol

- tiabendazol

- benzoato de benzila comp. $500 \mathrm{mg}$

susp. oral $250 \mathrm{mg} / 5 \mathrm{ml}$

sol. tópica $25 \%$

\section{MEDICAMENTOS DE USO TÓPICO}

\section{Pele}

- benzoato de benzila

- dexametazona

- neomicina + bacitracina

- permanganato de potássio

- óxido de zinco assoc. (pomada para assadura) sol. tópica. $25 \%$

creme $1 \%$

pornada, $5 \mathrm{mg}+250 \mathrm{ul} / \mathrm{g}$

comp. $100 \mathrm{mg}$

pormada

\section{Uso ginecológico}

- estrogênios conjugados

- metronidazol

- nistatina

creme vaginal $0,625 \mathrm{mg} / \mathrm{g}$ creme vaginal $500 \mathrm{mg} / 5 \mathrm{~g}$ creme vaginal $100.000 \mathrm{Ul} / 4 \mathrm{~g}$

Uso Otológico / Oftalmológico

- cloranfenicol colinio $0,5 \%$

- polimixina B + lidocaina sol. otológica 